$$
\text { " الرضا الوظيفي لمعلمات رياض الأطفال بالمدينة المنورة " }
$$

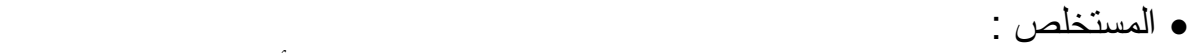

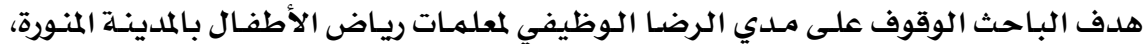

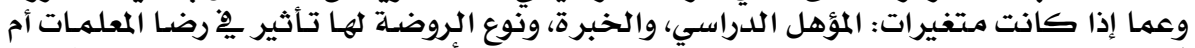

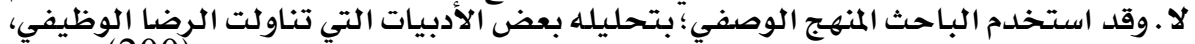

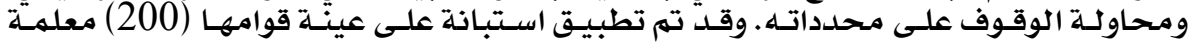

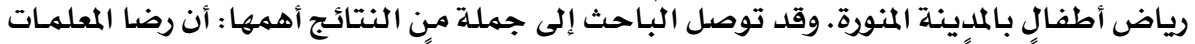

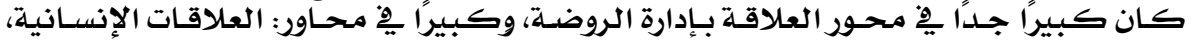

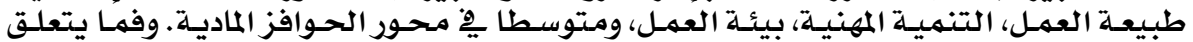

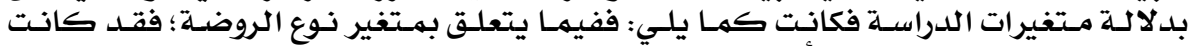

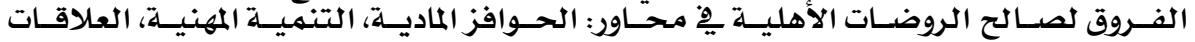

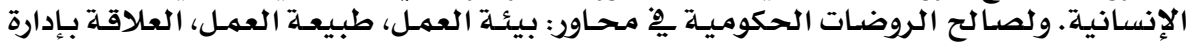

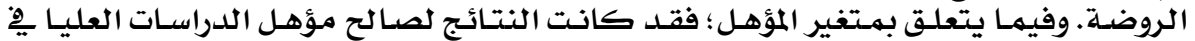

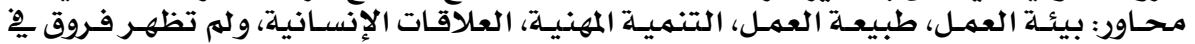

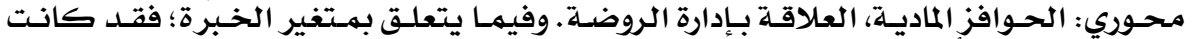

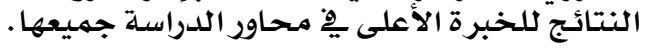

الكلمات المفتاحية : الرضا الوظيفي - رياض الأطفال

Job Satisfaction of Female Kindergarten Teachers in Madina, KSA

\title{
A Field Study
}

\section{Dr. Zakaria Mohamed Heiba}

\section{Abstract:}

The researcher aims at knowing the extent of job satisfaction of $K G$ female teachers in Madina, KSA, and whether there are variables such as qualification, experience and the $K G$ itself that may affect the satisfaction of the teachers. The descriptive approach has been used to analyse the data regarding job satisfaction and to know the defining elements. A survey has been conducted on $200 \mathrm{KG}$ teachers in Madina. The researcher has found out that teachers are so much satisfied as for their relations with the administration. They are very satisfied regarding human relations, work, career development and work environment. Satisfaction was average when it came to financial motivations.As for the variables of the study, the kind of $K G$ proved that private $K S$ 's are better when in comes to financial motivations, career development and human relations. Government $K G$ 's were, however, better as for work environment, nature of work, and relations with administration. As for qualifications, results were for $M$. A. holders when it comes to work environment, nature of work, career development and human relations, but no differences were shown in financial motivations, management, or experience. Results were for the more experienced in all.

Key Words: Job Satisfaction -Kindergartens .

\section{9}

در اسات عربية في الثربية و عنم النفس (ASEP) 


$$
\text { • • أو لا : الإطار العام للار اسة : }
$$

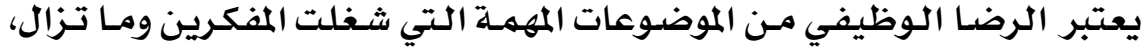

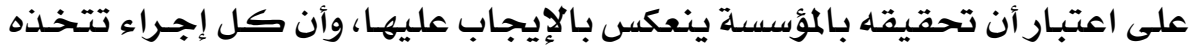

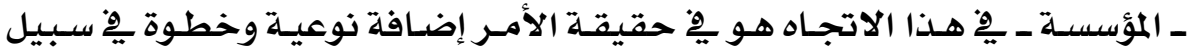

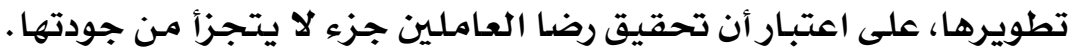

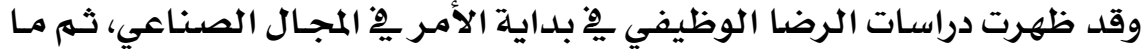

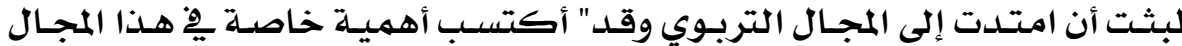

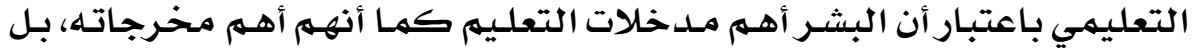

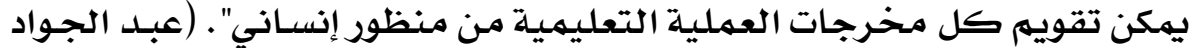
ومتولي، 1993).

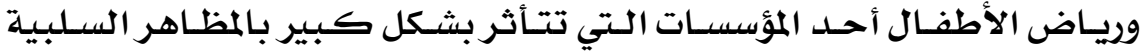

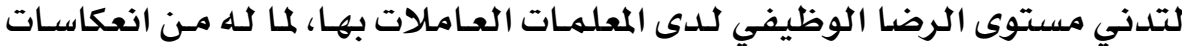

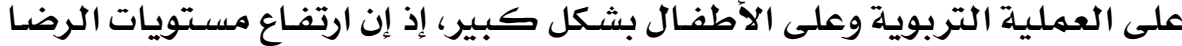

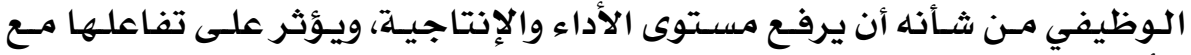

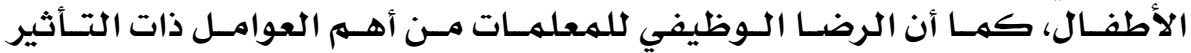

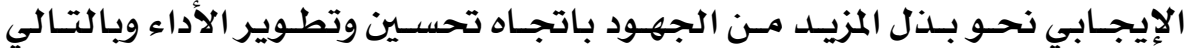

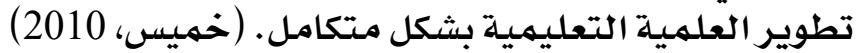

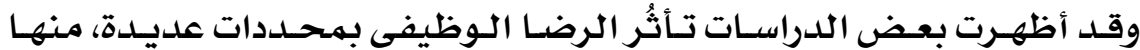

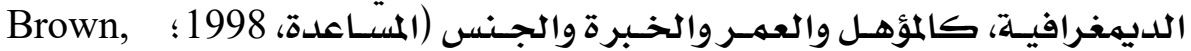

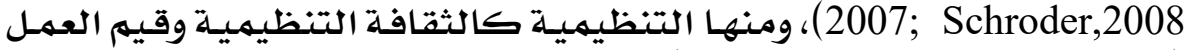

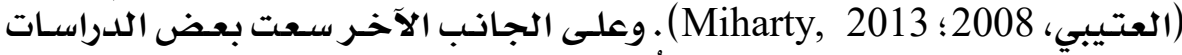

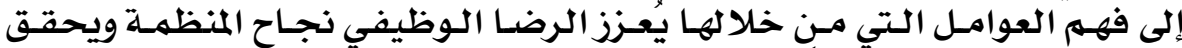

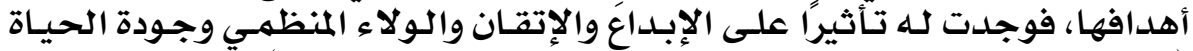

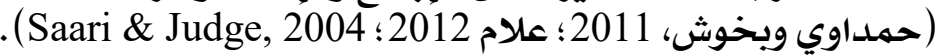

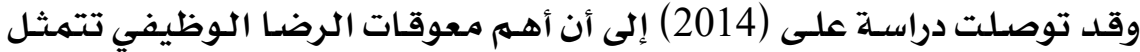

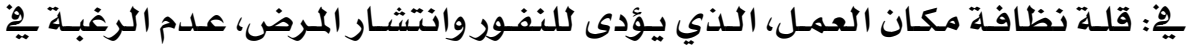

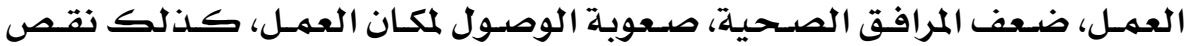

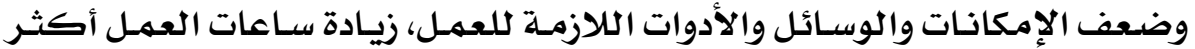

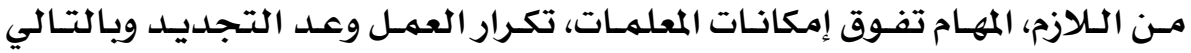

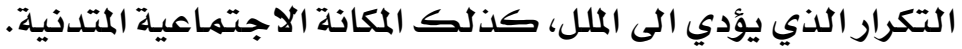

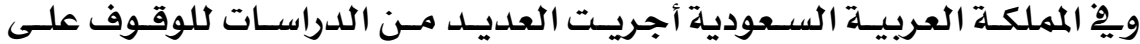

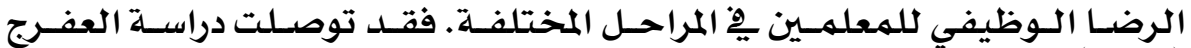

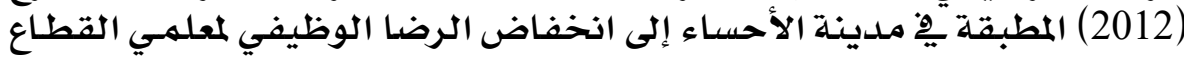

\section{0}




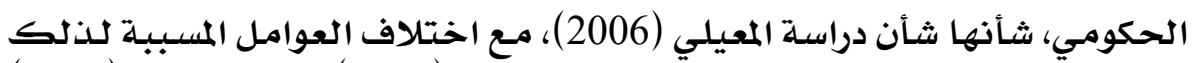

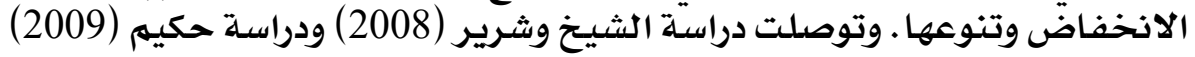

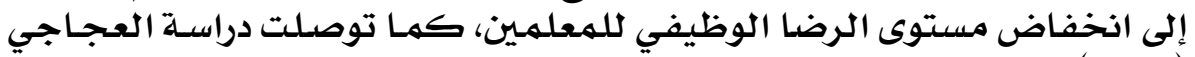

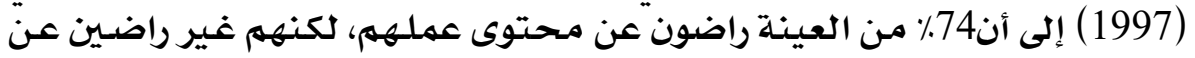

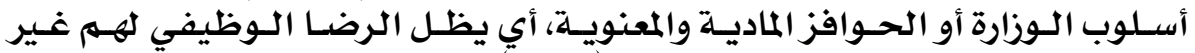

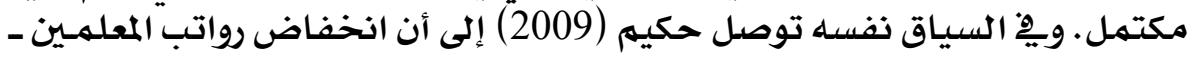

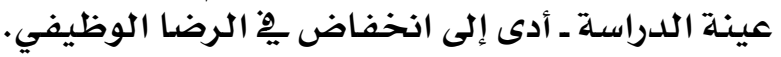

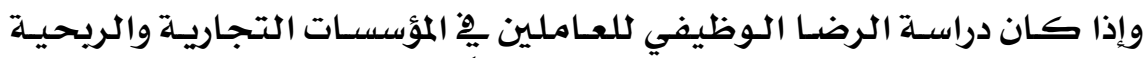

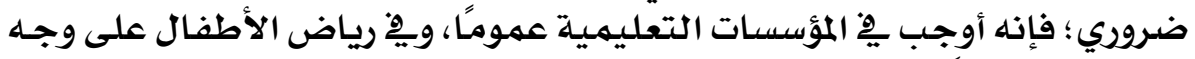

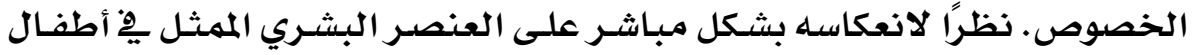

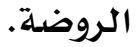

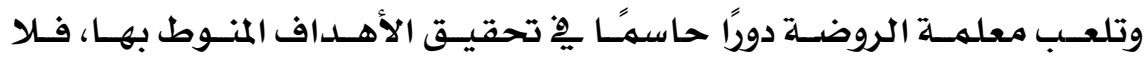

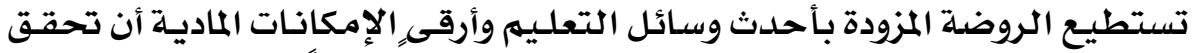

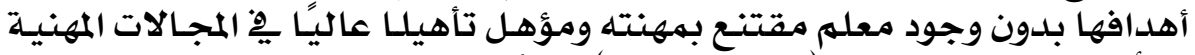

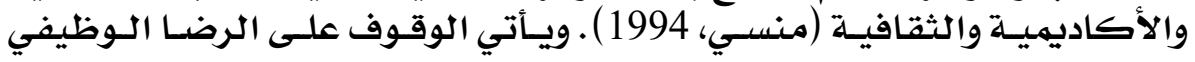

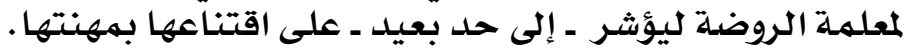

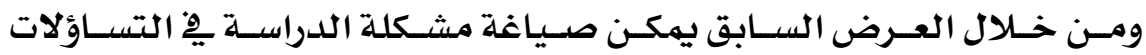
التالية:

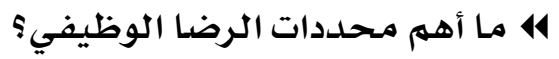

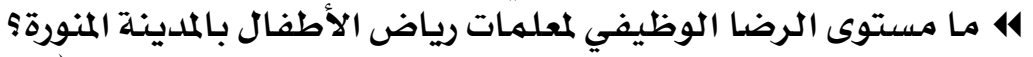

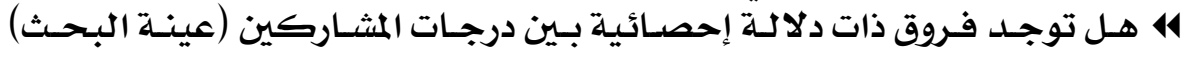

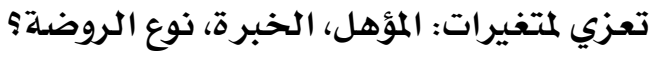

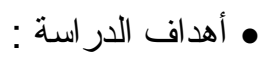

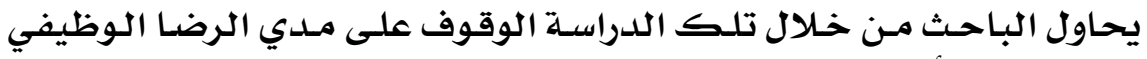

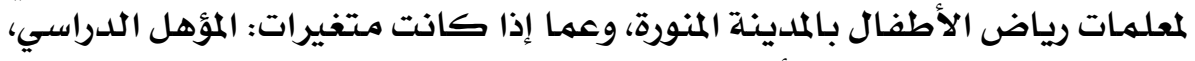

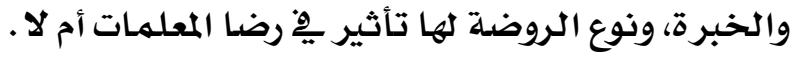

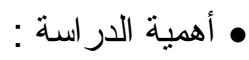

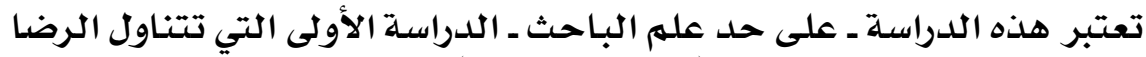

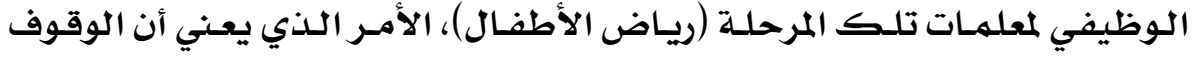

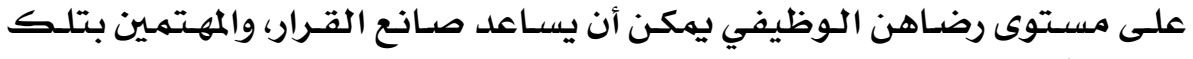

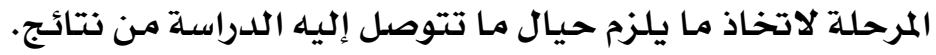

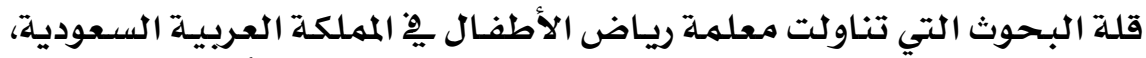

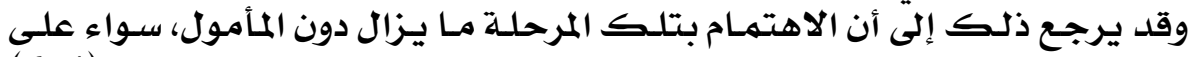

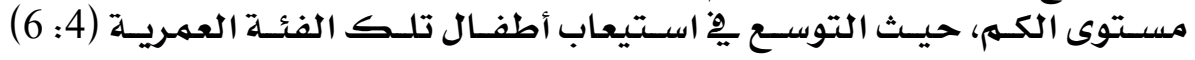

\section{1}

در اسات عربية في التزبية و عنم النفس (ASEP) 


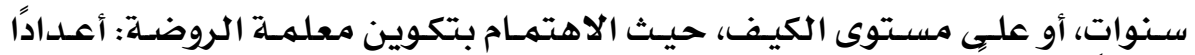

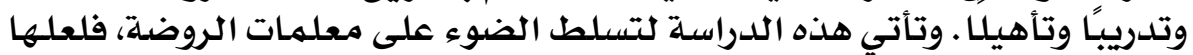

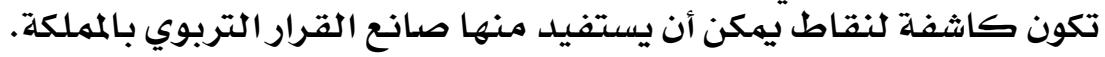

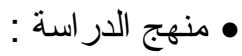

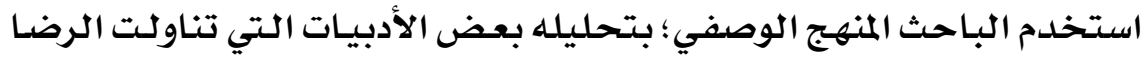

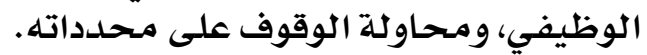

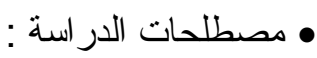

• Job Satisfaction الرضا الوظيفي

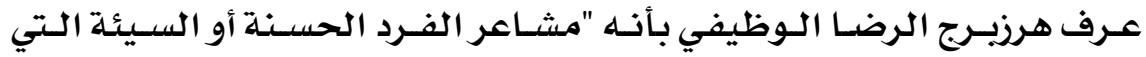

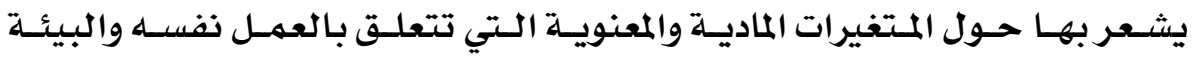
المحيطة بـه"(النهر، 1993)

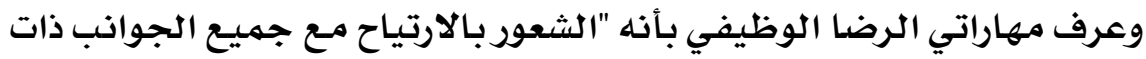

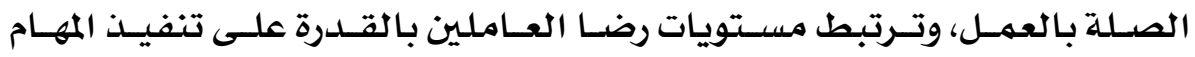

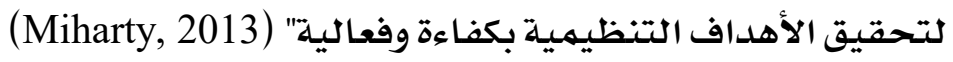

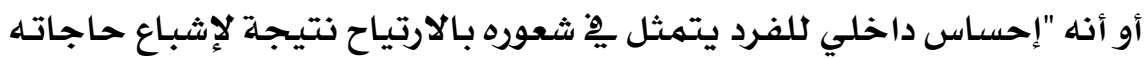

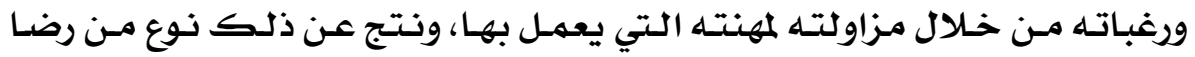

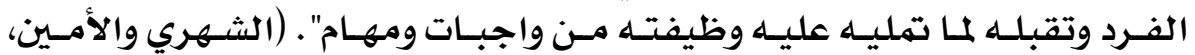

أمـا فريــل (Friedl Ander, 2009) فقـــ أثـار إلى أن مفهـوم الرضـا الوظيفي

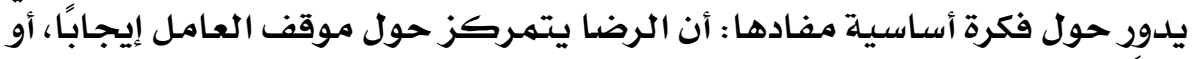

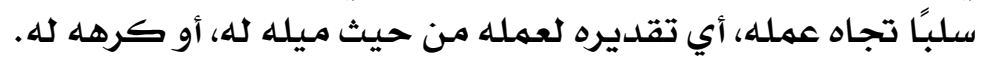

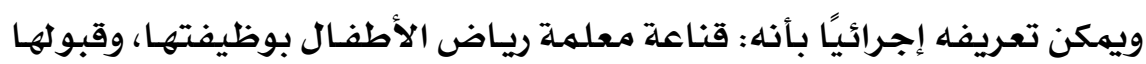

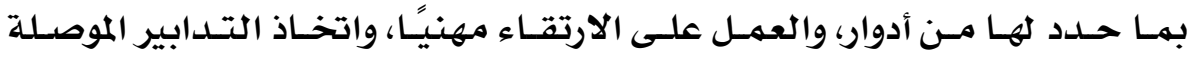
لذلك.

: Kindergarten باض الأطفال

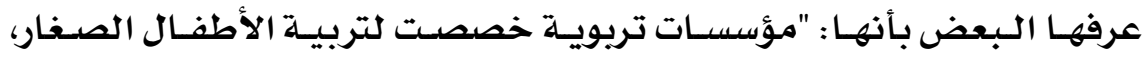

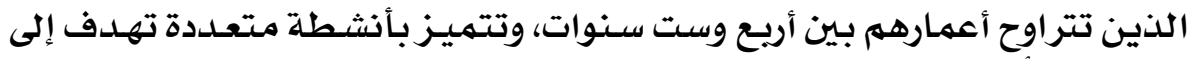

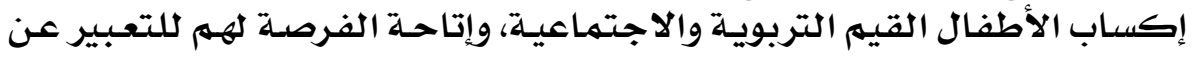

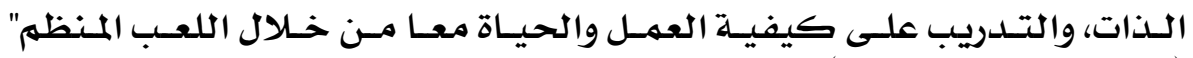

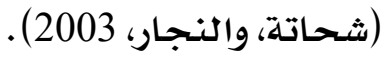

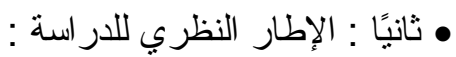

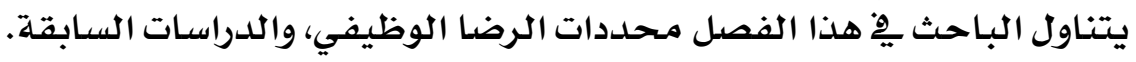

\section{2}

در اسات عربية في التزبية و عنم النفس (ASEP) 
• محددات الرضا الوظيفي:

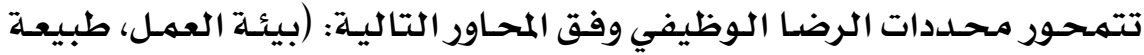

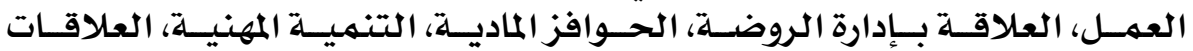

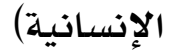

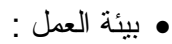

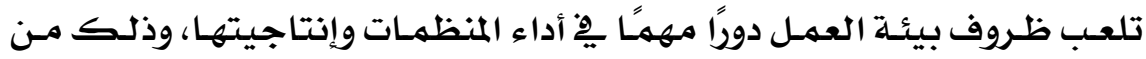

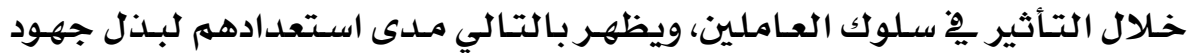

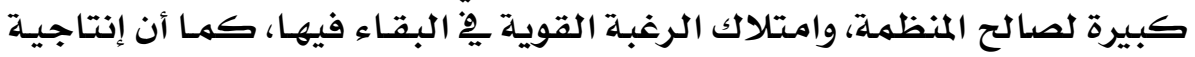

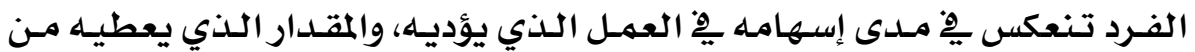

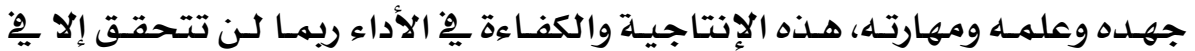

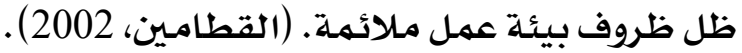

ويخ هـذا الجـانـب يشـير هيـجـان (1998) إلى أن العوامـل المتعلقـة بظـروف بيئهة

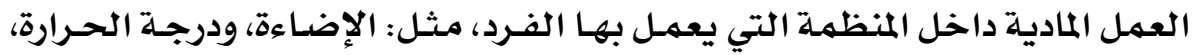
وطريقة تصهيهم المكاتب، وسـاعات العهل ؛ لها تأثير مبـاشر على الميلى الفرد وأدائه.

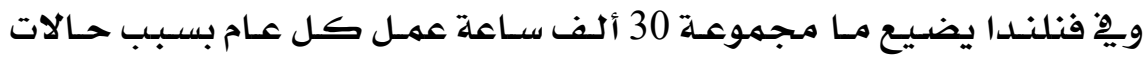

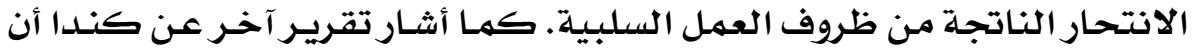

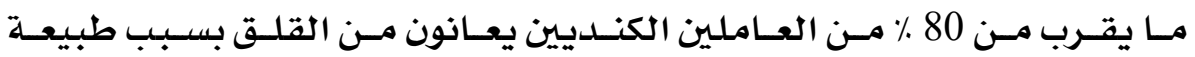
وظائفهم. (محهمود، 2012)

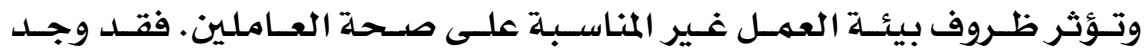

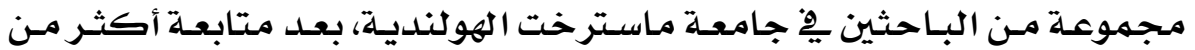

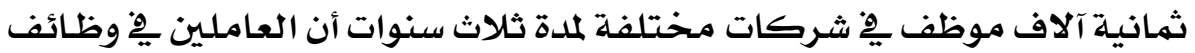
تتصف بظروف العمل غير مناسبـة يصسابون بـأمراض القنـاة الهضـميـة والتهاباتها

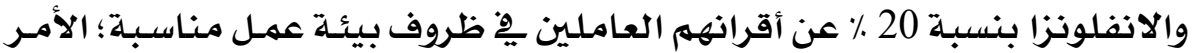

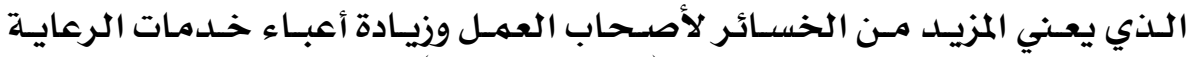

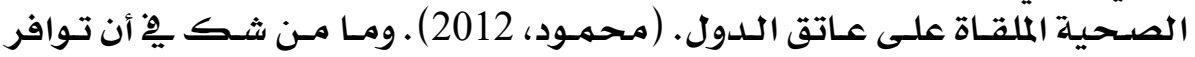

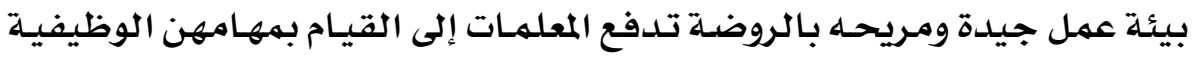

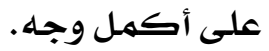

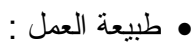

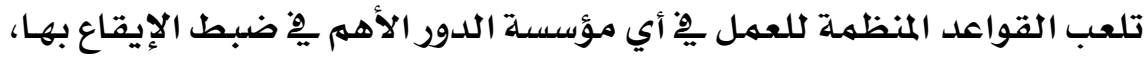

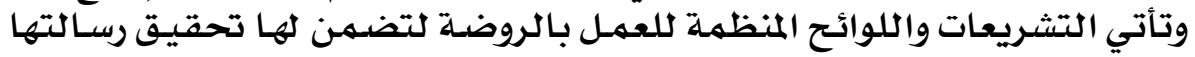

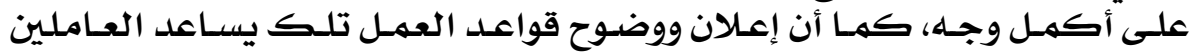

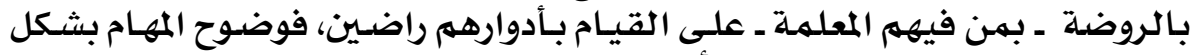

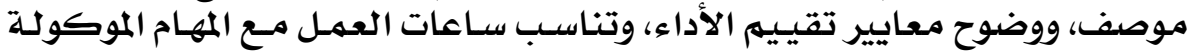

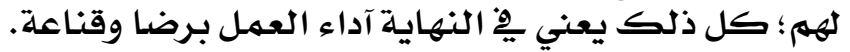

\section{3}




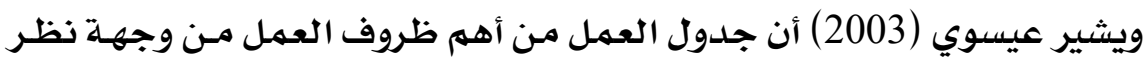

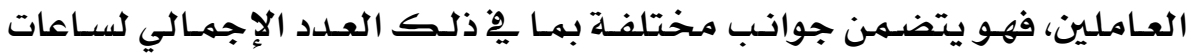

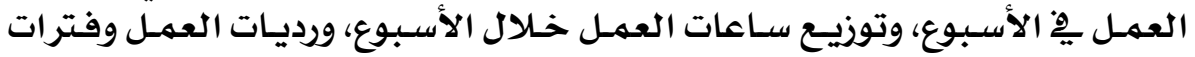

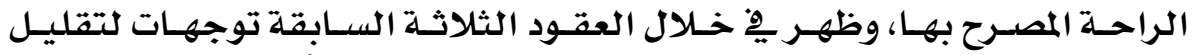

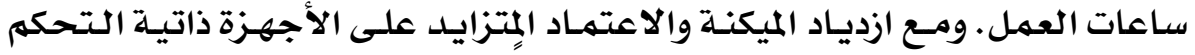

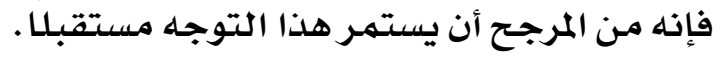

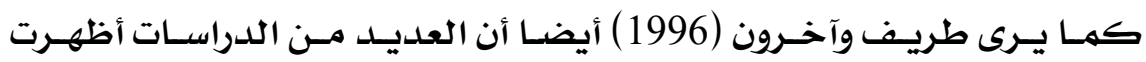

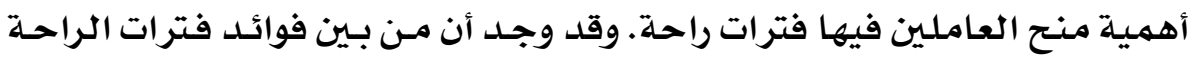

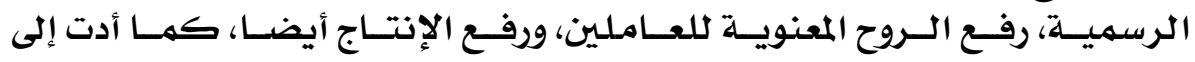

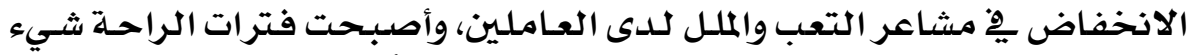

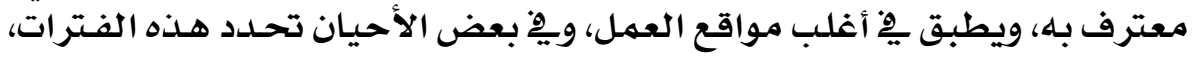

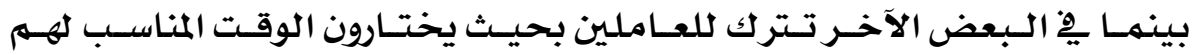
للحصول عليها.

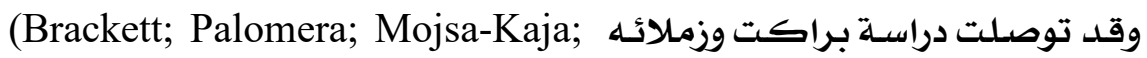
Reyes \& Salovey, 2010)

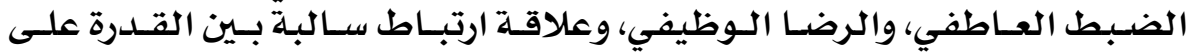

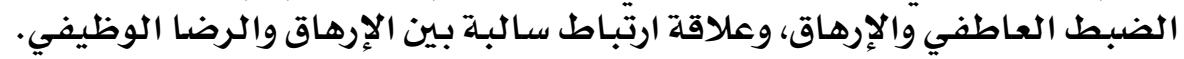

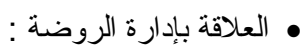

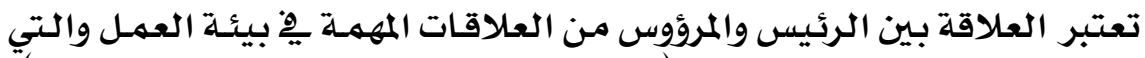

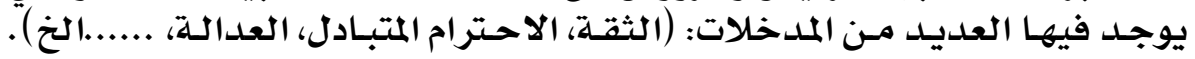

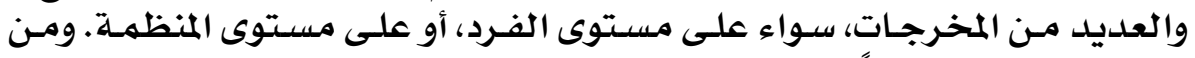

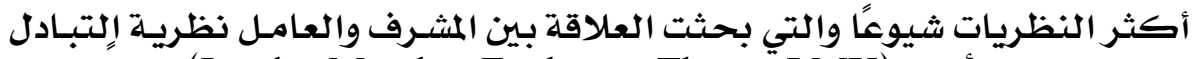

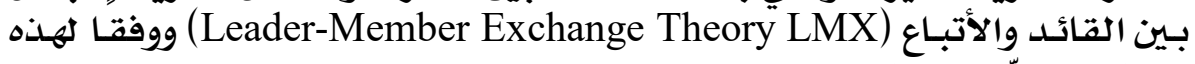

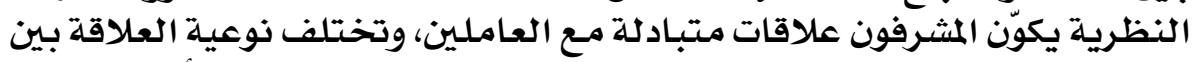

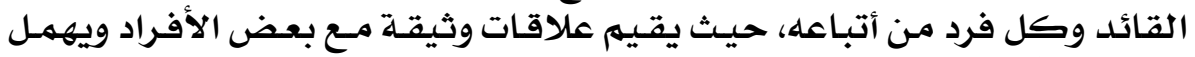

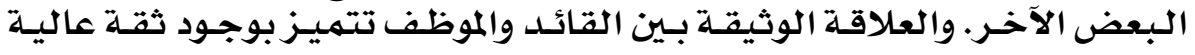

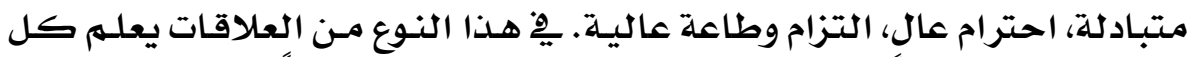

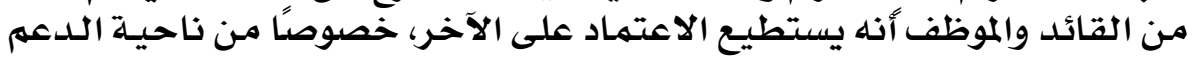

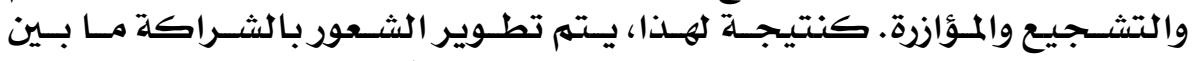

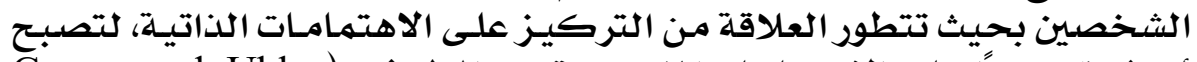

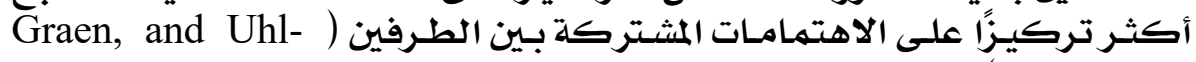
.(Bien, 1995

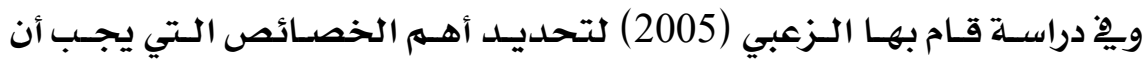

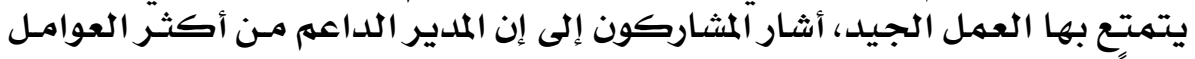

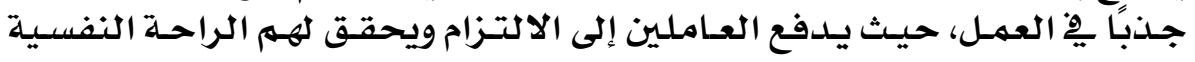

\section{4}




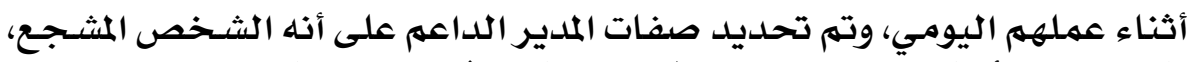

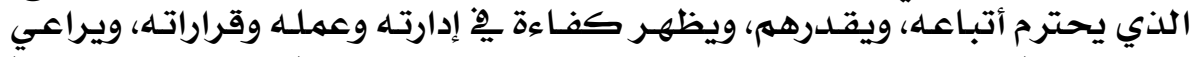

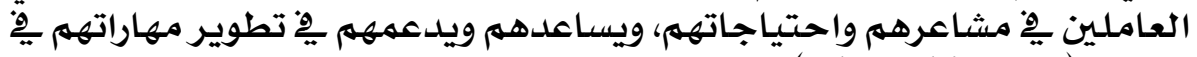
العمل. (Al-Zoubi, 2005).

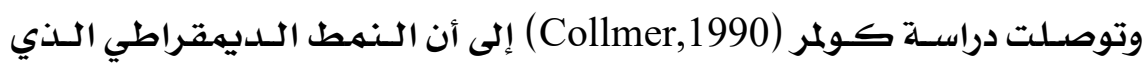

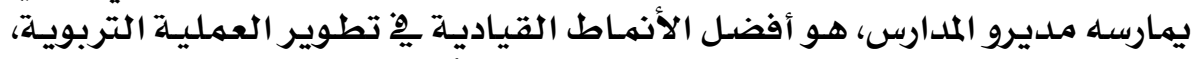

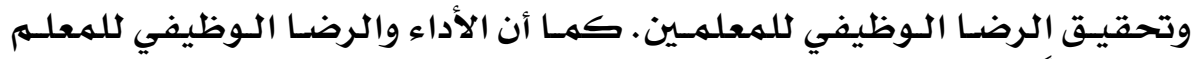

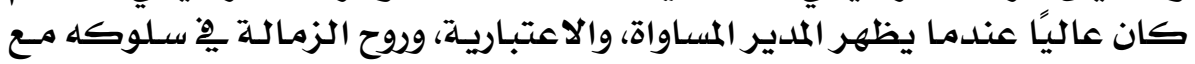

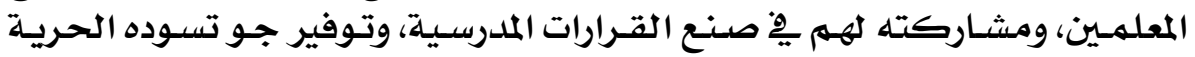

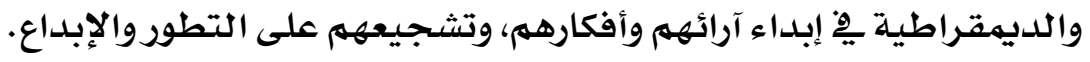

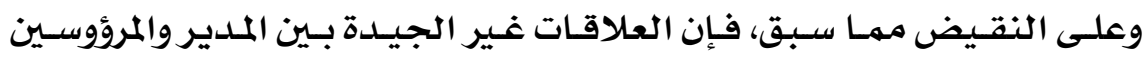

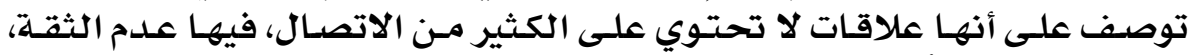

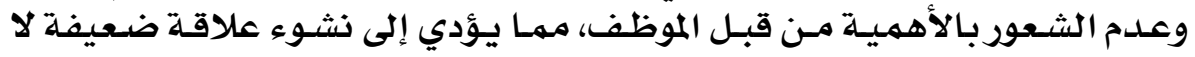

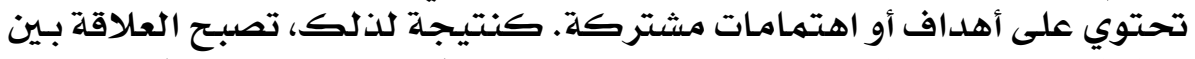

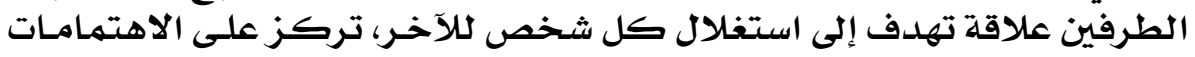

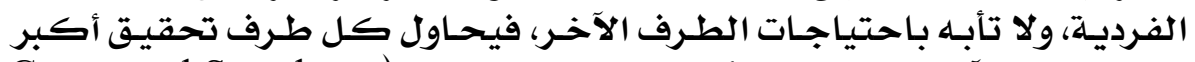

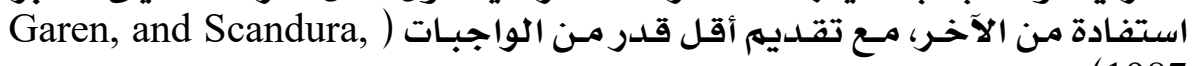

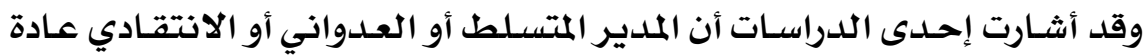

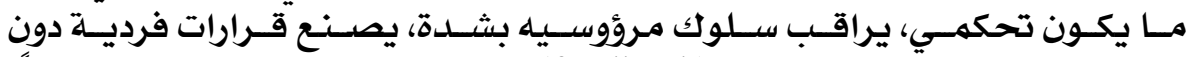

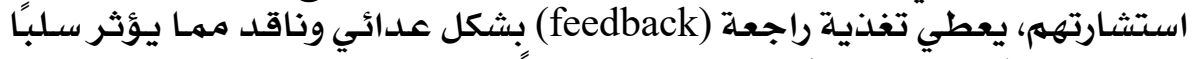

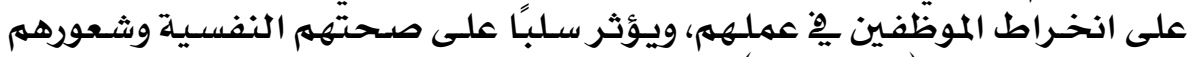

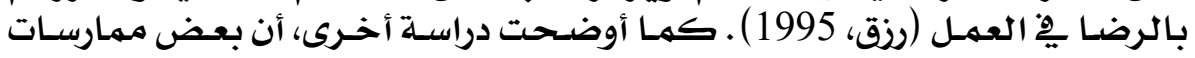

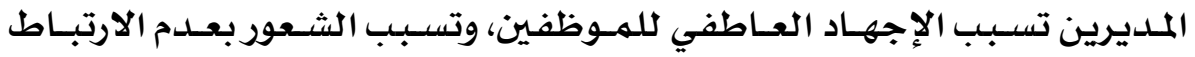

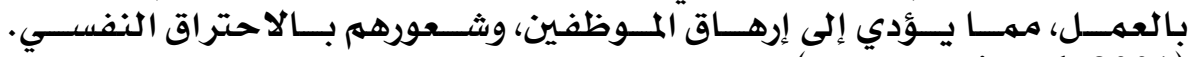
(Demorouti et al, 2001)

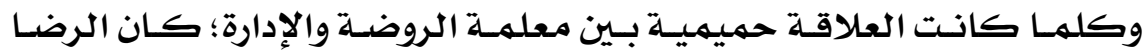

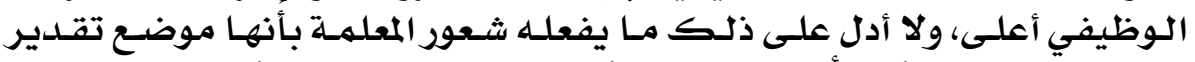

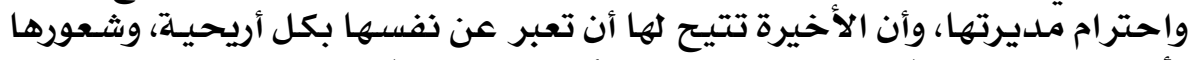

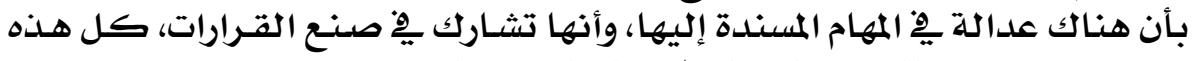

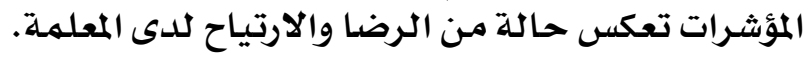

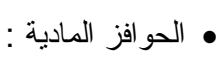

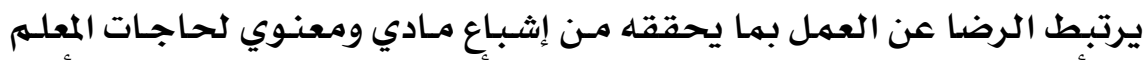

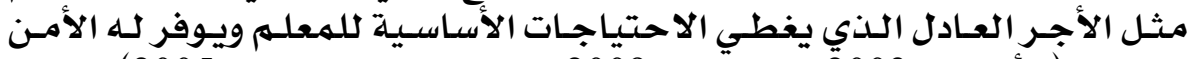

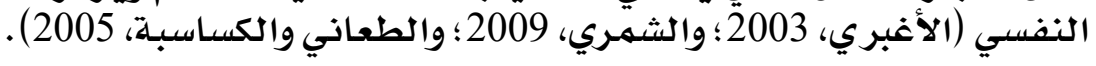

\section{5}




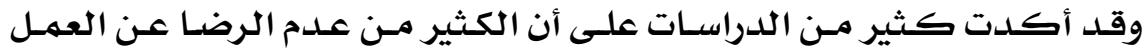

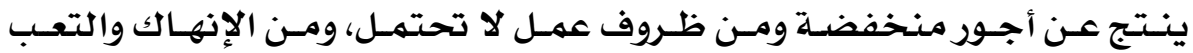

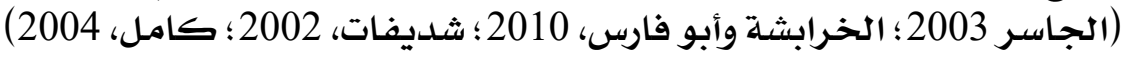

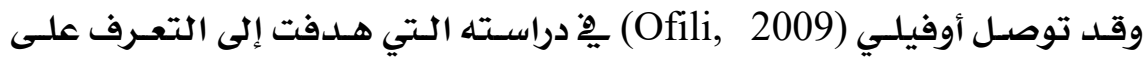

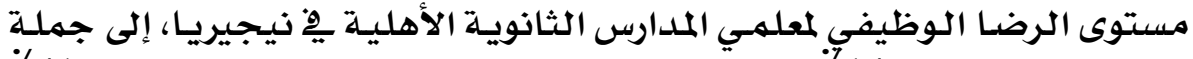

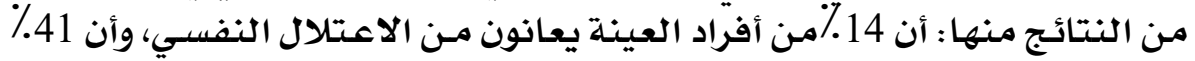

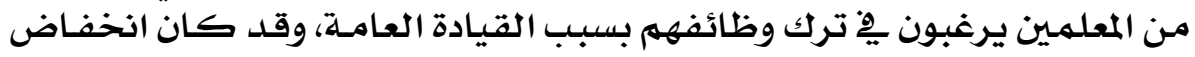

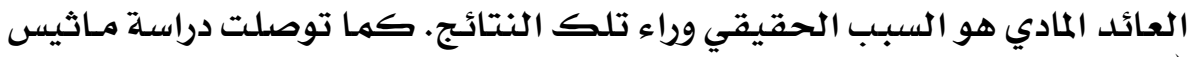
(Mathis, 2010)

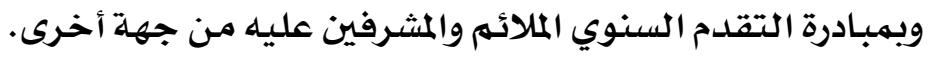

• (التمية المهنية :

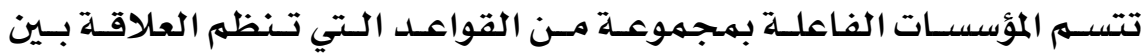

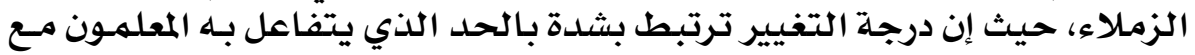

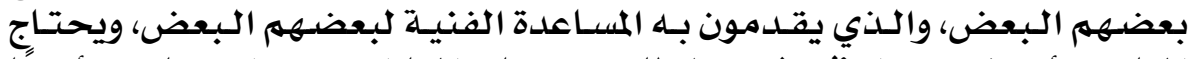

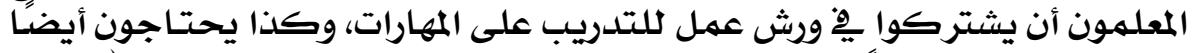

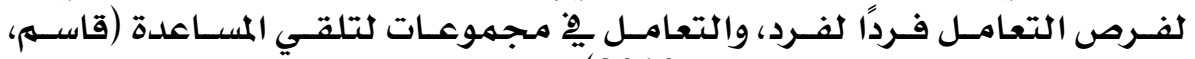

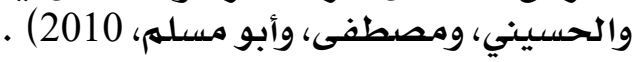

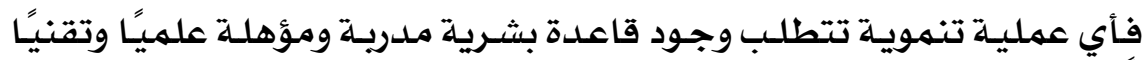

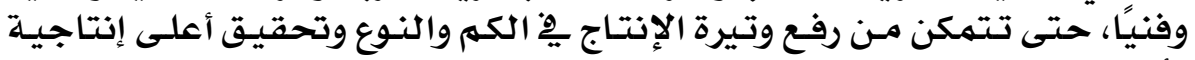

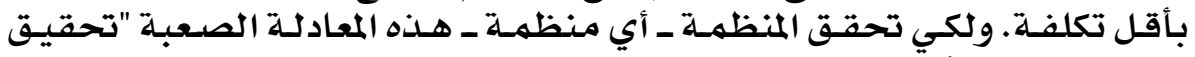

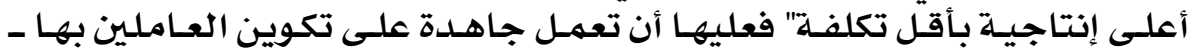

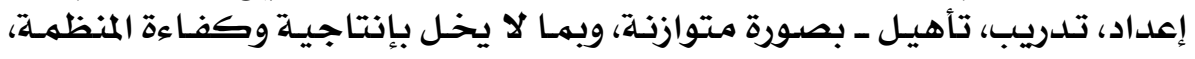

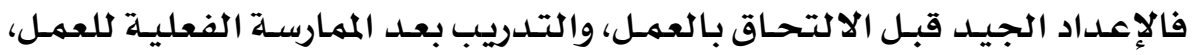

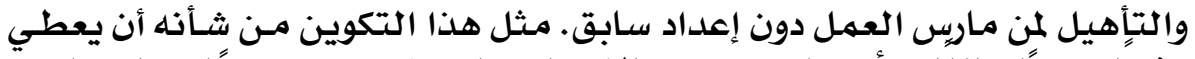

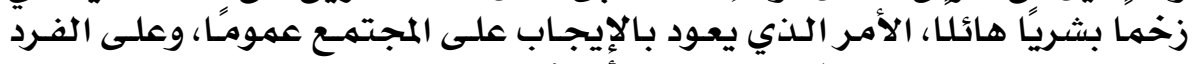

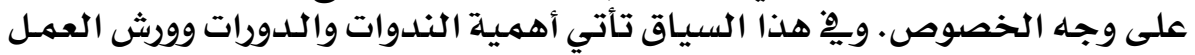

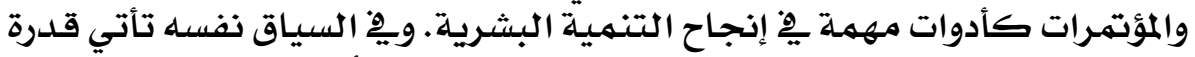

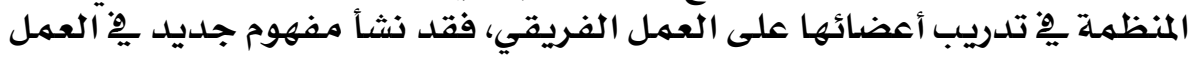

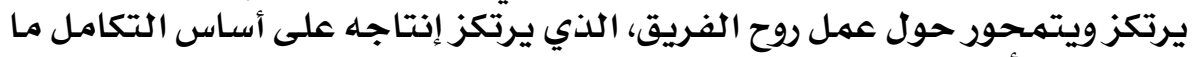

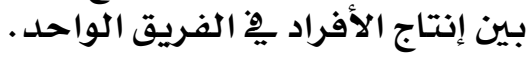

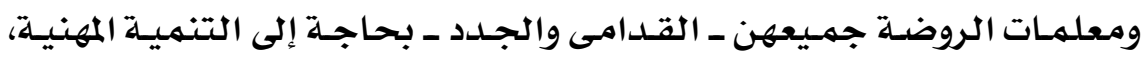

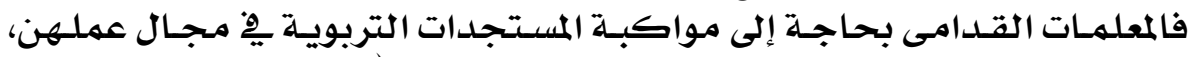

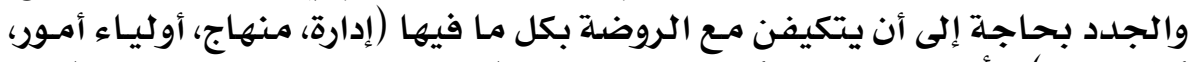

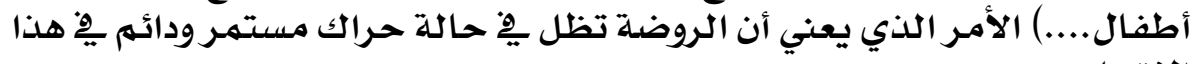
الاتجاه.

\section{6}

در اسات عربية في التزبينة و عنم النفس (ASEP) 


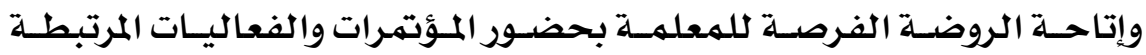

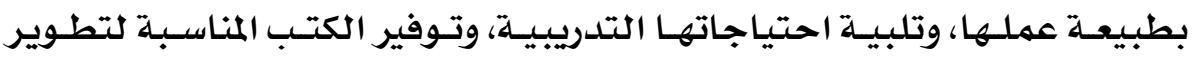

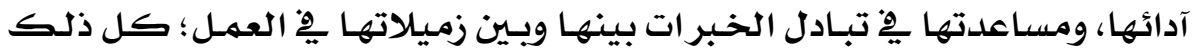

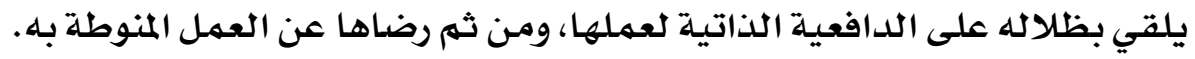

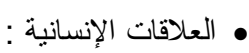

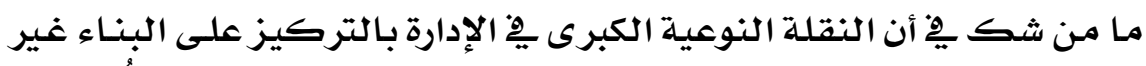

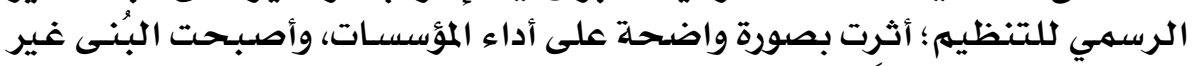

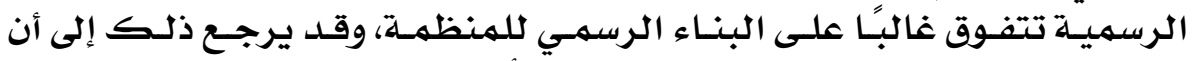

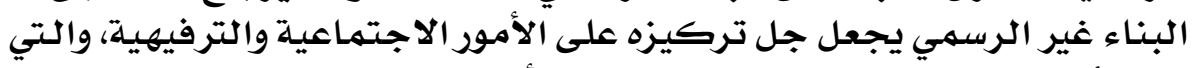

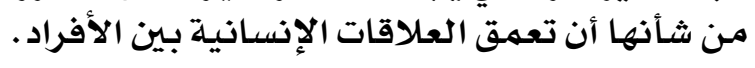

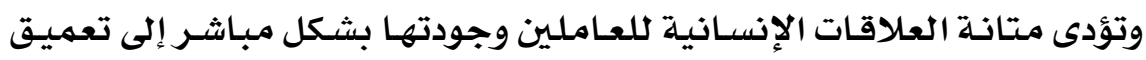

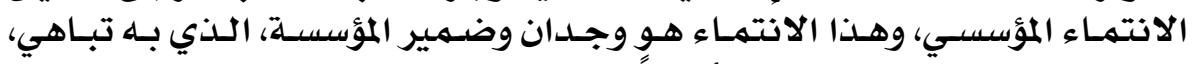

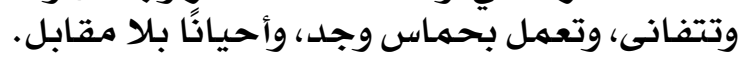

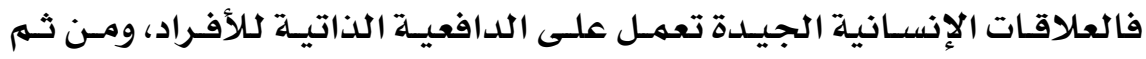

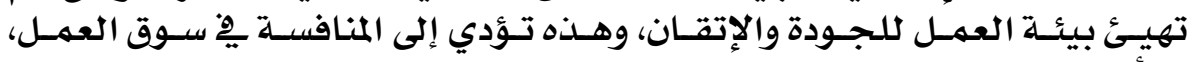

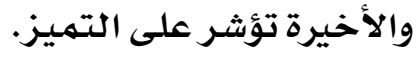

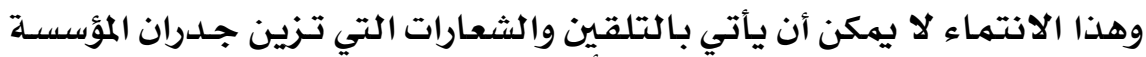

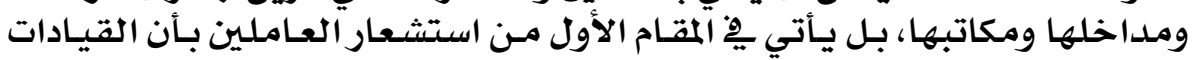

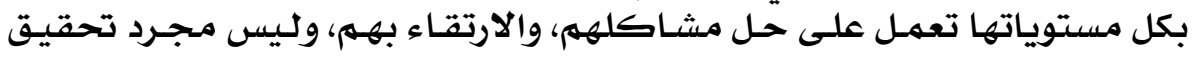

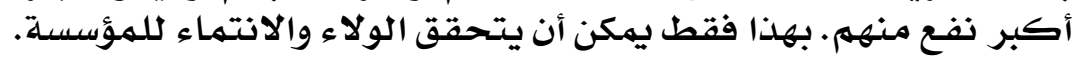

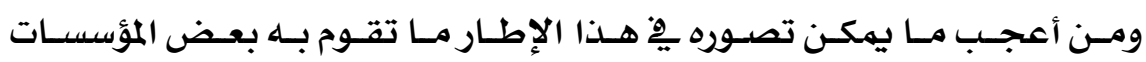

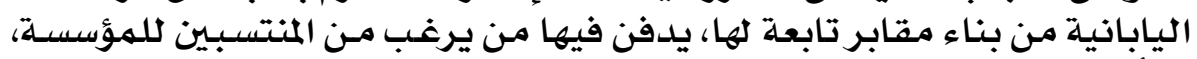

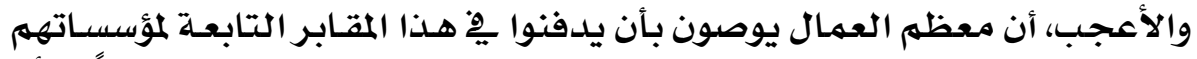

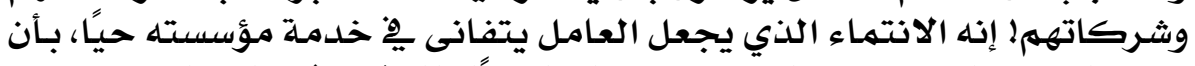

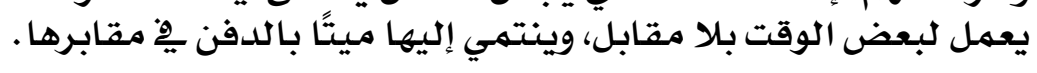

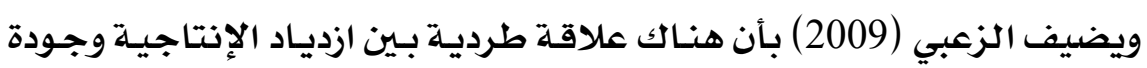

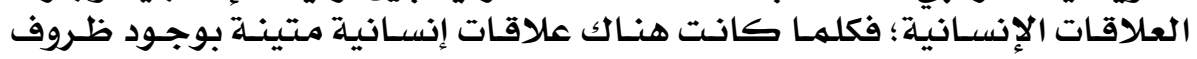

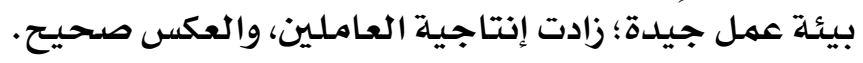

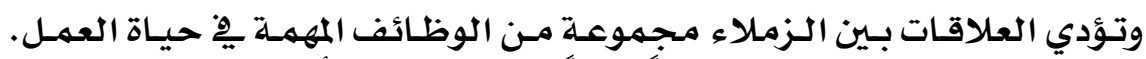

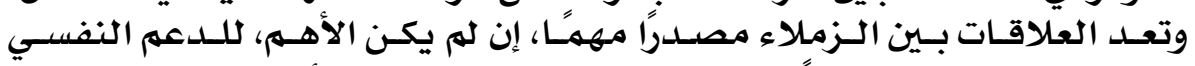

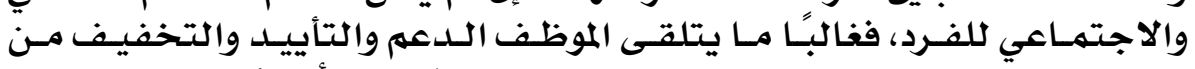

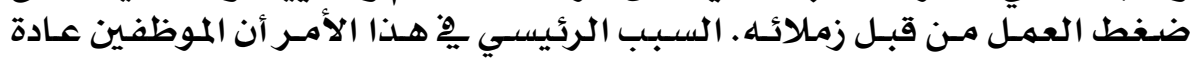

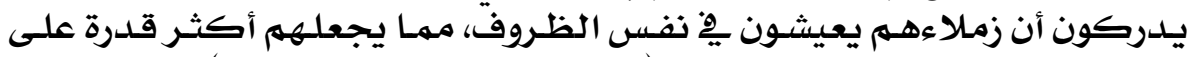

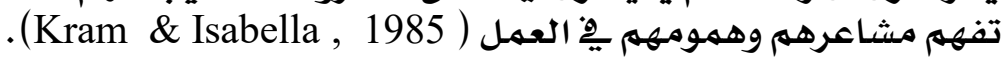

\section{7}




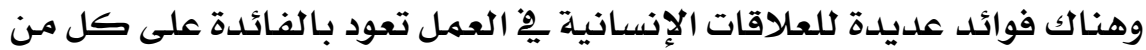

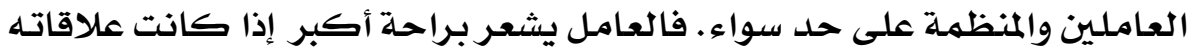

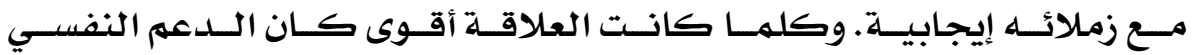

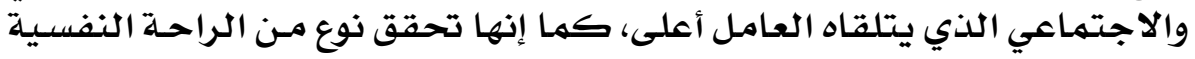

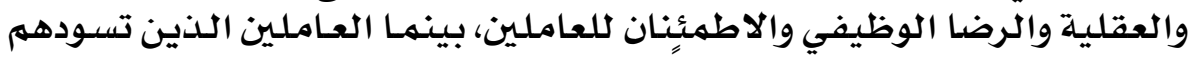

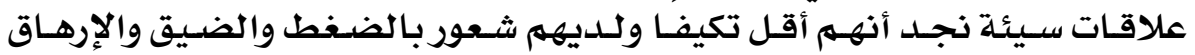
النفسي والجسدي (Demorouti et al, 2001).

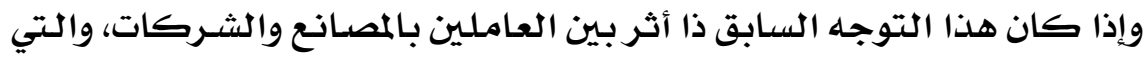

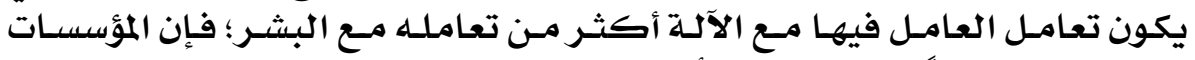

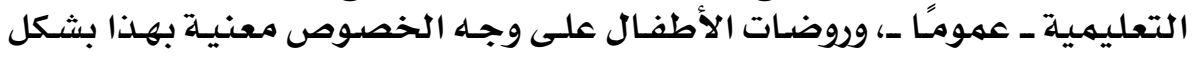

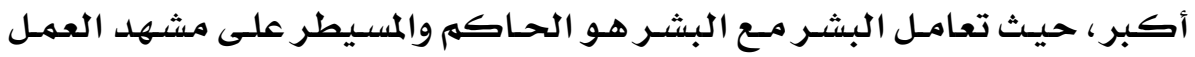
طوال الوقت.

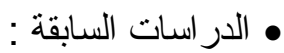

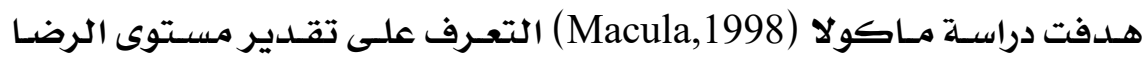

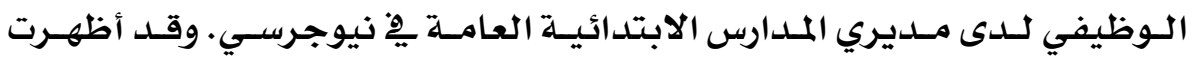

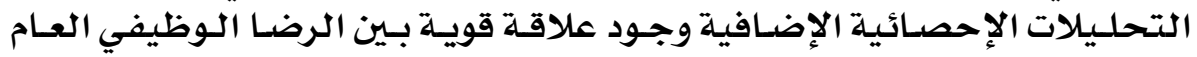

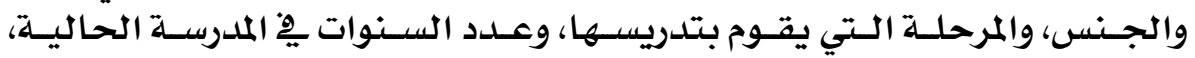

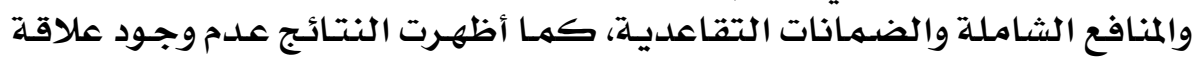

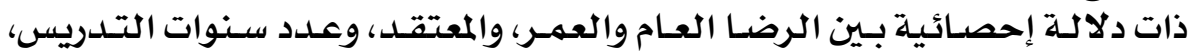

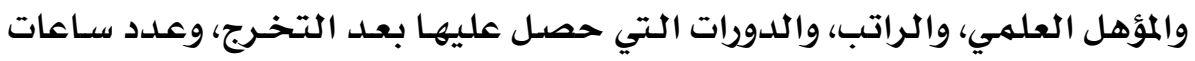

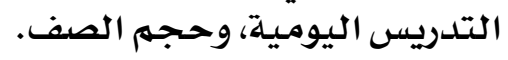

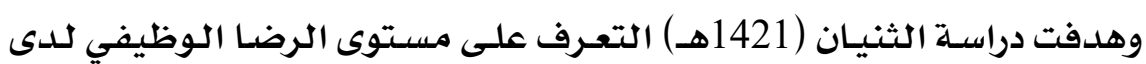

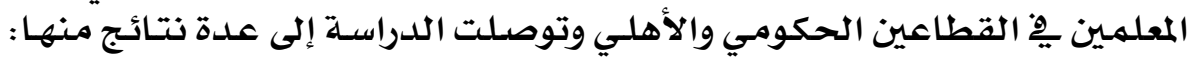

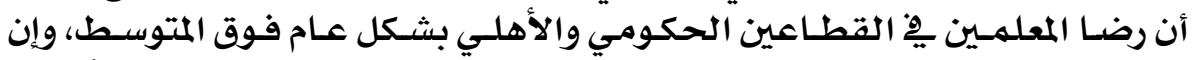

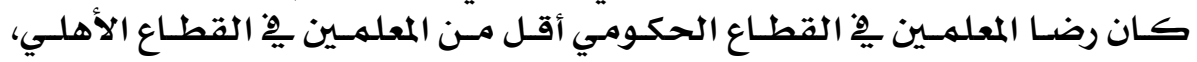

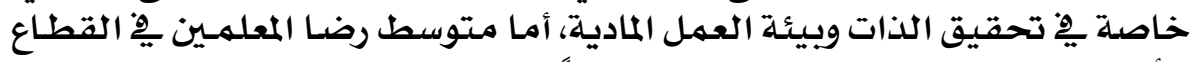

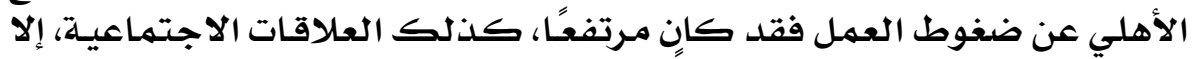

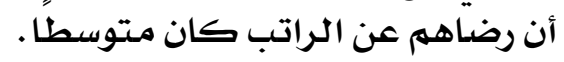

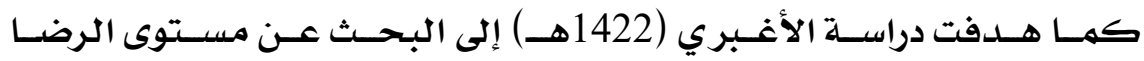

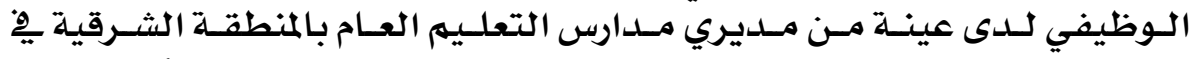

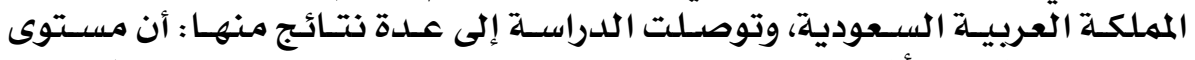

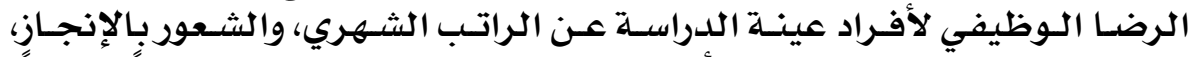

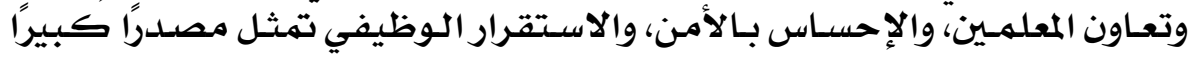

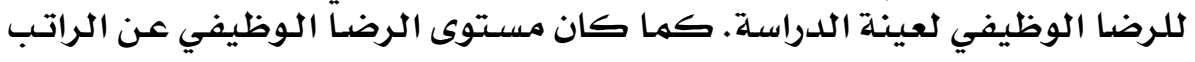

\section{8}




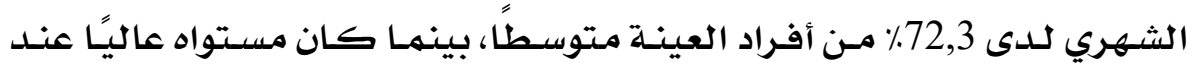

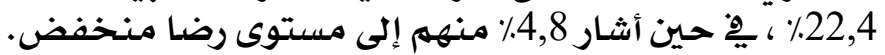

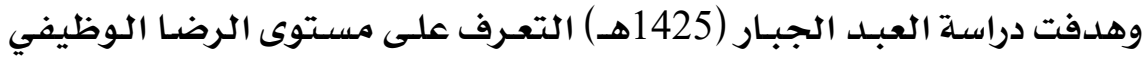

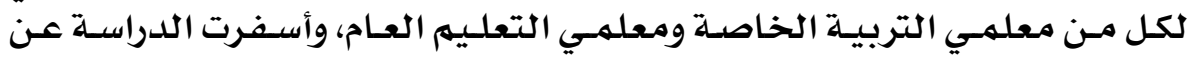

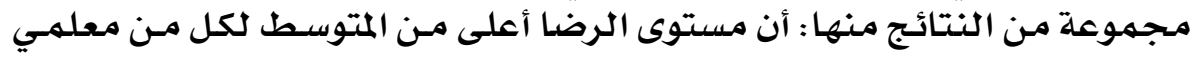

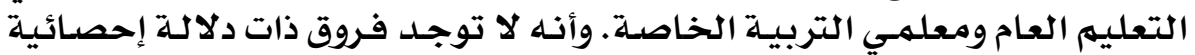
بين استجابات معلمي التعليم العام والتربيـة الخاهة وانهية الخاصدة.

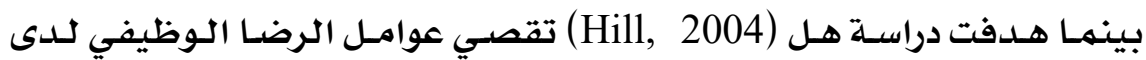

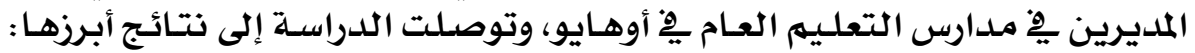

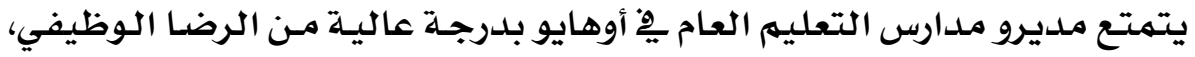

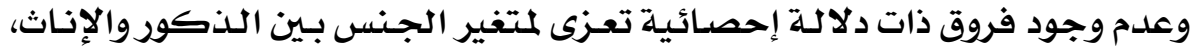

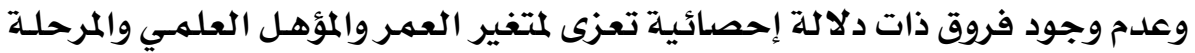

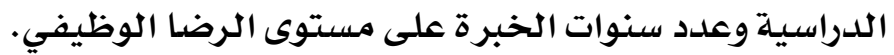

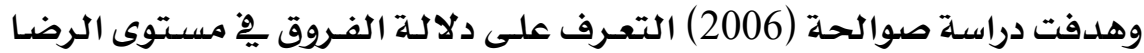

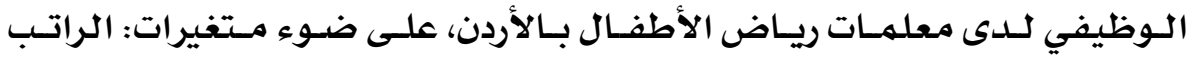

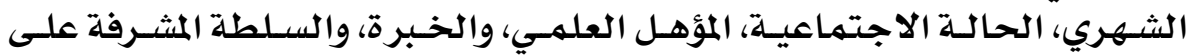

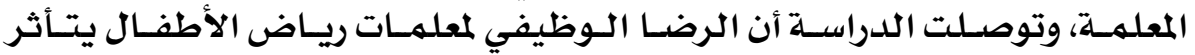

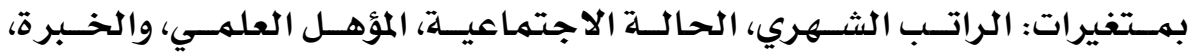

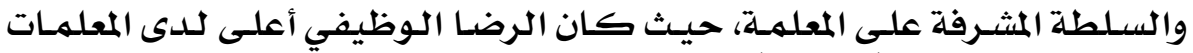

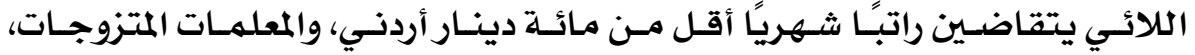

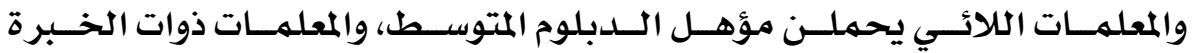

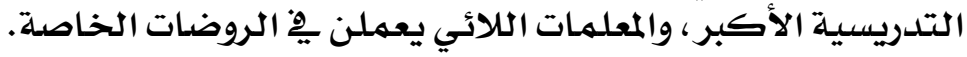

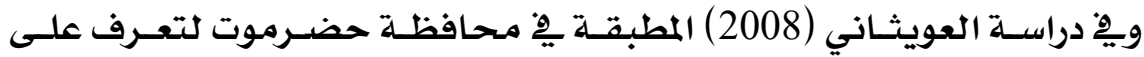

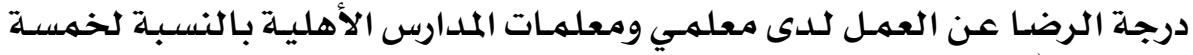

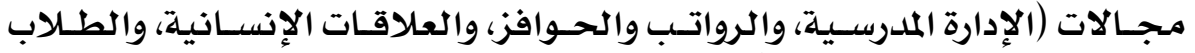

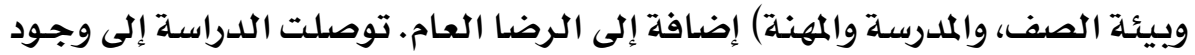

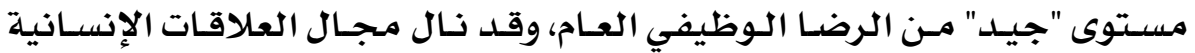

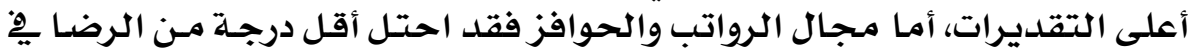
قائمة المجالات.

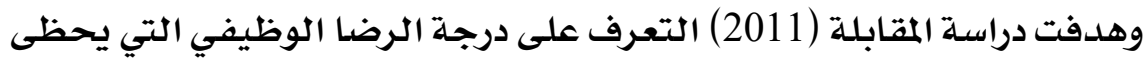

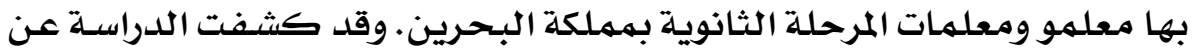

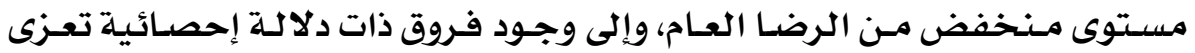

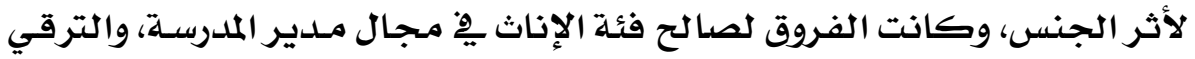

\section{9}




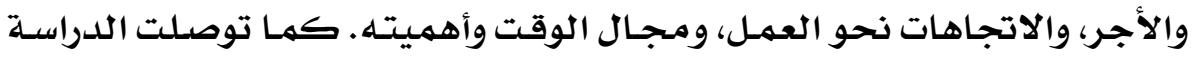

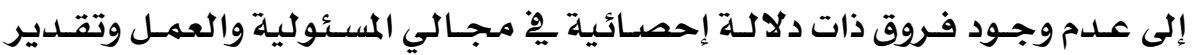

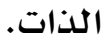

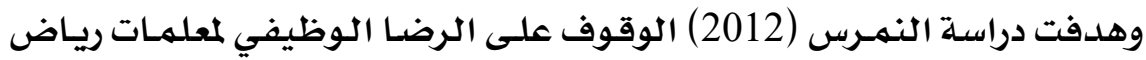

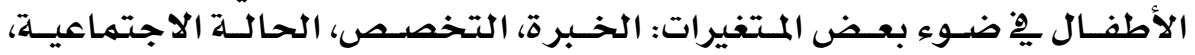

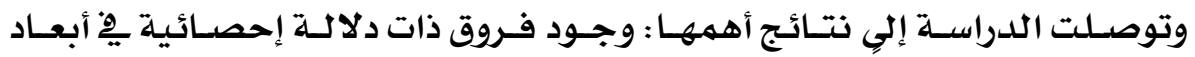

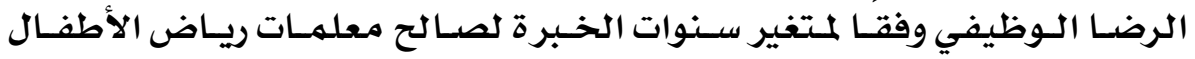

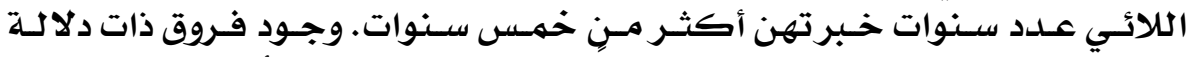

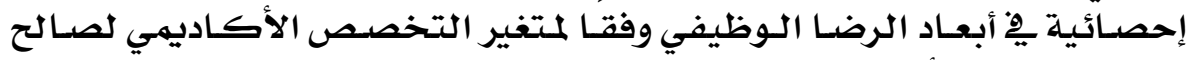

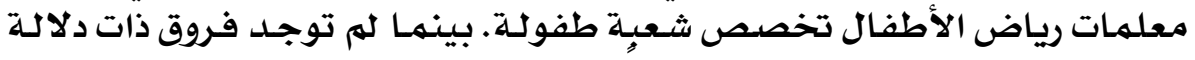
إحصائية فِ أبعاد الرضا الوطفال تحفيفي وفقا لمتغير الحالة الاجتهماعية.

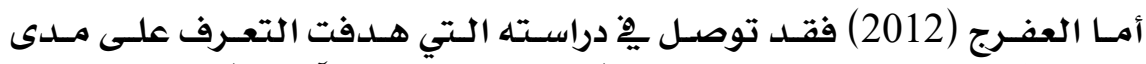

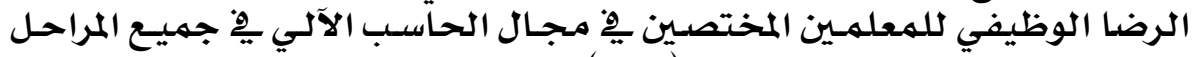

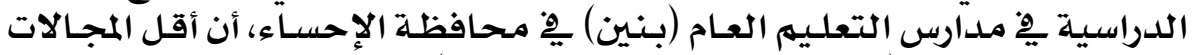

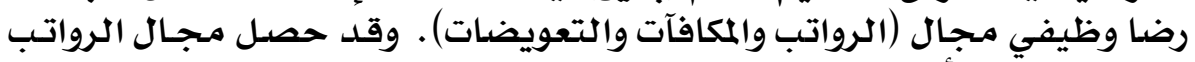

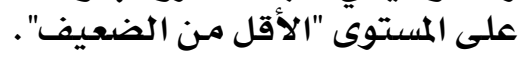

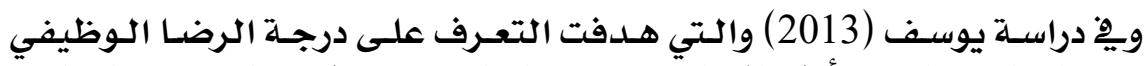

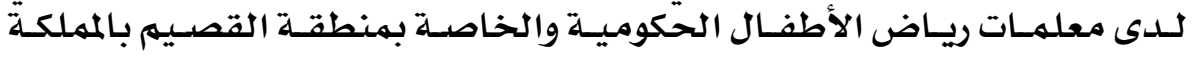

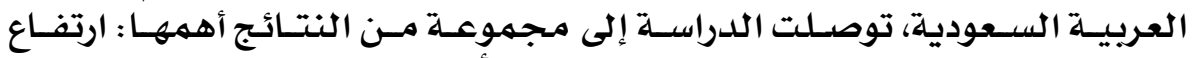

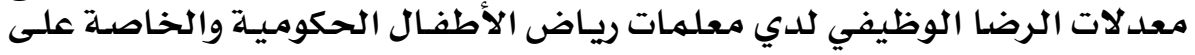

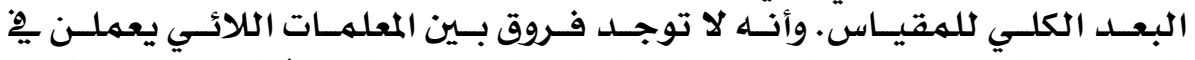

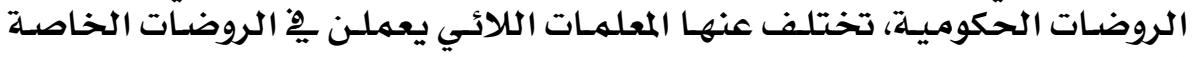

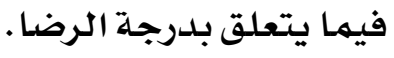

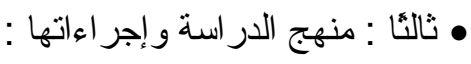

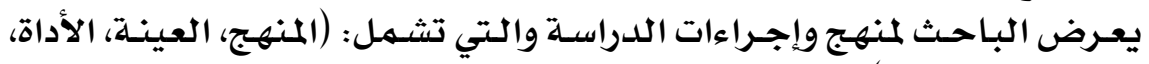

$$
\text { • الأسـاليب الإحصدائية). }
$$

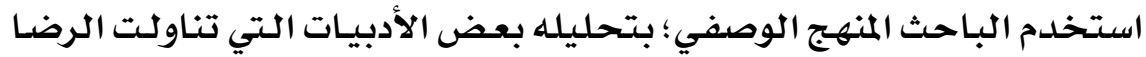

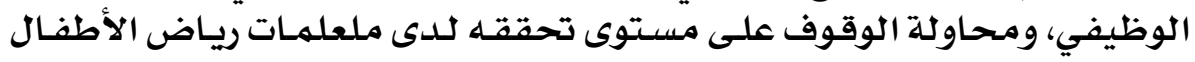
بالمدينة المنورة.

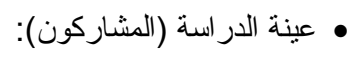

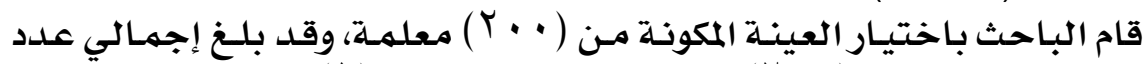

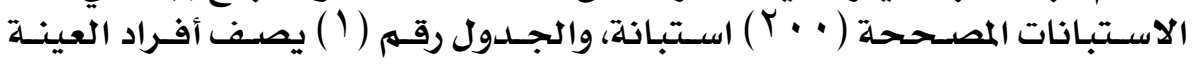

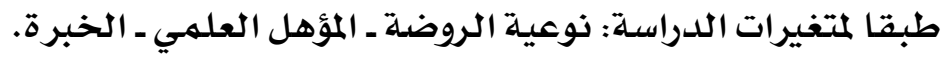

\section{0}

در اسات عربية في التزبينة و عنم النفس (ASEP) 


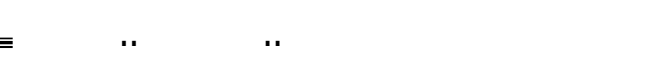

جدول (1) عينة الدراسة وفقًا لمتغيرات الدراسة

\begin{tabular}{|c|c|c|c|c|c|c|c|}
\hline \multicolumn{3}{|c|}{ الخبرة } & \multicolumn{3}{|c|}{ درجـة المؤهل } & \multicolumn{2}{|c|}{ نوعية الروضة } \\
\hline عشر سنوات & من من إن & خمس سنوات & البكالوريوس من & بكالوريوس & عراسات & أهلية & حكومية \\
\hline$\Gamma$ & $\varepsilon$. & $\pi$ & 0. & $T \leqslant V$ & $\Gamma$ & 119 & 71 \\
\hline \multicolumn{3}{|c|}{$r \ldots$} & \multicolumn{3}{|c|}{$r \ldots$} & \multicolumn{2}{|c|}{$r \ldots$} \\
\hline
\end{tabular}

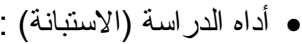

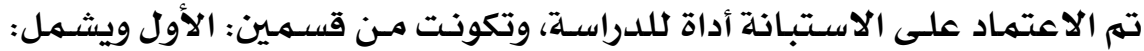

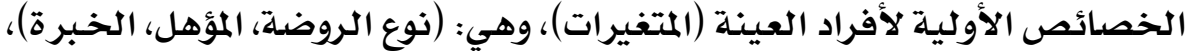

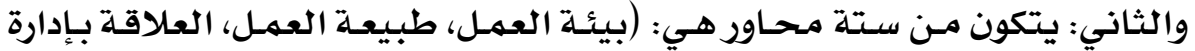

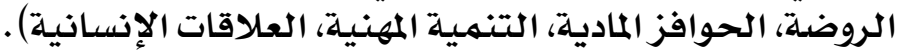

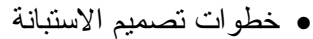

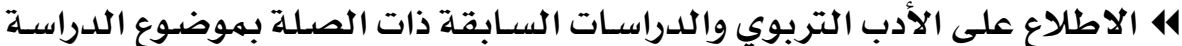

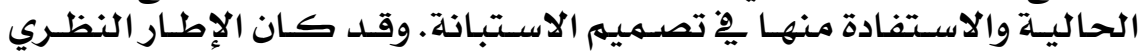

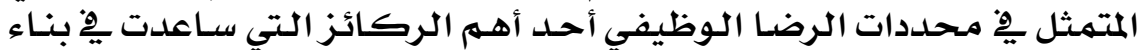

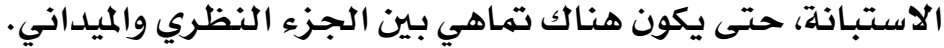

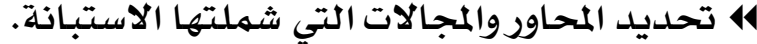

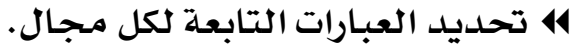
414 تصميم الاستبانة بصورتها العابتا الأولية.

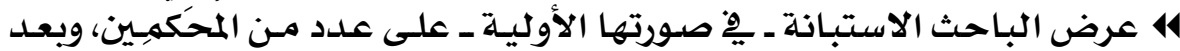

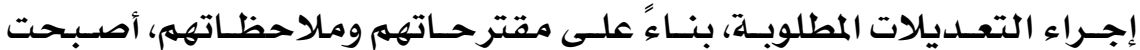

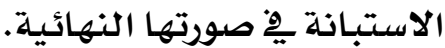

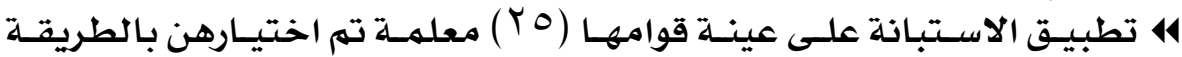

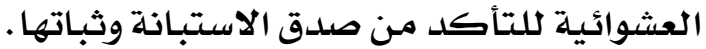

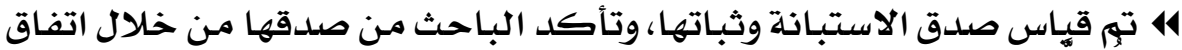

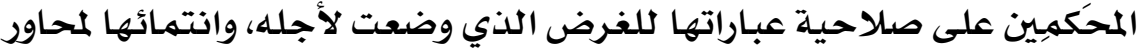

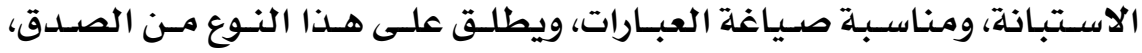

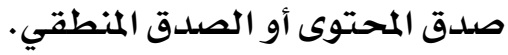

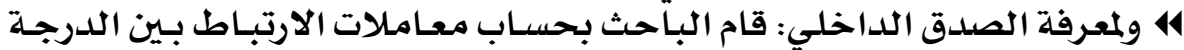

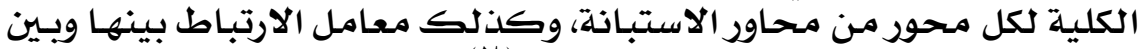

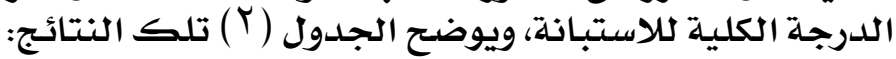

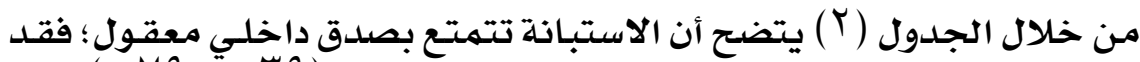

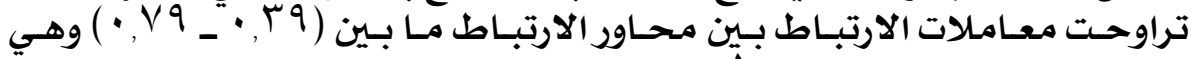

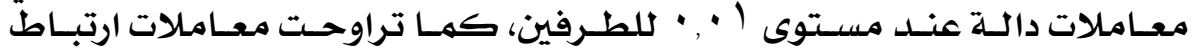

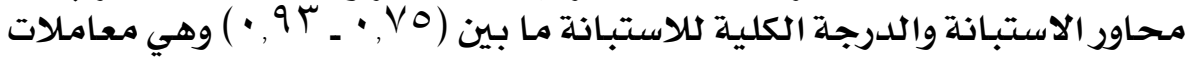

\section{1}

در اسات عربية في التربينة و عنم النفس (ASEP) 


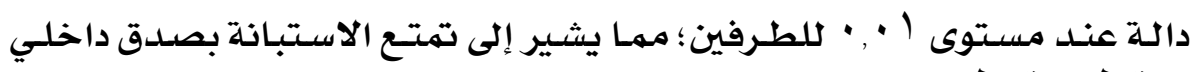

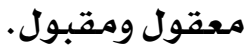

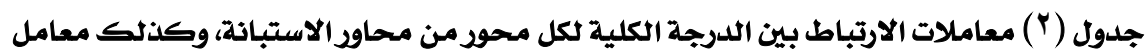
الارتباط بينها ويين الدرجة الكلية للاستيانة

\begin{tabular}{|c|c|c|c|c|c|c|c|}
\hline الدلية & الإنسلانية & التنمية & الحمادية & العلاقة بإدارة & طبيعة & بيئة العمل & المحور \\
\hline & & & & & & - & بيئة العمل \\
\hline & & & & & - & $\Leftrightarrow \Leftrightarrow, V T$ & طبيعة العمل \\
\hline & & & & - & 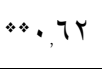 & $\because .0 Y$ & العلاقة بإدارة \\
\hline & & & - & $* ., 4 q$ & 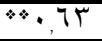 & $\because 4.70$ & الحوافز المادية \\
\hline & & - & $\because, 79$ & $* 6.74$ & $* 6,19$ & 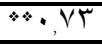 & التنميـية المهنيـية \\
\hline & - & $\Leftrightarrow, y 0$ & $\Leftrightarrow .0 \leqslant$ & $* 0.09$ & $\Leftrightarrow, 71$ & $\Leftrightarrow .0 \mathrm{~V}$ & الإنسانية العلاقات \\
\hline- & $\because, \wedge$ & $* .94$ & $\because, 199$ & $\because, y 0$ & $\because, \wedge \wedge$ & $\because \Leftrightarrow, \Lambda \varepsilon$ & الدرجـة الكليـية \\
\hline
\end{tabular}

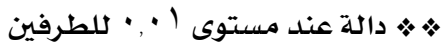

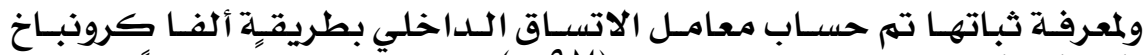

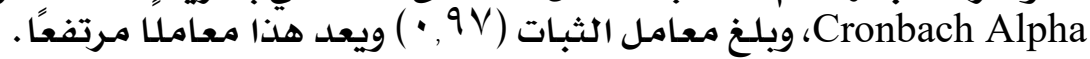

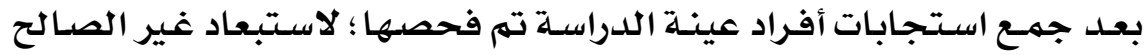

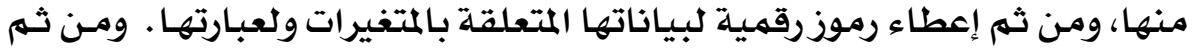

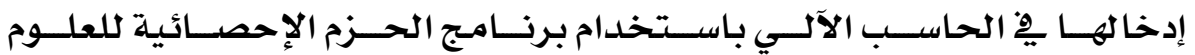
الاجتماعيـة (SPSS) (Statistical Package for the Social Sciences) . ولمعرفة

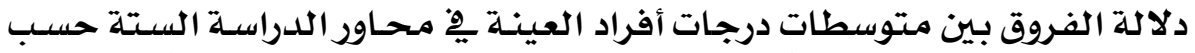

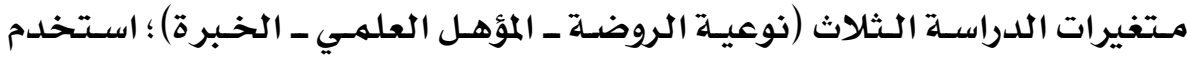

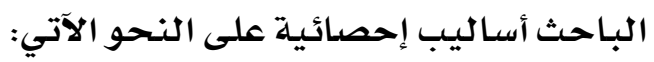

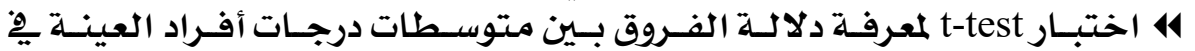

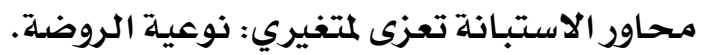

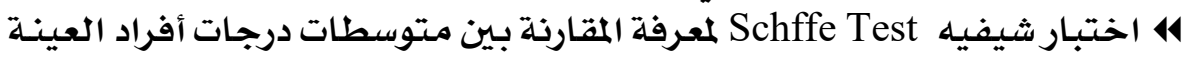

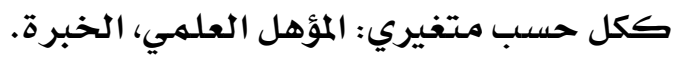

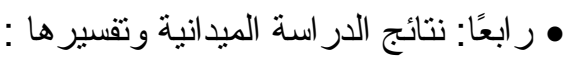

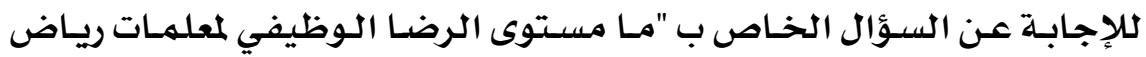

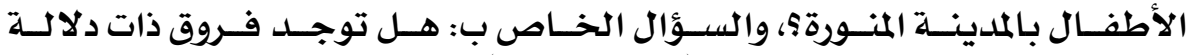

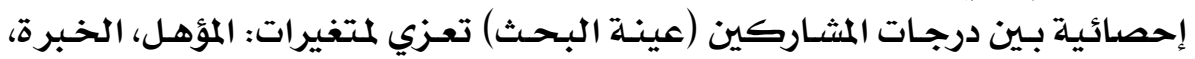

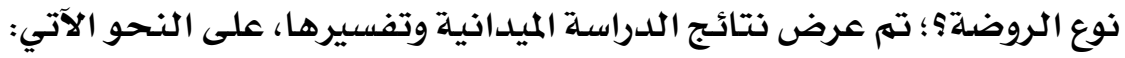

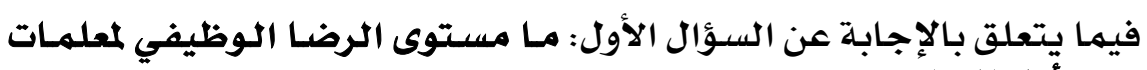

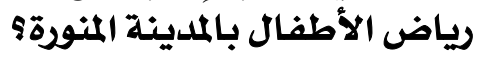

\section{2}




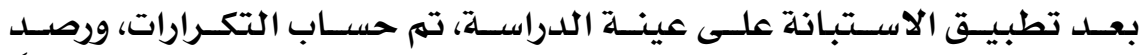

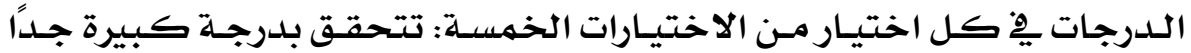

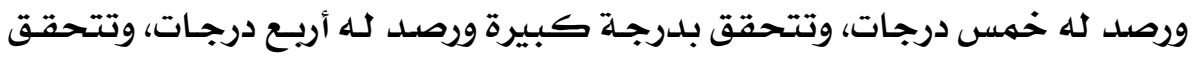

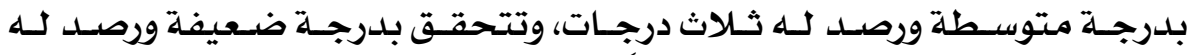

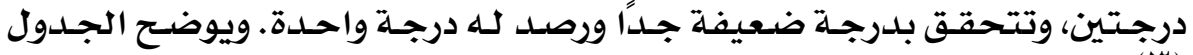

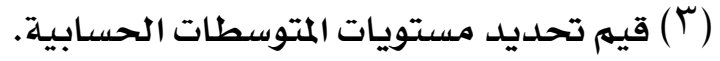

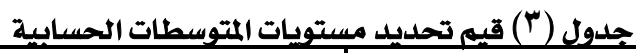

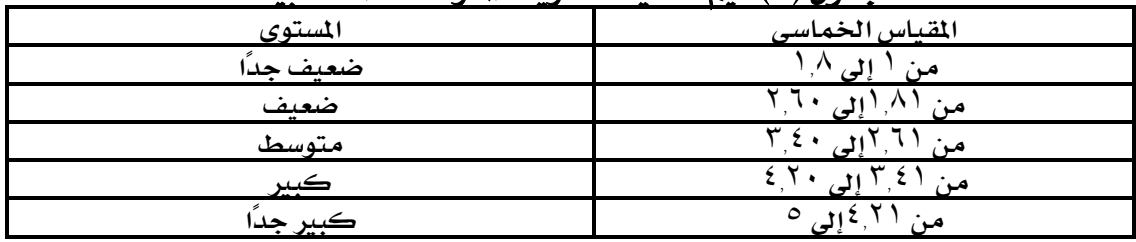

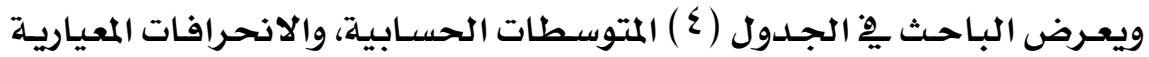

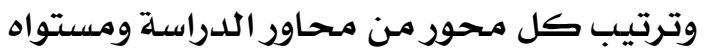

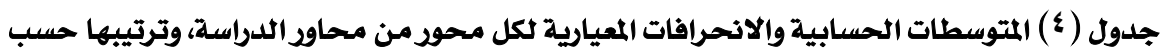

\begin{tabular}{|c|c|c|c|c|c|}
\hline \multicolumn{6}{|c|}{ 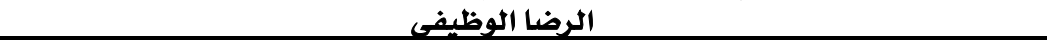 } \\
\hline الترتيب & التحقى & الالانحراف & الحسابي & المحور & r \\
\hline الخامس & كبيرة & 79 & 5.01 & بيئة العمل & $T$ \\
\hline الثالث & كبيرة & $\frac{V .17}{17}$ & $r, \Lambda T$ & طبيعة العمل & $r$ \\
\hline الأول & كبيرة جدًا & 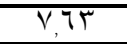 & $E, Y Y$ & العلاقة بإدارة الروضة & $T$ \\
\hline السادس & متوسطة & $V, 9 \varepsilon$ & T,VT & الحوافز المادية & $\varepsilon$ \\
\hline الرابع & كبيرة & $1 \cdot, \cdot 1$ & $r .7$. & التنمية المهنية & 0 \\
\hline الثاني & كبيرة & $0, \mathrm{~V}$. & 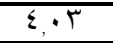 & العلاقات الإنسانية & 7 \\
\hline
\end{tabular}

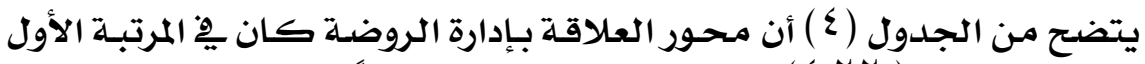

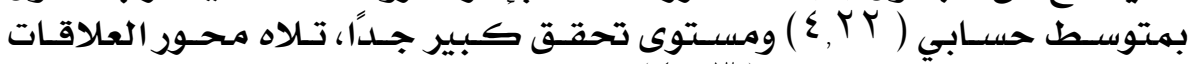

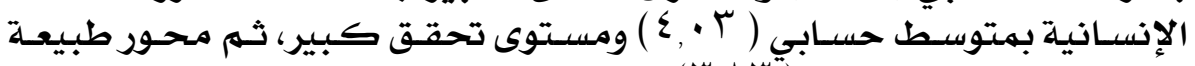

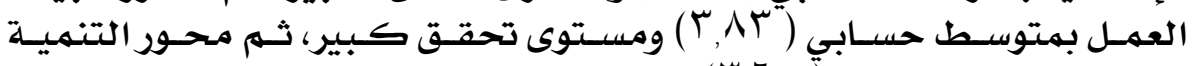

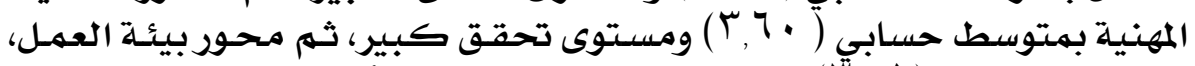

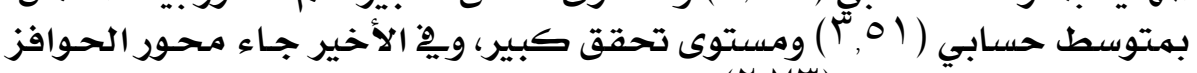

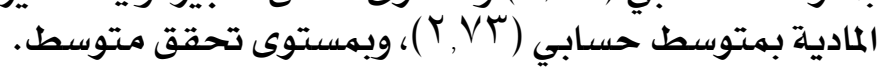

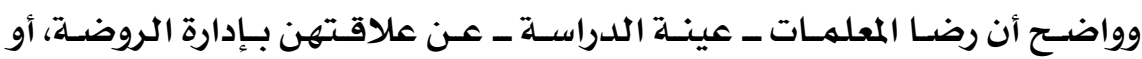

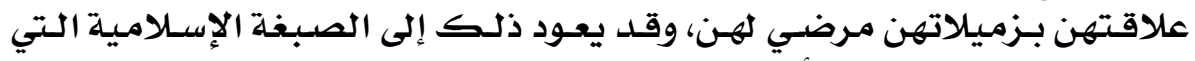

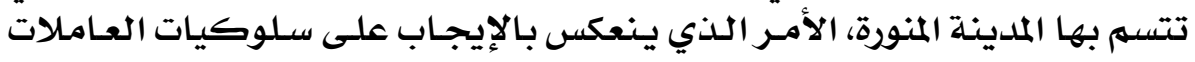
بالروضة سواء بينهن وبين بعضهن البعض، أو بينهن وبين الإين زميلاتهن.

\section{3}

در اسات عربية في التزبية و عنم النفس (ASEP) 


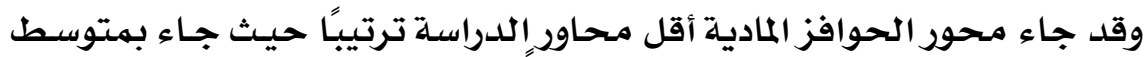

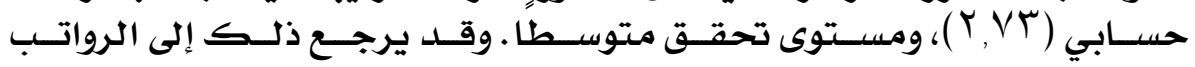

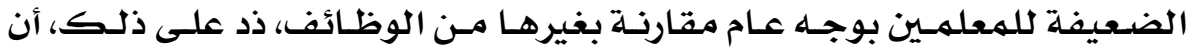

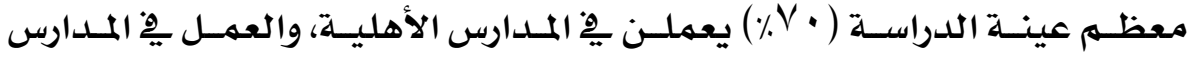

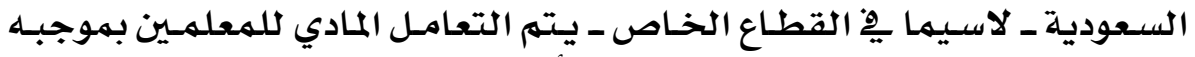

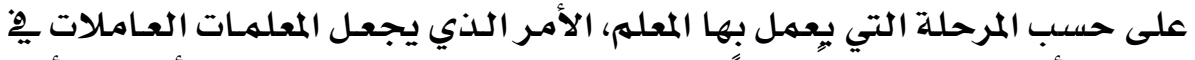

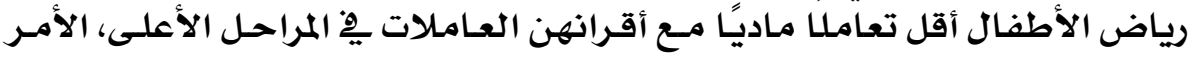

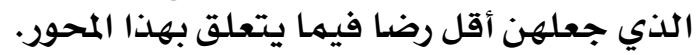

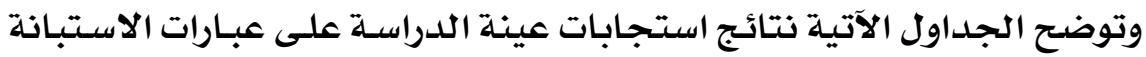

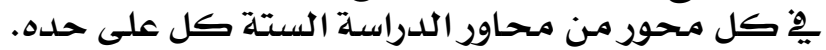

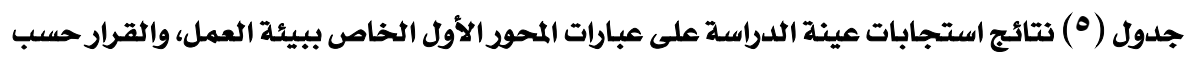

\begin{tabular}{|c|c|c|c|c|c|}
\hline القرار & & & 1 & & \\
\hline تـتحقق & الترتيب & الالمعياري & الحسسابي & الفقرة & م \\
\hline كبيرة & الثالث & .94 & r. vo & تشكل دائمر بالروضدة الامكانات اللازمـة لأداء العمل & 1 \\
\hline كبيرة & 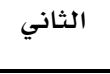 & .99 & r,VT & 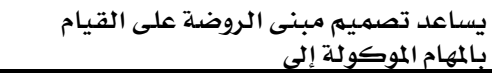 & r \\
\hline كبيرة & الأول & $1, r$ & r,人 & تالجوفرتبن بالروضدة مقومات الإضـاءة والتهوية & r \\
\hline كبيرة & الرابع & $1, Y 1$ & $r, 71$ & المسـافة بـين سكني وعملي مناسبـة & $\varepsilon$ \\
\hline كبيرة & 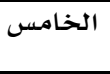 & 1,11 & $\Gamma \leq \Lambda$ & توفر الروضة لي مكانًا مناسبًا لإدارة أنشطة & 0 \\
\hline متوسطة & الثامن & 1,19 & r, $\wedge 0$ & توفر الروضـة لي الرعاية الصحيـة الكلازمة & 7 \\
\hline متوسطة & السـابع & سו, & سب, & 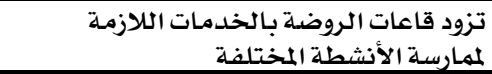 & 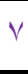 \\
\hline كبيرة & السادس & $1,1 \mathrm{~V}$ & $\Gamma \leq \varepsilon$ & تتوافر ِِ الروضـة أنشطة ترفيهية مختلفة & $\Lambda$ \\
\hline كبيرة & & $7,9$. & r.01 & إجمـالى & \\
\hline
\end{tabular}

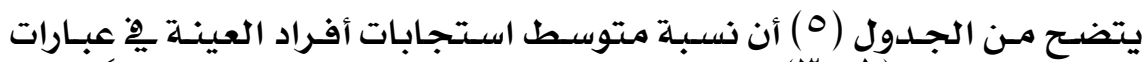

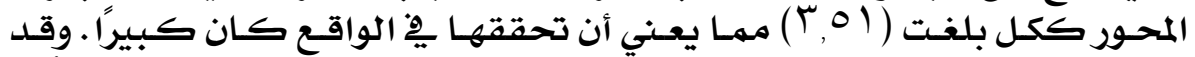

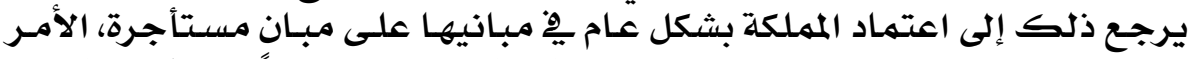

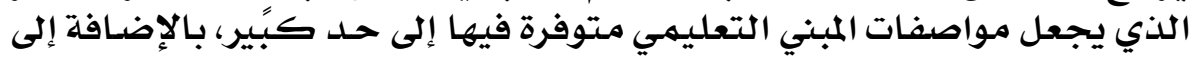

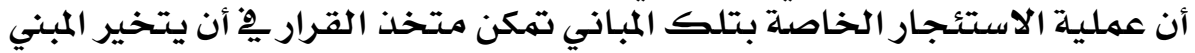

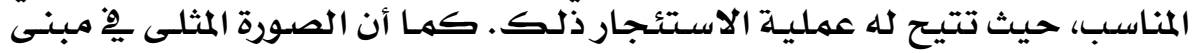

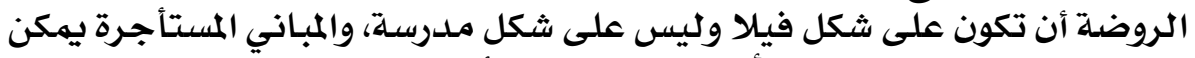

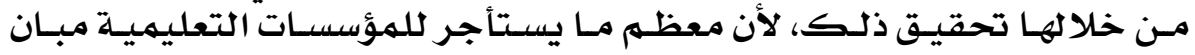

\section{4}

در اسات عربية في التزبيتة و عنم النفس (ASEP) 


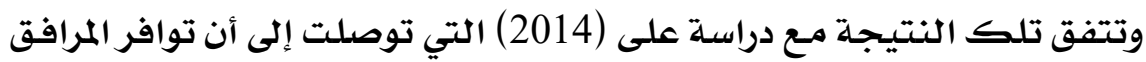

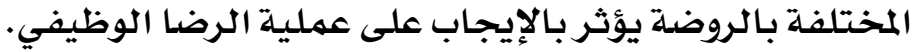

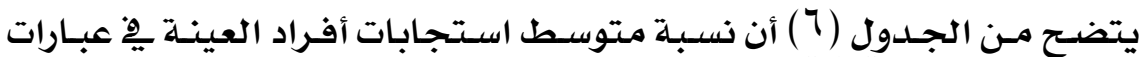

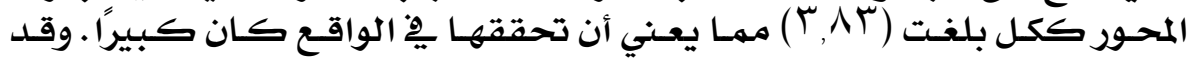

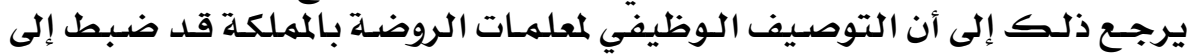

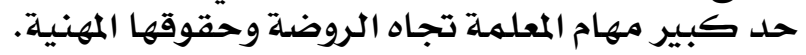

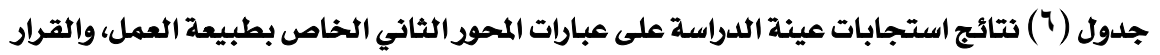

\begin{tabular}{|c|c|c|c|c|c|}
\hline 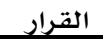 & \multirow[b]{2}{*}{ 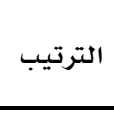 } & \multirow[b]{2}{*}{ الانحياري المراف } & \multirow[b]{2}{*}{ الحستوسطي ابلي } & \multirow[b]{2}{*}{ 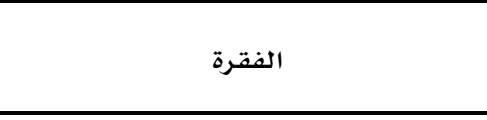 } & \multirow[b]{2}{*}{ s } \\
\hline ت بتحقق & & & & & \\
\hline 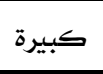 & 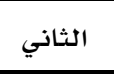 & 1,7 & $\varepsilon, 17$ & يتوافق العمل الذي أقوم به مـع مؤهلي & 1 \\
\hline كبيرة & 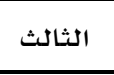 & .97 & $\varepsilon, r$ & يوجد توصيف واضح ومحدد ملما يوكل إلى مهام & r \\
\hline كبيرة & الأول & $\cdot 90$ & $\left\{, Y_{1}\right.$ & تقيم المديرة آدائي بناء على معايير واضحدة ومحسة & $r$ \\
\hline 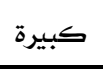 & 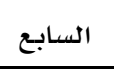 & $1, r$. & r, $\vee \wedge$ & تتناسب عدد ساعات عملي مـع مـا أقوم بها مـع & $\varepsilon$ \\
\hline كبيرة & الثامـن & 1,4 & $r, 01$ & الاجازات الرسمية التى أحصل عليها كافية & 0 \\
\hline متوسطة & التاسـع & $1, T$ & T,YT & الوقت المخصص لأجـازه الأمومـة كاف & 7 \\
\hline 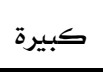 & 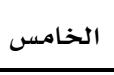 & $1, \cdot V$ & r, & 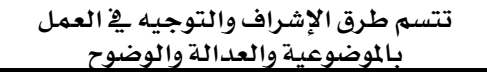 & V \\
\hline كبيرة & السادس & $1, \cdots$ & $r, \lambda Y$ & يتنـاسب عبء أعمالى بـالروضـة مـع قدراتي & $\Lambda$ \\
\hline 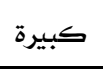 & 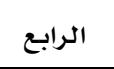 & $1, r$ & r,q & يتيح لي عملي فرصـة للتفاعل مـع المجتهـع & 9 \\
\hline كبيرة & & 8,17 & $r, \Lambda T$ & إجمالي & \\
\hline
\end{tabular}

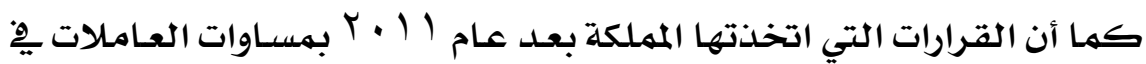

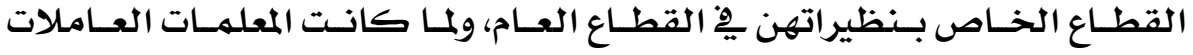

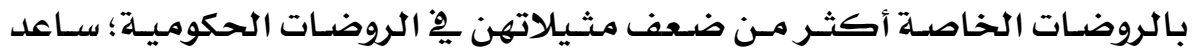

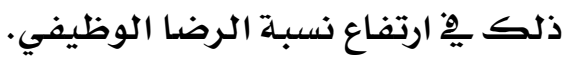

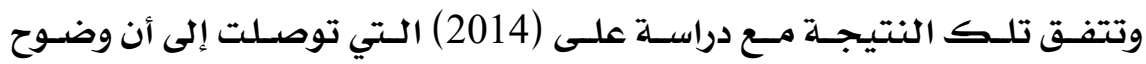

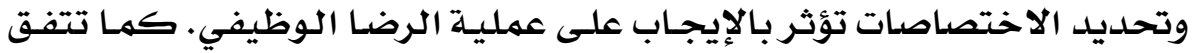

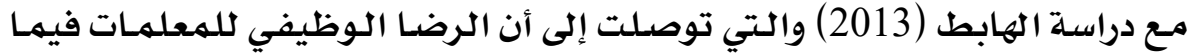
يتعلق بالأنظمة والتعليمات واتهات والقوانين مـرتفعًا.

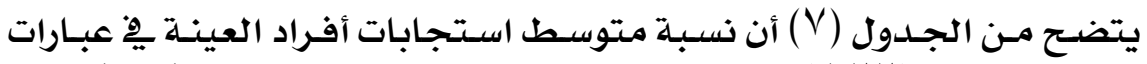

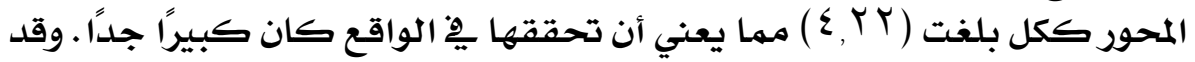

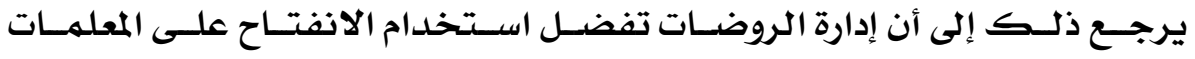

\section{5}

در اسات عربية في التزبينة وسنم النفس (ASEP) 
للتواصل الدائم بين المعلمات وأسرة الطفل، الأمـر الذي يتطلـب معـه انفتاح إدارة الروضة مـع المعلمات بهات التهات المعالعات

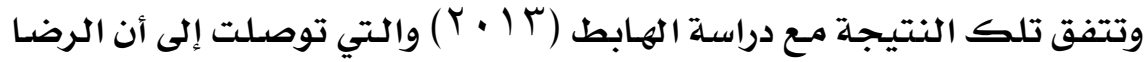

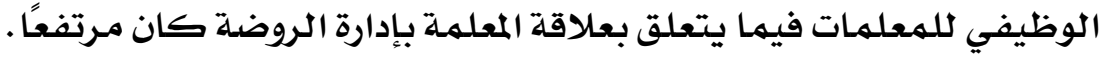

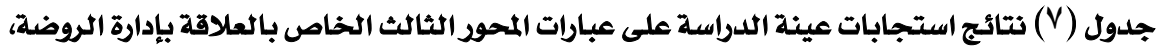

\begin{tabular}{|c|c|c|c|c|c|}
\hline القراد & & & & & \\
\hline تسحقق & الترتيب & المعياري & الحسـابي & 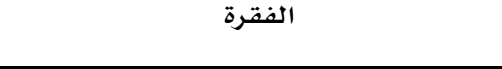 & r \\
\hline كبيرة & 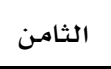 & $\cdot 91$ & $\varepsilon, 1 V$ & أشعر بأني موضع تقدير واهتمـام من قبل إدارة & 1 \\
\hline 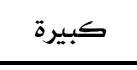 & العاشر & $\cdot 90$ & $\leqslant 10$ & تتيح إدارة الروضة لي فرصدة كافية للتعبير & r \\
\hline كبيرة & السـابع & $\cdot 94$ & $\varepsilon, 1 V$ & تتضح قنوات الاتصال بيني وبين رؤسـائي يف & $r$ \\
\hline كبيرة جداً & الرابـع - ابع & $\cdot 9 r$ & $\varepsilon, r \varepsilon$ & تعمل إدارة الروضمات على إيجادئ علدي الودات طيبـة مـع & $\varepsilon$ \\
\hline كبيرة & السـادس &., 94 & $\varepsilon, Y$ & توزع مديرة الروضـة العمل بـين المعلمـات بعدالة & 0 \\
\hline كبيرة جداً & 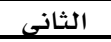 & $\cdot 9 \mathrm{~V}$ & $\varepsilon, Y 7$ & تتقبل المديرة مني النقد البناء بصدر رحب & 7 \\
\hline كبيرة & التاسـع & $\cdot 99$ & $\varepsilon, 10$ & أشارك ِِْ صناعة القرارات التي تتصل بههامي & $\mathrm{V}$ \\
\hline كبيرة جداً & 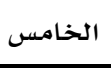 & $\cdot 9 \leq$ & $\varepsilon, Y_{1}$ & تشجعني المديرة عندما أقوم بالعمل على نحو & $\Lambda$ \\
\hline كبيرة جلـا & 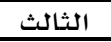 & $\cdot \wedge 0$ & $\varepsilon, Y_{0}$ & توجهنى المشرفة بطريقة مناسبة وبناءه & 9 \\
\hline كبيرة جداً & الأول & $\cdot \mathrm{VV}$ & $\varepsilon, \Gamma$ & علاقتى بمشرفة المادة تقوم على الود والاحتر ام & 1. \\
\hline كبيرة جداً & & $\mathrm{V,T}$ & $\varepsilon, Y Y$ & إجمالىي & \\
\hline
\end{tabular}

جدول (^) نتائج استجابات عينة الدراسة على عبارات المحور الرابع الخاص بالحوافز المادية، والقرار حسب درجة التحقق المحر الرقار

\begin{tabular}{|c|c|c|c|c|c|}
\hline القرار & & & & & \\
\hline تلتحقق & الترتيب & 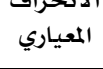 & 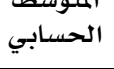 & 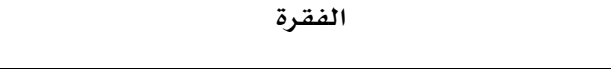 & م \\
\hline كبيرة & الأول & $1, r \cdot$ & $r, \varepsilon Y$ & ما اتقاضاه من راتب يتناسب مـع الجهد الذي أبذله & $T$ \\
\hline متوسطة & الرابع & ד, 1, & $r, V T$ & يمنحني عملي حوافز أفضل من غيره يِّ الجهات & r \\
\hline ضعيفة & السادس & $1, Y \Lambda$ & $r, \leqslant \varepsilon$ & ما سوف اتقاضاه من راتب بعد التقاعد كافِ بالنسبة لى & $r$ \\
\hline متوسطة & الثالث & $1, \Gamma$ & r,Vo & يتناسب راتبي مـع مستوى المعيشة السائدة ٍِِ المجتهـع & $\varepsilon$ \\
\hline متوسطة & 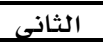 & $1, T V$ & $\Gamma, \varepsilon$ & يتناسب الراتب الذى اتقاضـاه مـع خبرتي فِ العمل & 0 \\
\hline ضعيفة & السابع & $1, \mu \nu$ & $r, r q$ & أحصل على أجر إضـايِّ عند زيادةً ساعات العمل عن ثمان & 7 \\
\hline ضعيفة & الخامس & $1, \Sigma 1$ & $r, \leq 9$ & أشعر بأن نسبة الزيادة السنوية على راتبى ملائمة وعادلة & $\bar{V}$ \\
\hline متوسطة & & V,9乏 & $r, V$ & إجمالى & \\
\hline
\end{tabular}

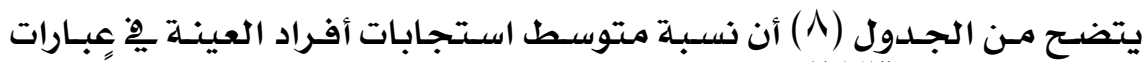

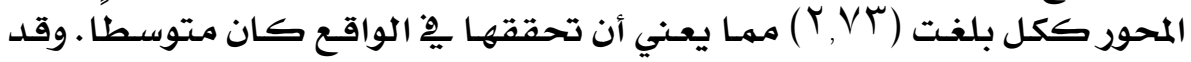

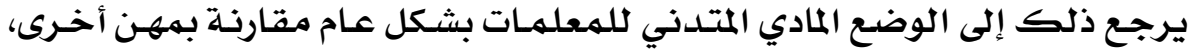

\section{6}

در اسات عربية في التزبيتة و عنم النفس (ASEP) 


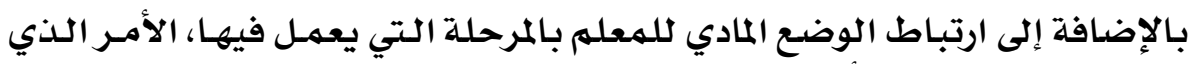

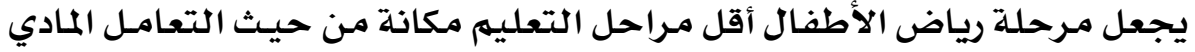

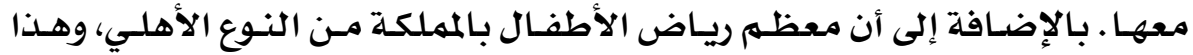

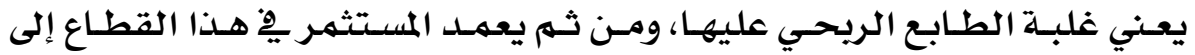

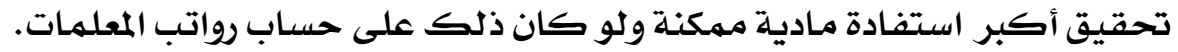

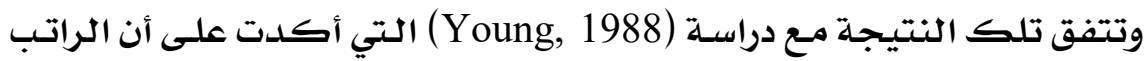

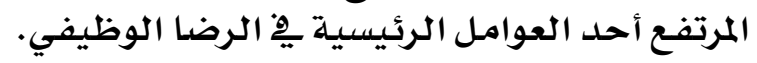
جلدول ( 9) نتائج استجابات عينة الدراسة على عبارات المحور الخامس الخاص بالتنمية المهنية، والقرار

\begin{tabular}{|c|c|c|c|c|c|}
\hline القرار & \multirow[b]{2}{*}{ الترتيب } & \multirow[b]{2}{*}{ الانحياري } & \multirow[b]{2}{*}{ الحستوسطي } & \multirow[b]{2}{*}{ 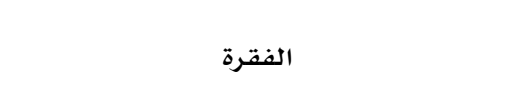 } & \multirow[b]{2}{*}{ r } \\
\hline تلتحقق & & & & & \\
\hline كبيرة & الأول & $1, \cdot 1$ & r,Ar & يتيح العمل لى إمكانية تطوير مهاراتى المختلفة & 1 \\
\hline 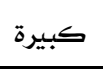 & 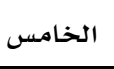 & $1, \mu$ & $r .79$ & تتيح لي مديرة الروضلت المتصلة فرص حضور المؤتمرات & r \\
\hline متوسطة & الثامن & 1,19 & T,T & يوفر لي عملي فرصنًا مناسبـة للترقي الوظيفي & $\Gamma$ \\
\hline 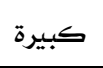 & 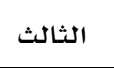 & س & $r, y$, & 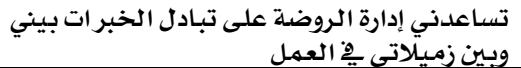 & $\varepsilon$ \\
\hline كبيرة & السـابع & $1,1,4$ & T, ह1 & يتاح لي التدريب الكاف لتطوير أدائي المهني & 0 \\
\hline 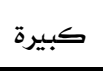 & السادس & $1, r \varepsilon$ & r.or & توفر لي إدارة الروضة فرضية، & 7 \\
\hline 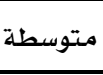 & التاسـع & $1, \leqslant 0$ & וזبr & 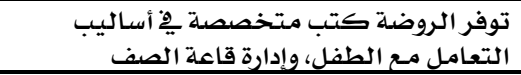 & V \\
\hline كبيرة & 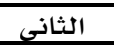 & $1, Y \Lambda$ & $r, V V^{2}$ & تمدنى زميلاتى بما احتاج من عون لتطوير أدائي & $\Lambda$ \\
\hline كبيرة & الرابع & 1,17 & $r, 79$ & يوفر لي عملي بـالروضـة فرصـا للإبداع & 9 \\
\hline كبيرة & & $1 \cdot, 1$ & $r, 7$. & إجمالي & \\
\hline
\end{tabular}

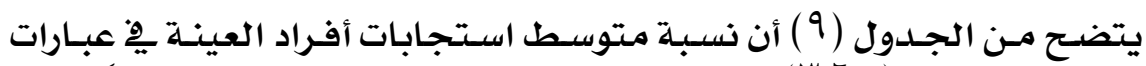

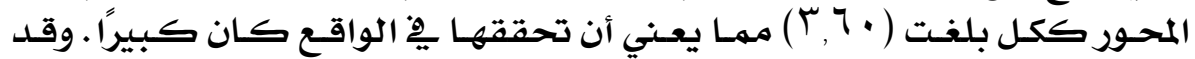

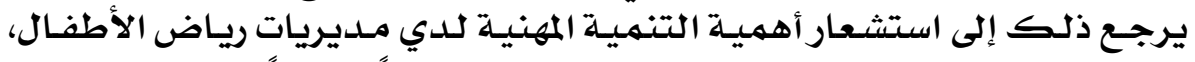

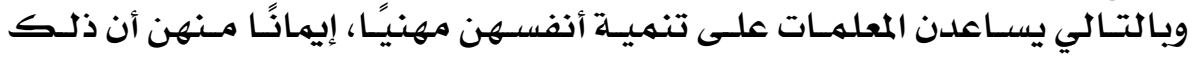

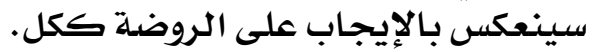

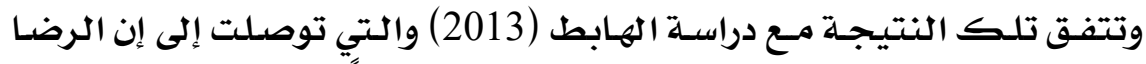

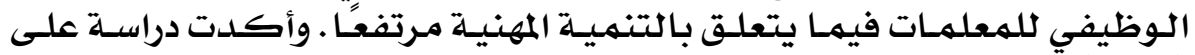

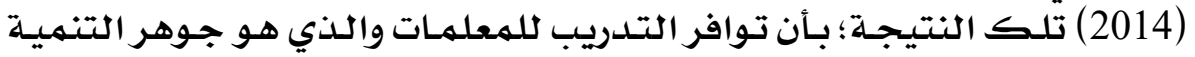

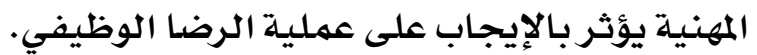

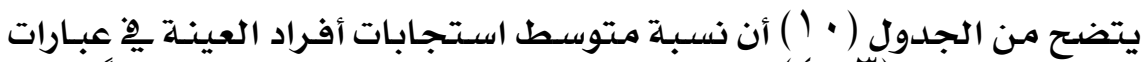

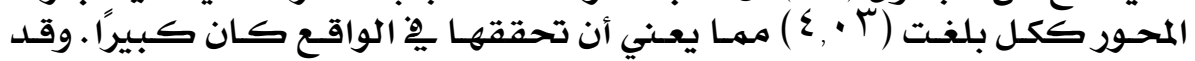

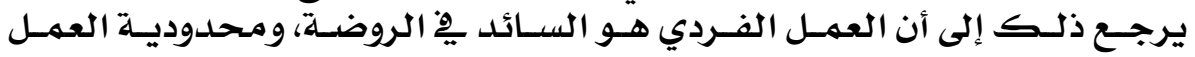

\section{7}

در اسات عربية في التزبية و عنم النفس (ASEP) 


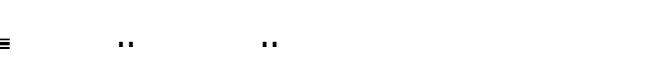

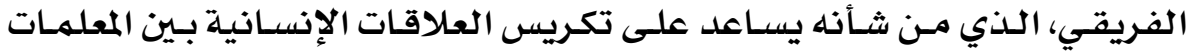

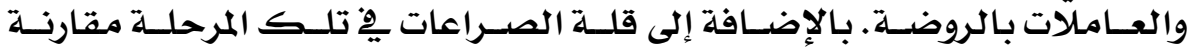

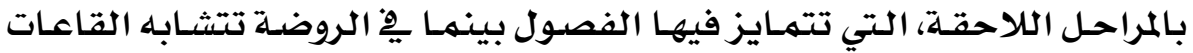

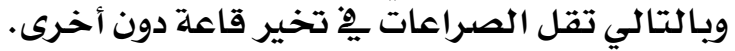

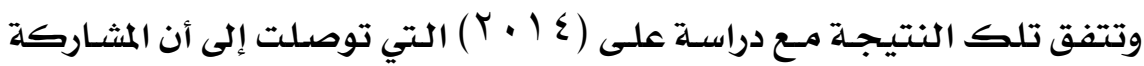

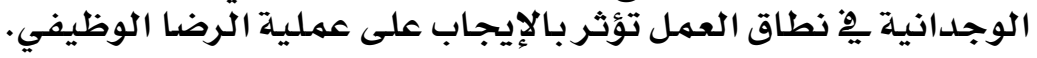

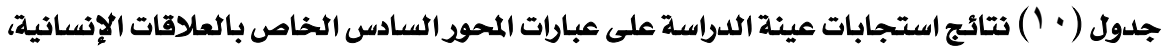

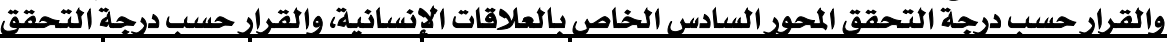

\begin{tabular}{|c|c|c|c|c|c|}
\hline القرار & & & & & \\
\hline ت تلدرجقة & الترتيب & المعياري & الحسابي & الفقرة & م \\
\hline 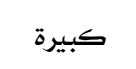 & 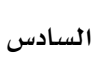 & $1,1 \mathrm{r}$ & $T, Y V$ & تقلف مستوي طبيعة عملي مستوى الصراع مـع زميلاتي إلى & 1 \\
\hline كبيرة جدًا & 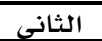 & $\cdot, 19$ & $\sum, r \Lambda$ & تتسهم علاقاتى بزميلاتى بالود والاحتر ام المتبـادل & r \\
\hline كبيرة & الخامس & 1,0 & $\varepsilon, \cdots$ & يغلب على أداء الزميلات العمل بروح الفريق & $r$ \\
\hline كبيرة & 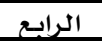 & $\cdot 94$ & $\varepsilon, 1 Y$ & تقدم لزميلاتي المساندة والدعم الاجتمـاعي والشخصي & $\varepsilon$ \\
\hline كبيرة جدًا & الأول & $\cdot, Y Y$ & $\{, \Sigma 1$ & تتسهم علاقتى بـأولياء أمور الأطفال بالود & 0 \\
\hline 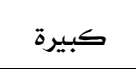 & السـابع & $1,1,4$ & r.,7 & 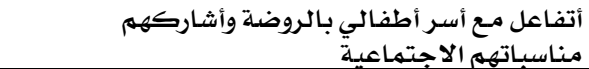 & 7 \\
\hline كبيرة جدًا & 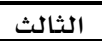 & $\cdot, \mathrm{VV}$ & $\xi, \Gamma \xi$ & أجد من أولياء أمور الأطفال رد فعل إيجابي تجاه عملي & $\mathrm{V}$ \\
\hline كبيرة & الثامن & $1, \leqslant 1$ & $r, 07$ & تحرص المديرة على أن تشاركنى مناسباتى الاجتماعية & $\Lambda$ \\
\hline كبيرة & & $0, \mathrm{~V} \cdot$ & $\varepsilon, \cdot r$ & إجمالى & \\
\hline
\end{tabular}

وبالإجابة على السؤال الثاني: هل توجد فروق ذات دلالثة إحصسائية بـين درجات

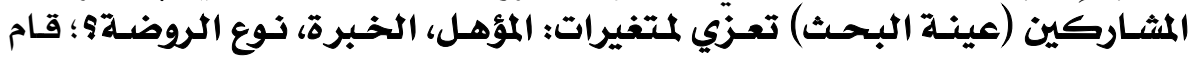

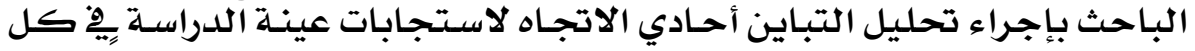

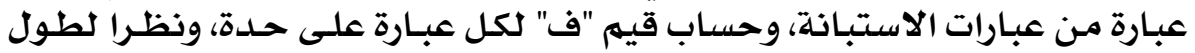

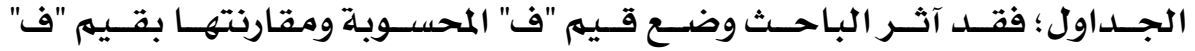

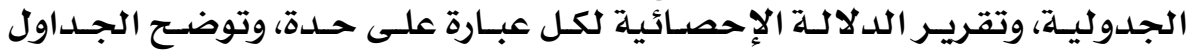

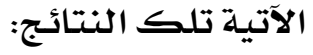

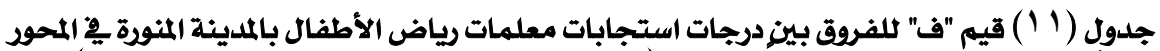

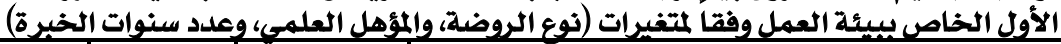

\begin{tabular}{|c|c|c|c|c|}
\hline علد الخبرة & العلموهل المول & 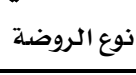 & 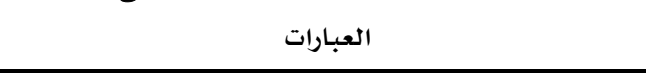 & $\hat{r}$ \\
\hline$\because \Lambda, \varepsilon$ & $Y, \leqslant 0$ & $* 11, \lambda \mu$ & تتوفر بالروضة الامكانات اللازمـة لأداء العمل بشكل دائم. & 1 \\
\hline$\$ 9, \wedge \varepsilon$ & r,Yq & $8, Y \mu$ & يساعد تصميهم مبنـي الروضـة على القيام بالمهام الموكولة إلى & r \\
\hline$\$ 1 \cdot 07$ & r,T & $\$ 10,7$ & تتوفر بالروضة مقومات الإضاءة والتهوية الجيدتين. & $r$ \\
\hline r,97 & $1, \wedge \Lambda$ & $1,1,7$ & المسافة بين سكني وعملى مناسبـة & $\xi$ \\
\hline$* V, 1 \cdot$ & 1,91 & $r, \leqslant \Lambda$ & توفر الروضة لي مكانًا مناسبًا لإدارة أنشطة القاعة & 0 \\
\hline .70 & $\because A, \cdot r$ & $\cdot, r \leqslant$ & توفر الروضـة لي الرعاية الصحية الكلازمـة & 7 \\
\hline Y, rq & $1, r$. & 1,90 & تزود قاعات الروضة بالخدمات اللازمة لممارسة الأنشطة & V \\
\hline T,IT & .70 & r,ON & تتوافر يِ الروضة أنشطة ترفيهية مختلفة & $\Lambda$ \\
\hline
\end{tabular}

\section{8}




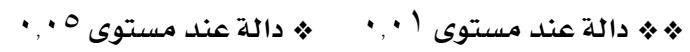

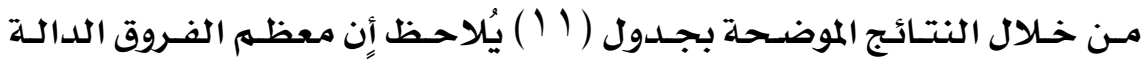

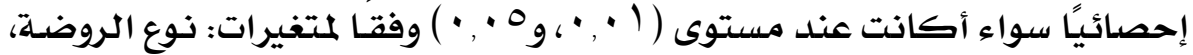

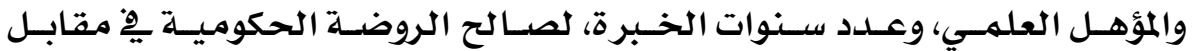

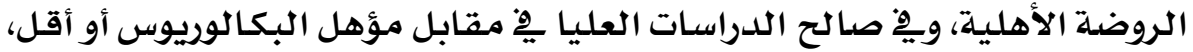

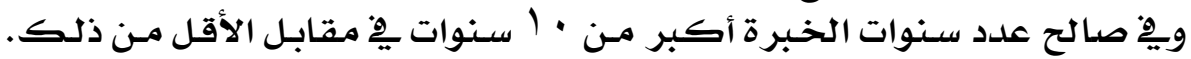

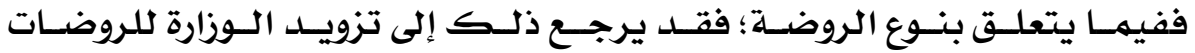

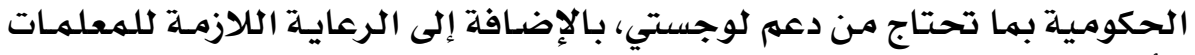

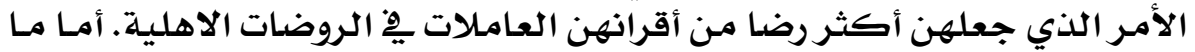

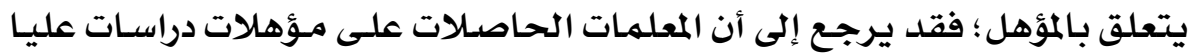

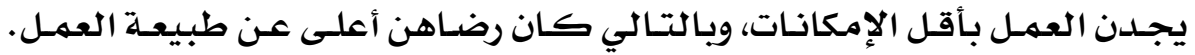

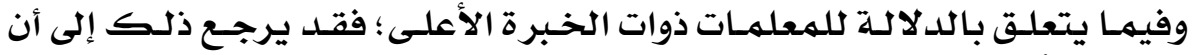

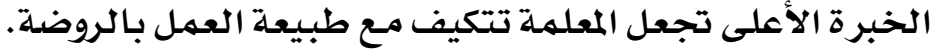

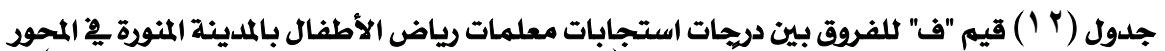

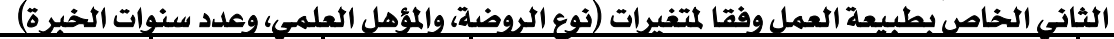

\begin{tabular}{|c|c|c|c|c|}
\hline عدد سنوات & المؤهل الملهـي & 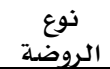 & 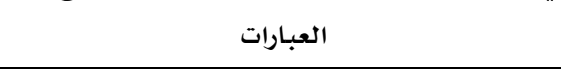 & r \\
\hline 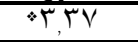 & $* 4 \cdot 1 \cdot$ & $* 17, \cdot 1$ & يـتوافق العمل الذيى أقوم بـه مـع مؤهلي الدراسي & 1 \\
\hline T, & .91 & $r, 1 \Lambda$ & يوجد توصيف واضح ومحدد لما يوكل إلى من مهام & r \\
\hline$* \wedge, \varepsilon$ & .95 & $* 1 \cdot, r \varepsilon$ & تقيم الملديرة آدائي بنـاء على معابير واضحلة ومـحددة & $r$ \\
\hline 1,17 & $1, \leq 0$ & 1, YO & تتنـاسب عدد سـاعات عملي مـع مـا أقوم بها مـع مهامـي & $\varepsilon$ \\
\hline r., & $\because V \varepsilon$ & 1,7 & الاجـازات الرسيمية التى أحصل عليها كافية & 0 \\
\hline$\div \leqslant 0$ & 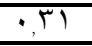 & $\cdot, 19$ & الوقت المخصص لأجـازه الأمومـة كاف & 7 \\
\hline$* \leqslant, 97$ & .19 &., $1 \mathrm{r}$ & 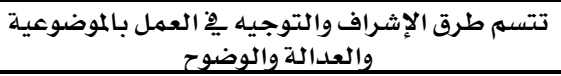 & V \\
\hline$* \varepsilon, 49$ & $\cdot \wedge$. & r. 0 & يتناسب عبء أعمالى بـالروضـة مـع قدراتي & $\Lambda$ \\
\hline $1, T$ & $\cdot, 19$ & r,07 & يتيح لي عملى فرصدة للتفاعل مـع المحتـمع الخارجي & 9 \\
\hline
\end{tabular}

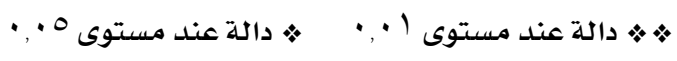

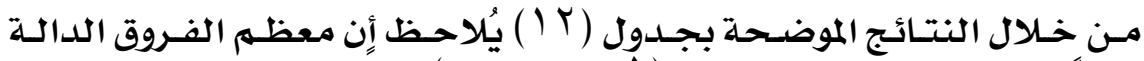

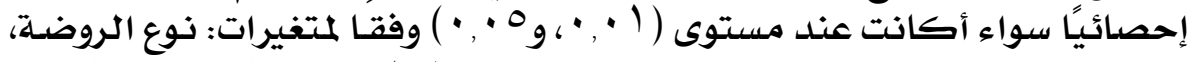

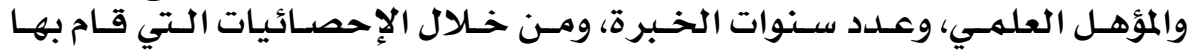

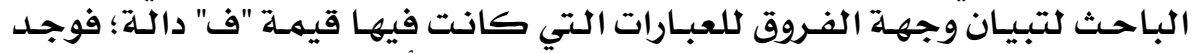

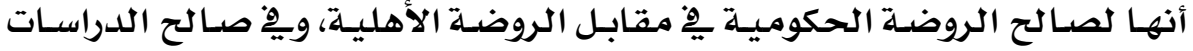

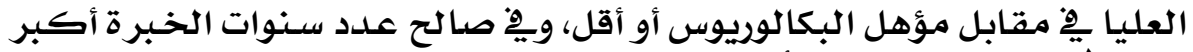

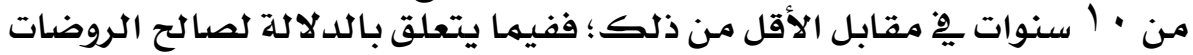

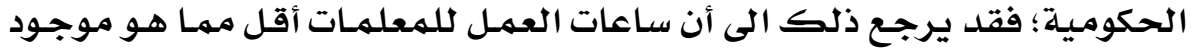

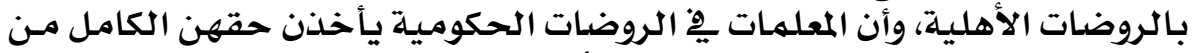

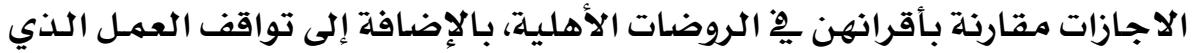

\section{9}

در اسات عربية في التزبينة و عنم النفس (ASEP) 


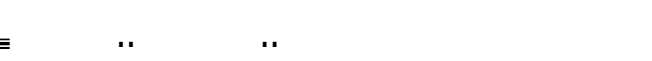

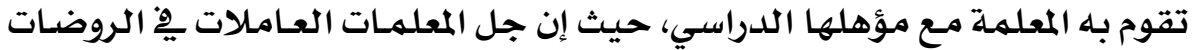

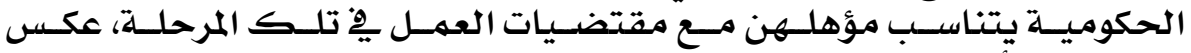

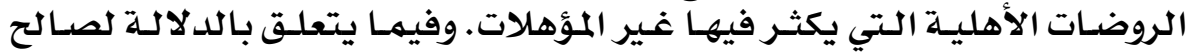

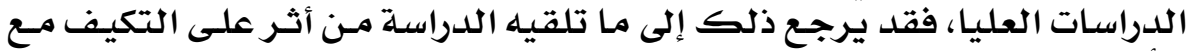

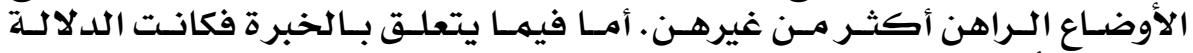

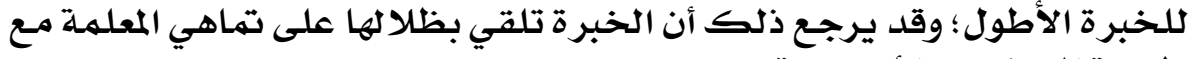

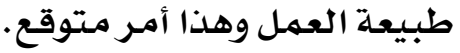

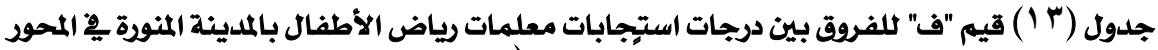

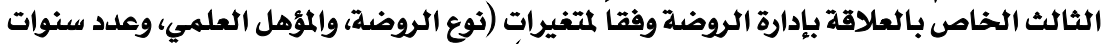
الخبرة)

\begin{tabular}{|c|c|c|c|c|}
\hline ع الخبرة سنوات & 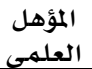 & الروضـة & 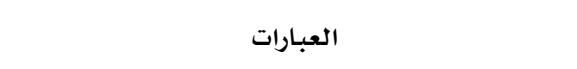 & م \\
\hline$* \varepsilon, \wedge 1$ & Y,IY & r, Is & أشعر بأنى موضـع تقدير واهتمام من قبل إدارة الروضـة & 1 \\
\hline$=7, \cdots$ & $1, v$. & $* 0, \mu$ & تتيح إدارة الروضة لي فرصدة كافية للتعبير عن أرائي & r \\
\hline$r, \xi)$ & .0 & T,AT & تتضـح قنوات الاتصال بيني وبين رؤسائي فِ العمل & $r$ \\
\hline$* 0,1 T$ & $1, \varepsilon r$ & $=7,9$ & 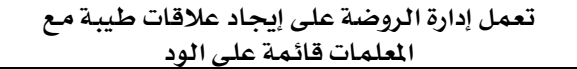 & $\varepsilon$ \\
\hline $1, V T$ & $\cdot \varepsilon \cdot$ & $* T, \leq 7$ & توزع مديرة الروضة العمل بين المعلمات بعدالة & 0 \\
\hline *1, & $\cdot 91$ & $* \Sigma, \mu V$ & تتقبل المديرة مني النقد البناء بصدررححب & 7 \\
\hline$* \mu, \Lambda \cdot$ & $\cdot, \leqslant 7$ & $r, \wedge \wedge$ & أشارك ِِْ صناعة القرارات التى تتصل بههامي & $\mathrm{V}$ \\
\hline$\therefore \mathrm{V}, \mathrm{TO}$ & $\cdot .71$ & $\$ 2,17$ & تشجعنى المديرة عندما أقوم بالعمل على نحو أفضل & $\Lambda$ \\
\hline$* 1,0$ & $1,0$. &.$\leqslant 0$ & توجهنى المشرفة بطريقة مناسبة وبناءه & 9 \\
\hline r,Vo & $1, Y$, & $1, \wedge 1$ & تقوم علاقتي بمشرفة المادة على الود والاحترام & $1 \cdot$ \\
\hline
\end{tabular}

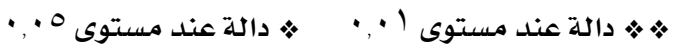

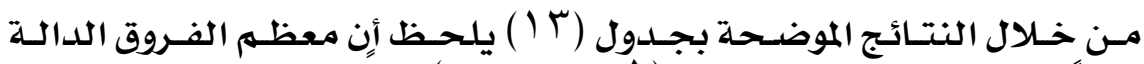

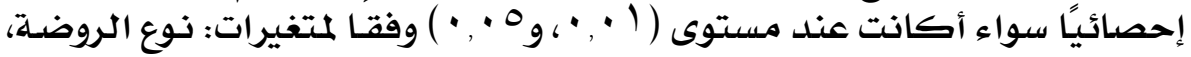

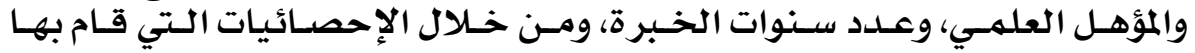

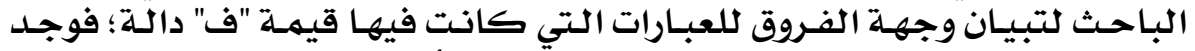

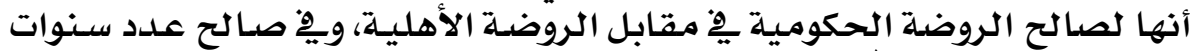

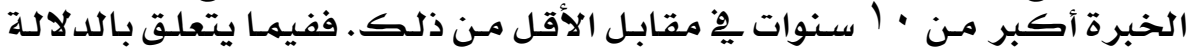

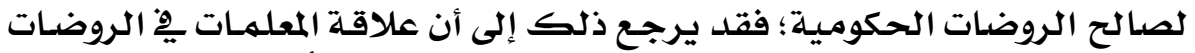

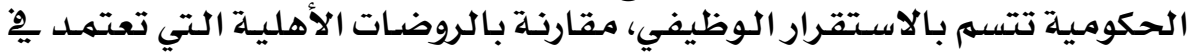

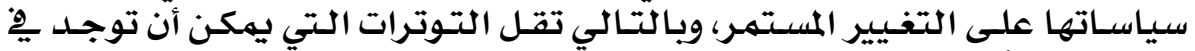

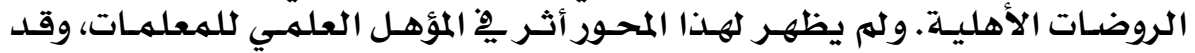

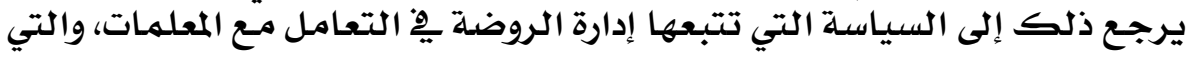

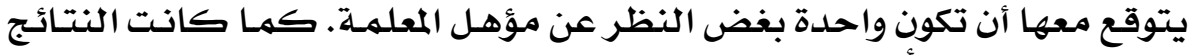

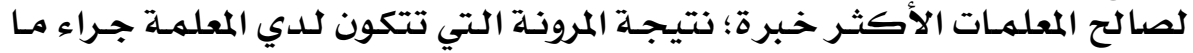

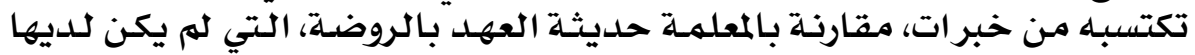

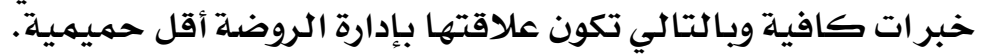

\section{0}

در اسات عربية في الثربيتة و عنم النفس (ASEP) 


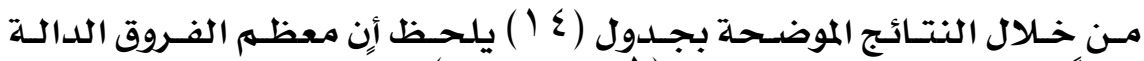

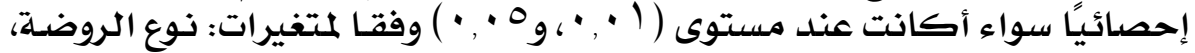

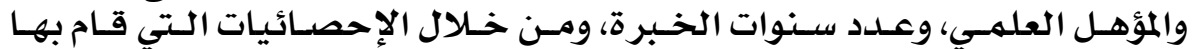

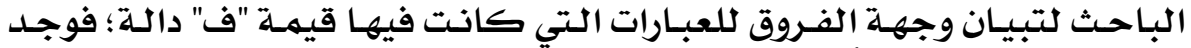

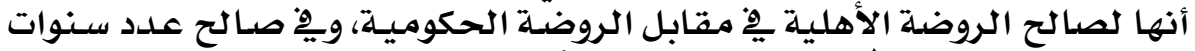

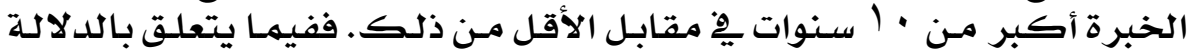

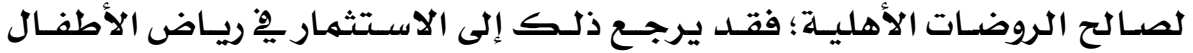

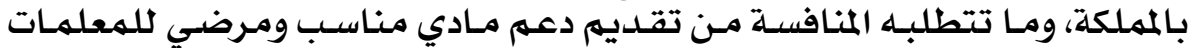

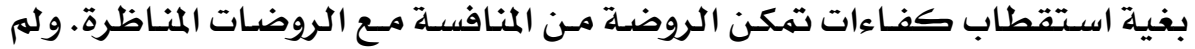

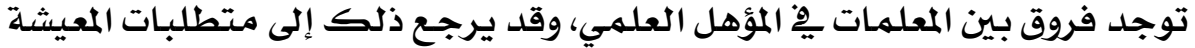

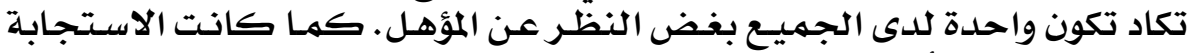

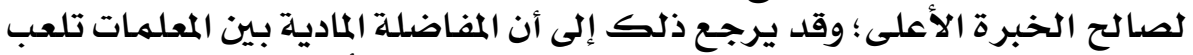

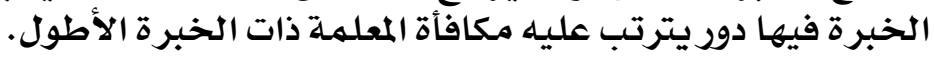

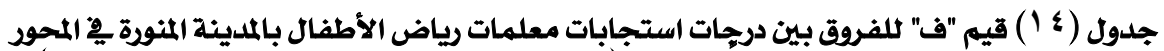

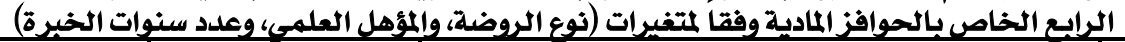

\begin{tabular}{|c|c|c|c|c|}
\hline عدد سنوات & المؤهل & نوغ الروضة & 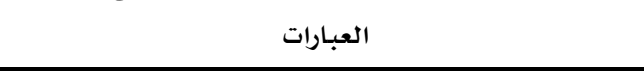 & r \\
\hline ríq & $\cdot, 7 \pi$ & $\cdot, 9$ & مـا اتقاضـاه مـن راتب بتتناسب مـع الجهد الذى أبذله & 1 \\
\hline$* * \vee \wedge$ & $\cdot 11$ & $1, \leqslant \Lambda$ & يمنحنى عملى حوافز أفضل من غيره ٍِِ الجهات الحكومية الأخرى. & r \\
\hline$* \varepsilon, \wedge 7$ & $\cdot \mathrm{V}$ & $* r, \Lambda$. & مـا سوف اتقاضاه من راتب بعد التقاعد كافٍ بـالنسبة لى & r \\
\hline$\left.* T^{2}, 1\right\}$ & 1,87 & t,AT & يتنـاسب راتبى مـع مستوى المعيشة السائدة ٍِِ المجتمـع & $\varepsilon$ \\
\hline Y,VT & $\cdot \Gamma \Lambda$ & $* \pi, 7 \mu$ & يتناسب الراتب الذي اتقاضساه مـع خبرتي ِِ العمل & 0 \\
\hline$r \cdot \varepsilon$ & r,VA & $\cdot \mathrm{V}$ & أحصل على أجر إضـاِِّ عند زيادة سـاعات العمل عن ثـان & 7 \\
\hline$* 1 \cdot, 17$ & $.7 \varepsilon$ & 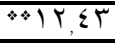 & أشعر بـأن نسبـة الزيادة السنويـة على راتبي ملائمـة وعادلة. & $\mathrm{V}$ \\
\hline
\end{tabular}

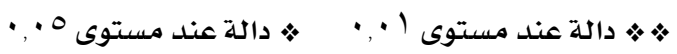

جدول (0 1 ) قيم "ف" للفروق بين درجإت استجابات معلمات رياض الأطفال بالمدينة المنورة بِّ المحور

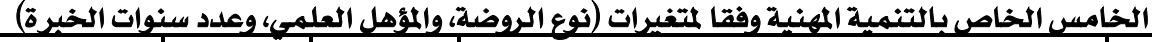

\begin{tabular}{|c|c|c|c|c|}
\hline ع الخد سنوات & 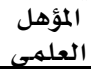 & المروضة & 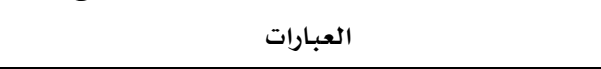 & b \\
\hline 1,17 & $.9 \mathrm{~V}$ & $\cdot, 11$ & يتيح العمل لي إمكانية تطوير مهاراتي المختلفة. & 1 \\
\hline .4 .09 & 1,11 & $0.7,90$ & 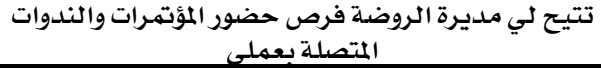 & r \\
\hline$* \varepsilon, 19$ & $1, \leqslant 1$ & $1,7 Y$ & يوفر لي عملي فرصًا مناسبة للترقي الوظيفي & $r$ \\
\hline$* T, Y$ & $* T, V Y$ & $* \leqslant, r q$ & تساعدني إدارة الروضيلة على تبـادل إلعمل الخبر ات بيني وبين & $\varepsilon$ \\
\hline $8 \%, 0$ & $r, \wedge T$ & 1,17 & يتاح لى التدريب الكاف لتطوير أدائى المهنى. & 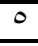 \\
\hline$* r, V \varepsilon$ & $* \Gamma, \varepsilon \wedge$ & & توفر لي إدارة الروضة فرصنا لتطوير إمكاناتي ومهاراتي & 7 \\
\hline $1 \cdot, \leqslant r$ & $1,1 \pi$ & $* 1.09$ & توفر الروضة كتب متخصل، وإدارة قاعة الصِّف أساليب التعامل مـع & $\mathrm{V}$ \\
\hline $1,7 \cdot$ & $* 7, Y T$ & $1,1 \mathrm{~V}$ & تمدلني زميلاتي بما احتاج مـن عون لتطوير أدائي & $\Lambda$ \\
\hline$* \varepsilon, 91$ & $1, r 9$ & $* r, \varepsilon$ & يوفر لي عملي بـالروضة فرصًا للإبداع & 9 \\
\hline
\end{tabular}

\section{1}

در اسات عربية في التزبيتة و عنم النفس (ASEP) 


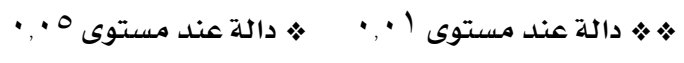

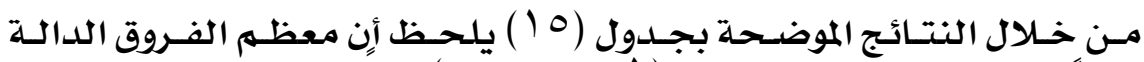

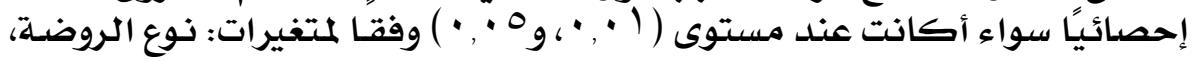

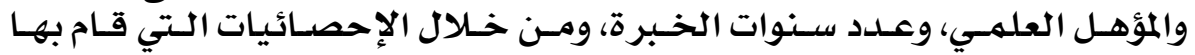

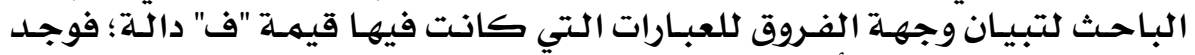

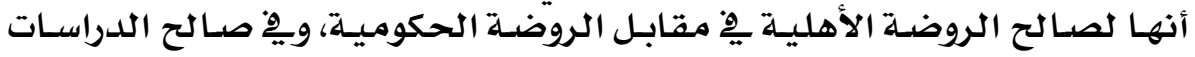

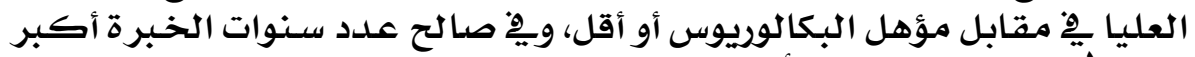

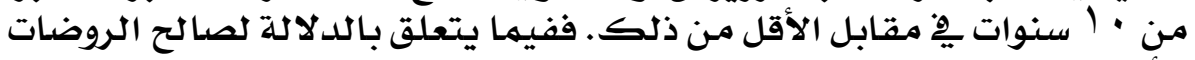

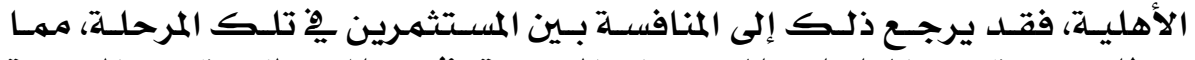

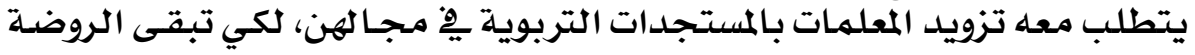

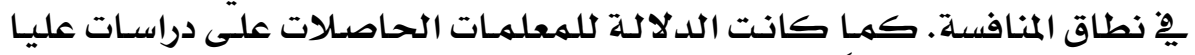

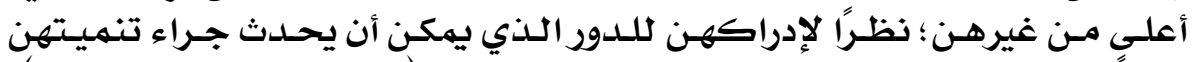

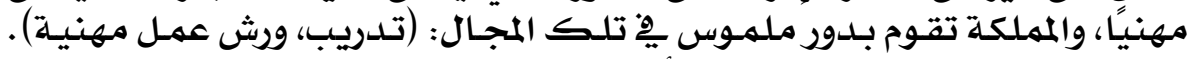

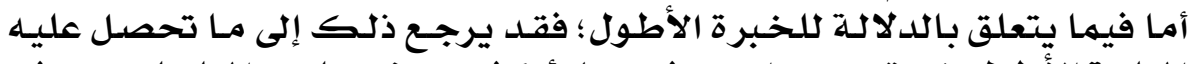

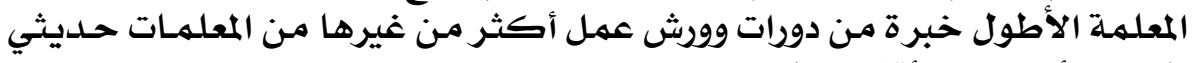

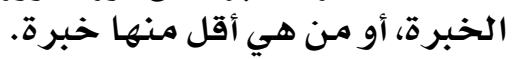

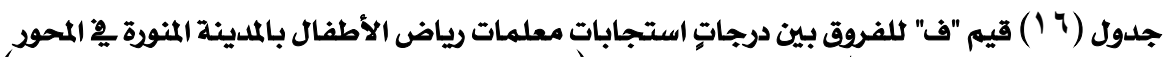

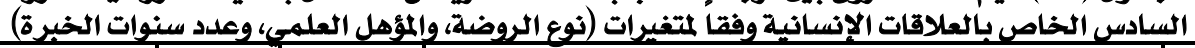

\begin{tabular}{|c|c|c|c|c|}
\hline عددسنوات الخبرة & المؤهل & نوع الروضية & 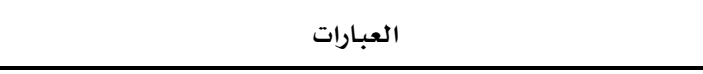 & r \\
\hline 1,49 & $r \cdot V$ & $1, \wedge 9$ & تخفض طبيعة عملي مستوى الصراع مـع زميلاتي إلي أقل مستوى & 1 \\
\hline$* \forall, V V$ & 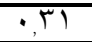 & 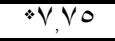 & تتسيم علاقاتي بزميـلاتي بالود والاحتر ام المتبـادل & r \\
\hline .01 & $\cdot, \wedge 9$ & 1,10 & يغلب على أداء الزميلات العمل بروح الفريق & r \\
\hline$\cdot, 49$ & $84 \cdot 9$ & $\cdot 1$ & تقدم لي زميلاتي المسـاندة والدعم الاجتمـاعي والشخصي & $\varepsilon$ \\
\hline r. & .07 & t, ro & تتسهم علاقتى بأولياء أمور الأطفال بالود & 0 \\
\hline $1, V \cdot$ & $* 7,0 \mathrm{~V}$ & 1,17 & أتفاعل مـع أسر أطفالي بالروضـة واشـاركهم مناسبـاتهم الاجتماعية & 7 \\
\hline$\because 10$ & r, $9 \mathrm{~V}$ & $\cdot Y$ & أجد من أولياء أمور الأطفال رد فعل إيجـابى تجـاه عملى & V \\
\hline$* 0, \vee \leqslant$ & $* 7, v$ & $* * 10 \leqslant 7$ & تحرص المديرة على أن تشاركني مناسبـاتي الاجتماعية & $\Lambda$ \\
\hline
\end{tabular}

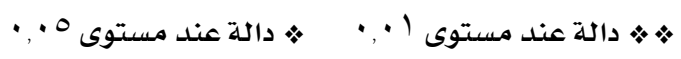

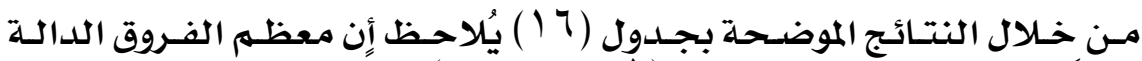

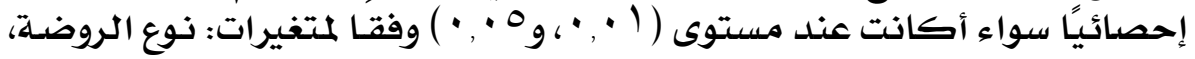

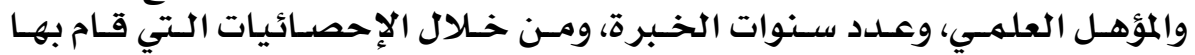

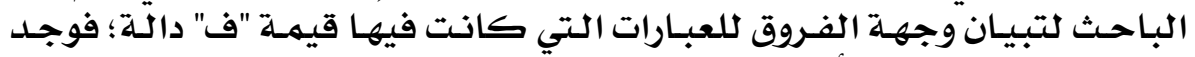

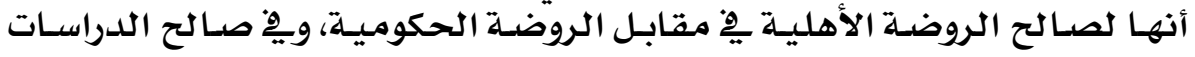

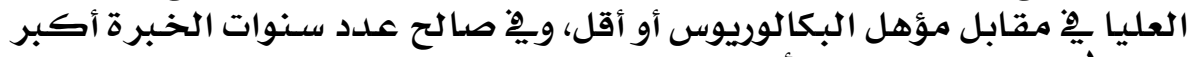

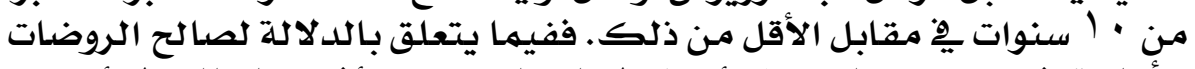

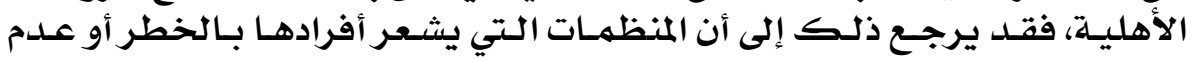

\section{2}




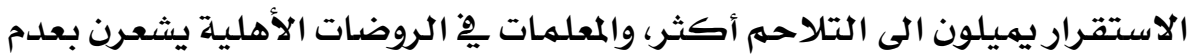

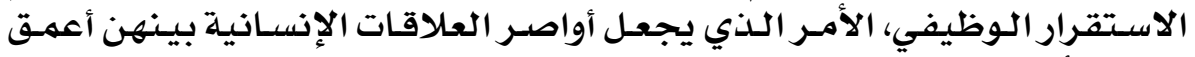

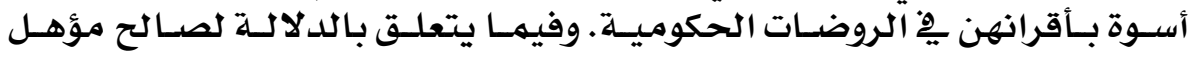

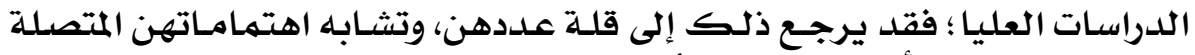

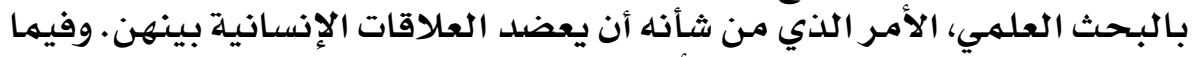

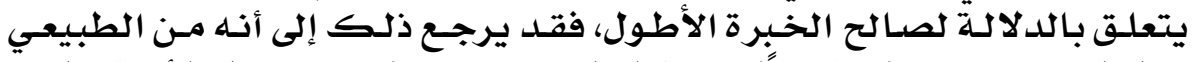

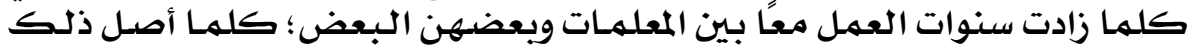
لعلاقات إنسانية جيدة

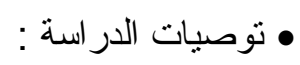

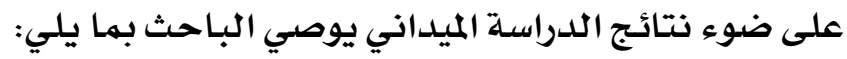

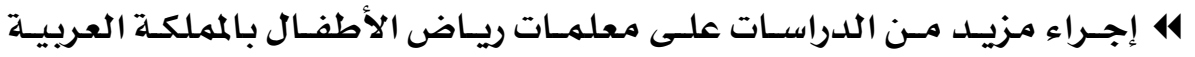

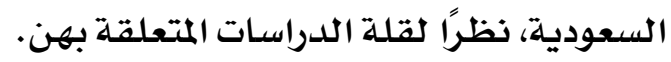

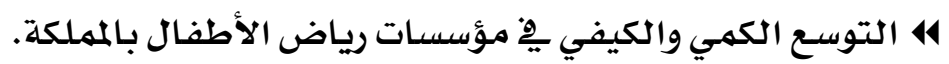

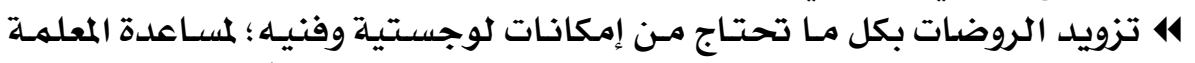

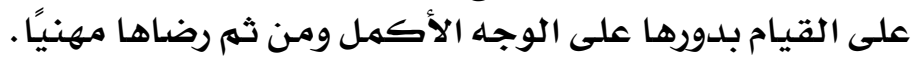

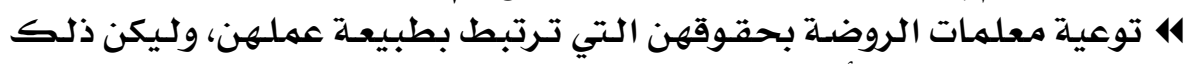

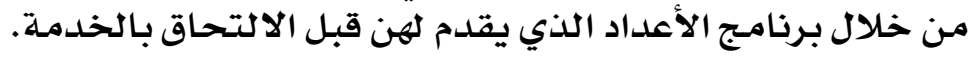

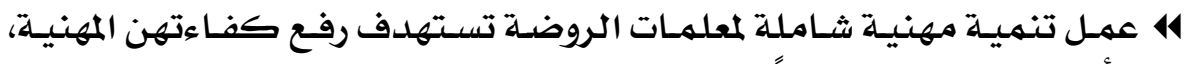

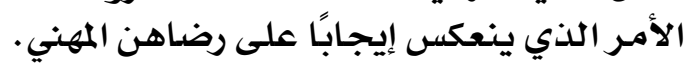

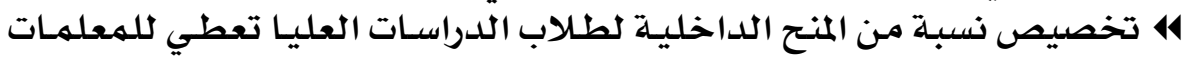

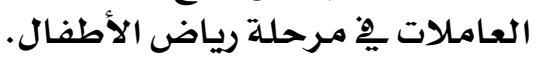

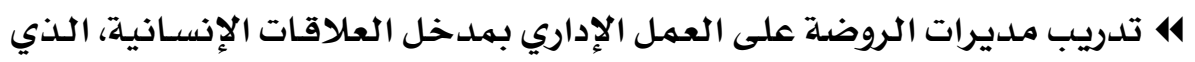

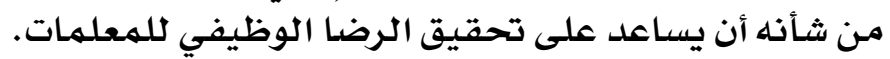

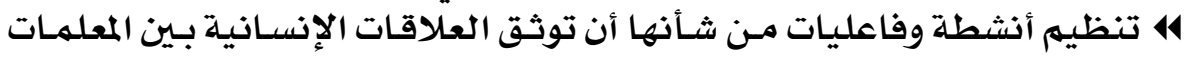

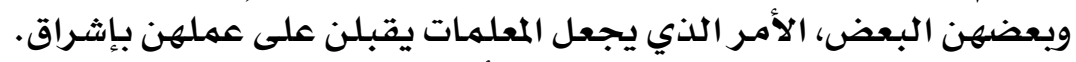

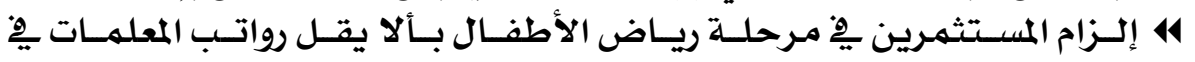

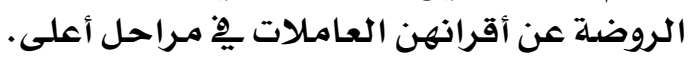

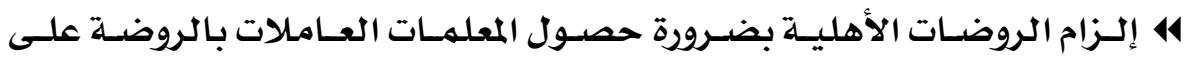

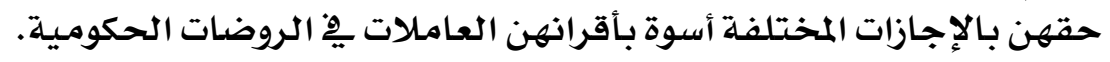

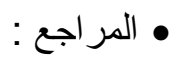

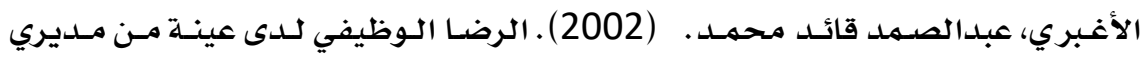

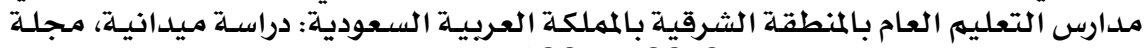
دراسات الخليج والجزيرة العربية 2، 109- 129.

\section{3}

در اسات عربية في التربينة و عنم النفس (ASEP) 


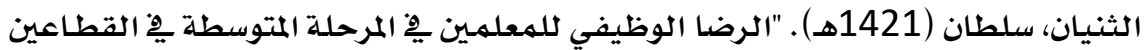

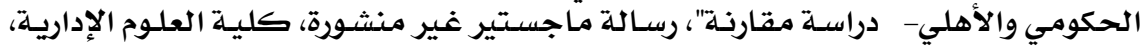

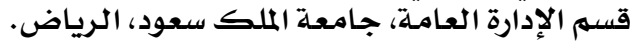

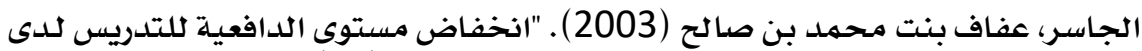

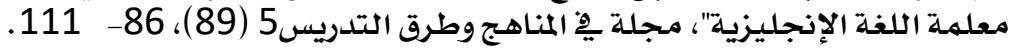

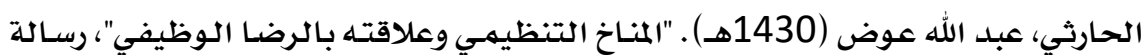

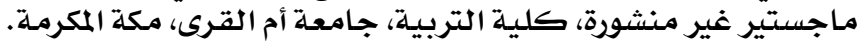

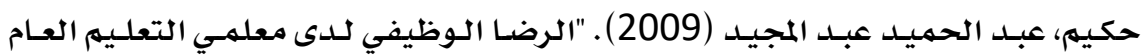

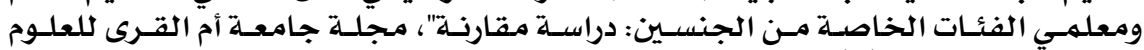

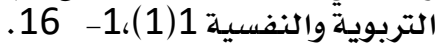

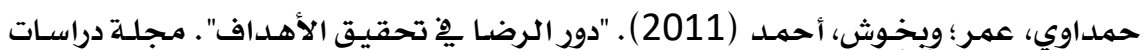

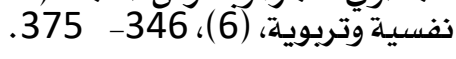

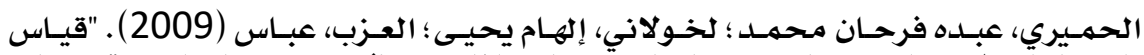

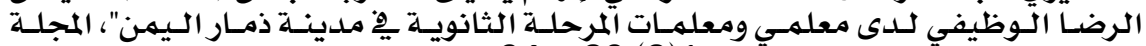

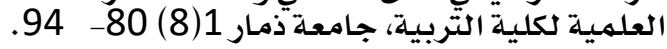

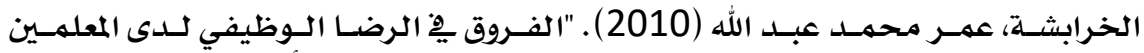

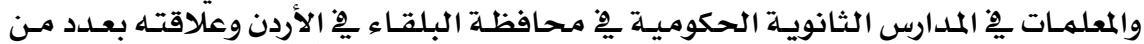

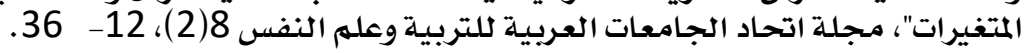

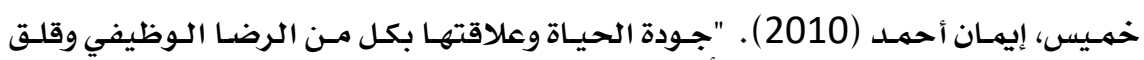

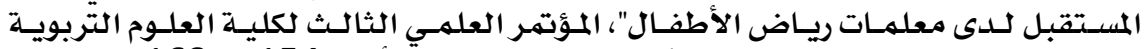

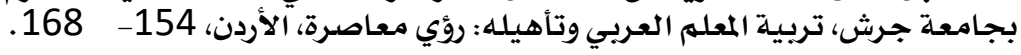

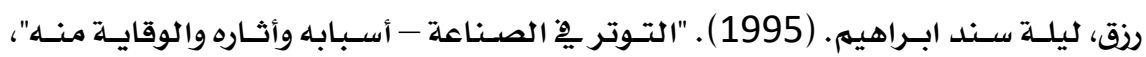
بيروت: دار النهضة لينة العربيـة اهيه.

الروقي، سعد معتاد (2002) ـ "الضغوط الإدارية وعلاقتها بـالأداء والرضـا الوظيفي، دراسـة

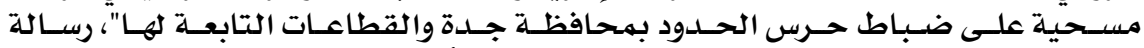

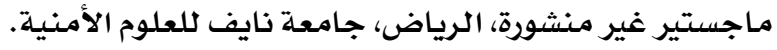

رونالدو، ريجيو (1999) . "مـدخل الى علـم النفس الصسناعي والتنظيهـي"، ترجمـة : حلهـي،

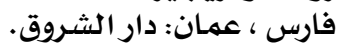

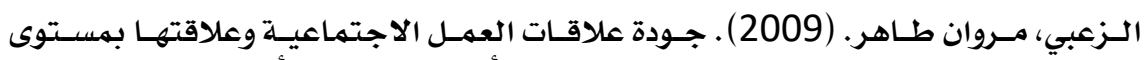

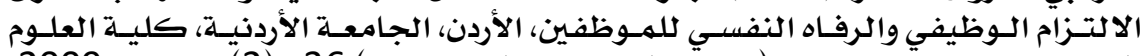

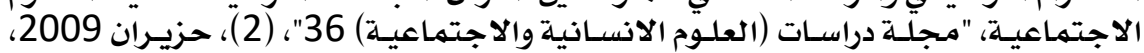
.479-465

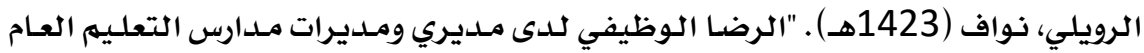

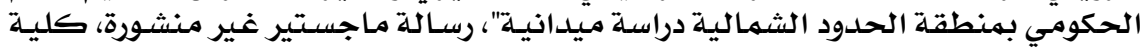

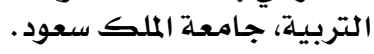

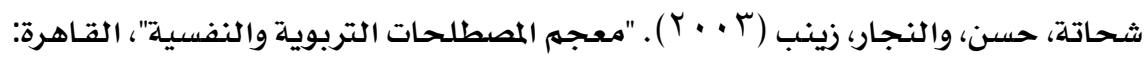
الدار المصرية اللبنانية حسنية.

\section{4}

در اسات عربية في الثربيتة و عنم النفس (ASEP) 


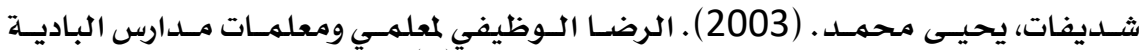

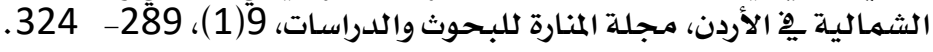

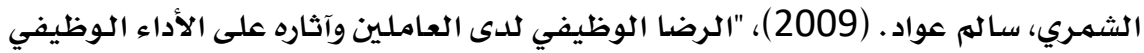

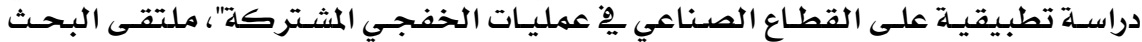

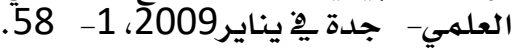

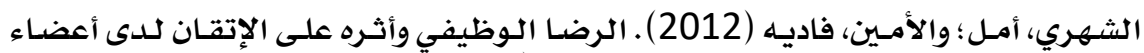

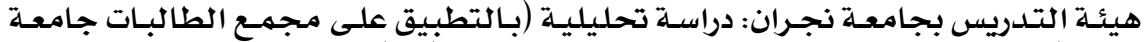

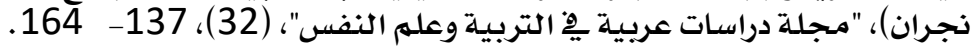

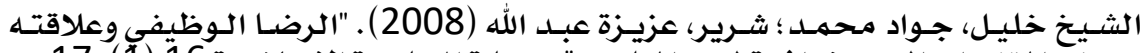

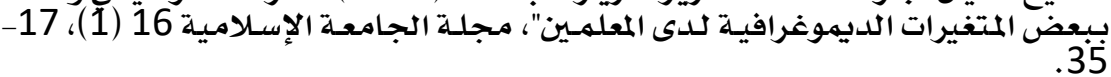

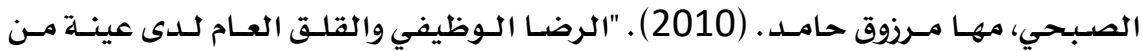

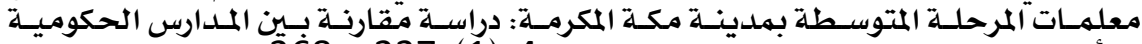

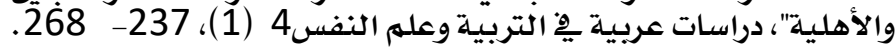

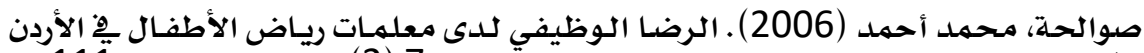

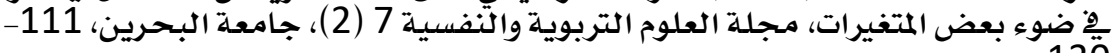
.130

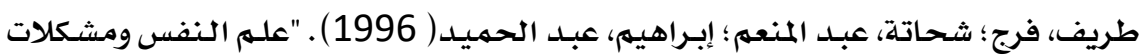

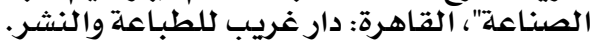

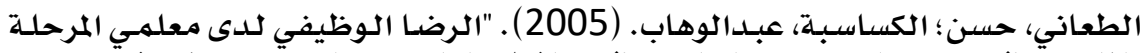

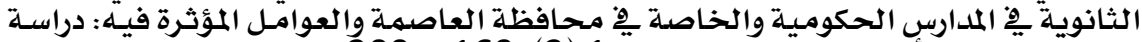

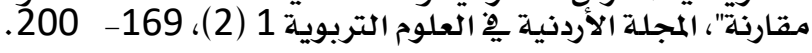

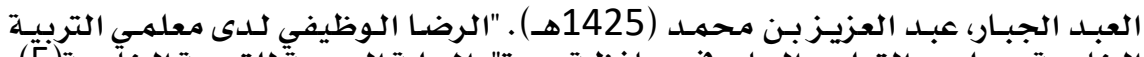

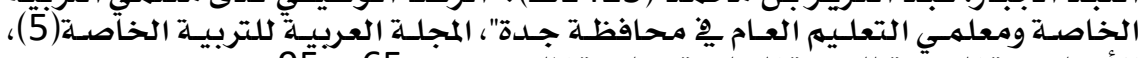

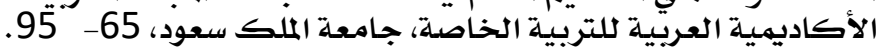

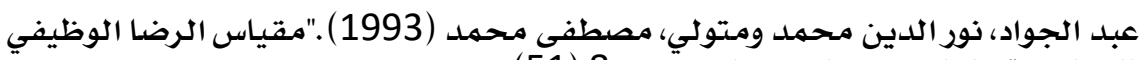

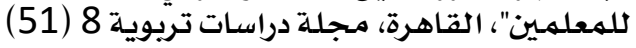

العجاجي، عبد الله بن إبراهيه. (1997) . "الرضا الوظيفي لدى معلمهي المواد الاجتمـاعيـة

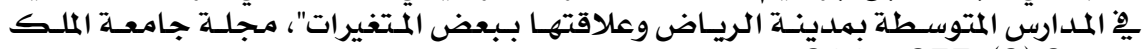
سعود 9 (2)، 277 - 2714

العتيبي، سعد (2008) . "اتجاهات المديرين نحو الالتزام بالقيهم التتظيمية ِِيخ وزارة التربية

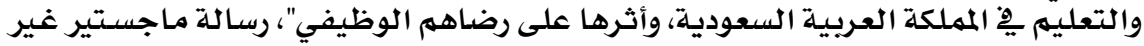
منشورة، كلية الإدارة، جامعـة مؤتة.

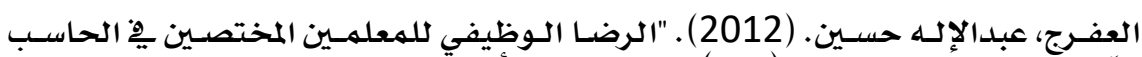

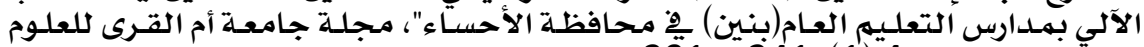
التربوية والنفسية 4 (1)، 241 291 291.

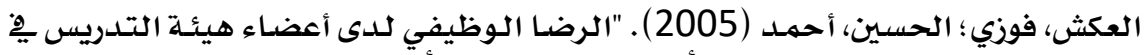

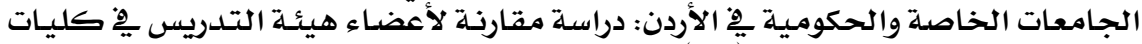

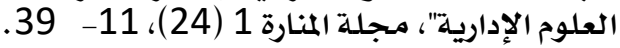

\section{5}

در اسات عربية في الثربيتة و عنم النفس (ASEP) 


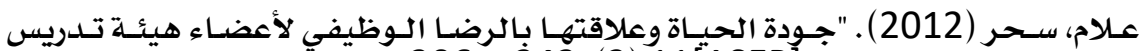

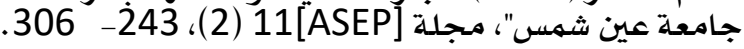

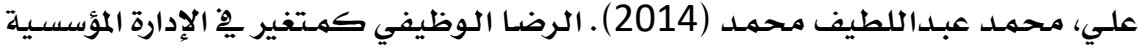

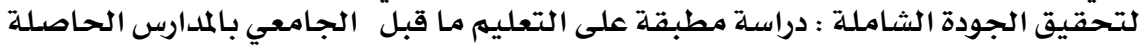

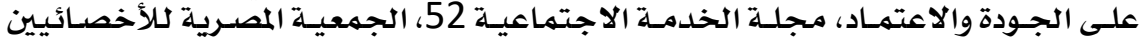

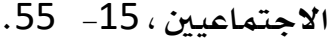

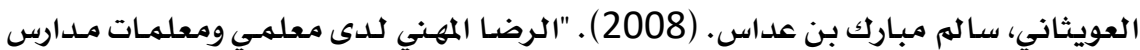

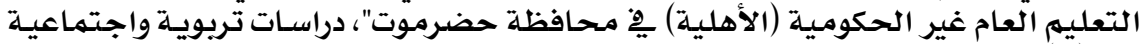
. 504 -438، (2) 14

عيسـوي، عبـدالرحمن محهمــ (2003) . "علـم النفس الصـنـاعي"، بـيروت: دار الفكر العربـي للنشر والتوزيع.

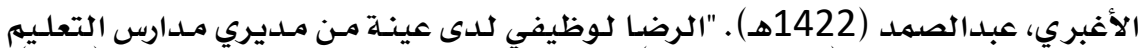

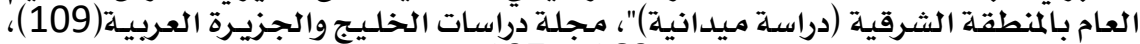

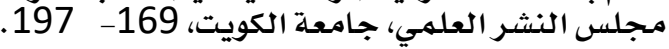

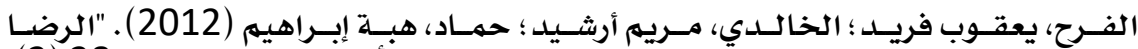

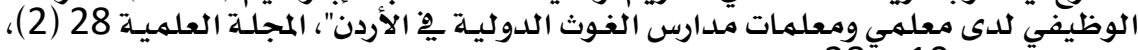

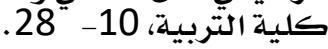

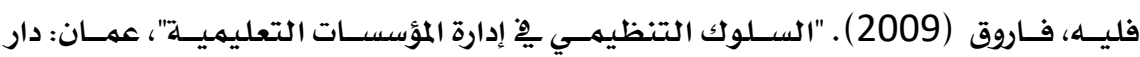
المسيرة.

القطـامـين، أحمــ (2002) . "الادارة الاسـتراتيـجية: مفـاهيهم وحـالات تطبيقيـة"، عمـان: دار مجدلاوي للنشرورالتوزين.

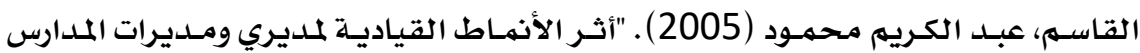

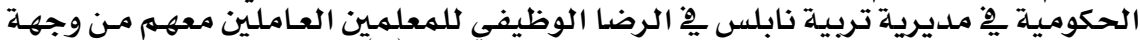

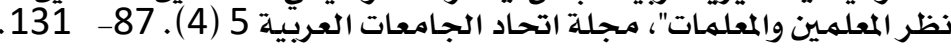

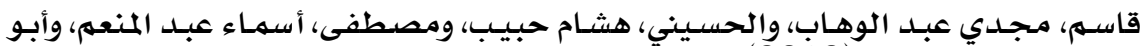

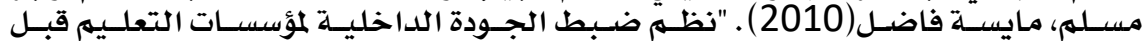

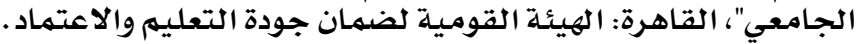

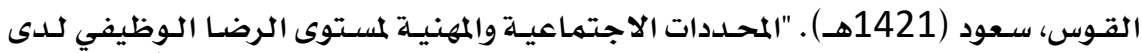

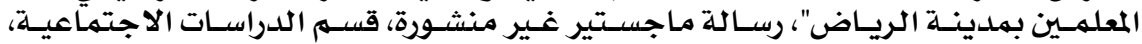
جامعة الملك سعود، الرياض.

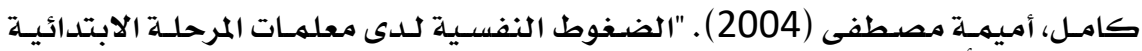

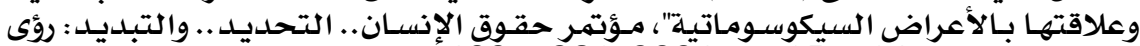

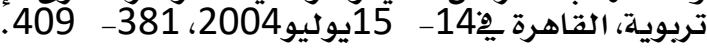

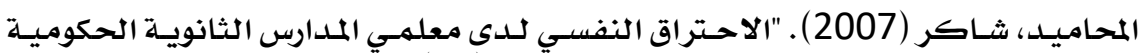

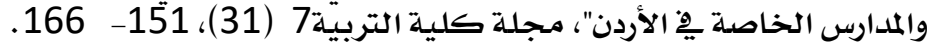

محمهود، محمدد مصطفى(2012) . "موسوعة إدارة الموارد البشريـة"، (الجزيء الأول)، القاهرة:

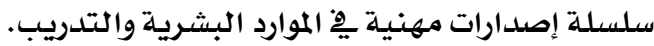

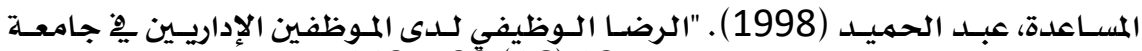

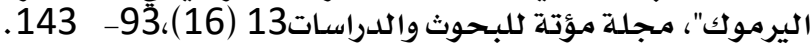

\section{6}

در اسات عربية في الثزبية و عنم النفس (ASEP) 


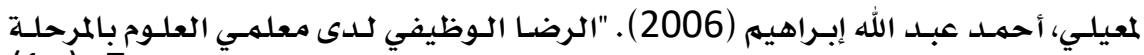

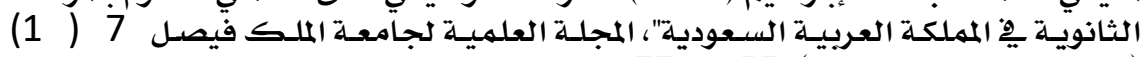

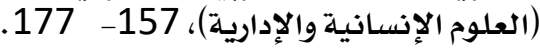

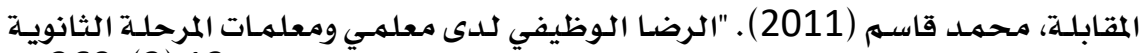

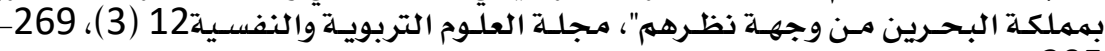
295

منسـي، مـحمـود عبـــ الحلـيهم (1994) ـ "الرووضـة وإبـداع الطفـل"، الإسـكندريـة: دار المعرفـة

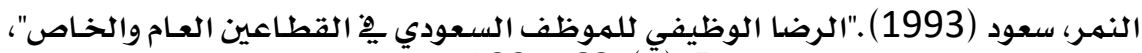

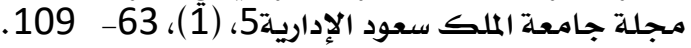

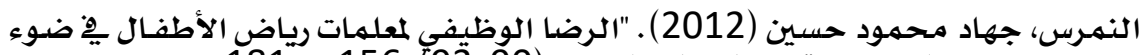

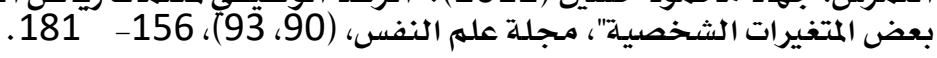

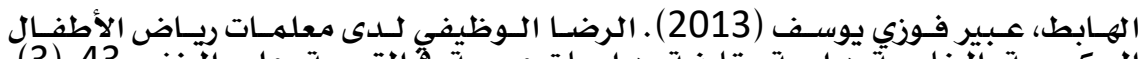

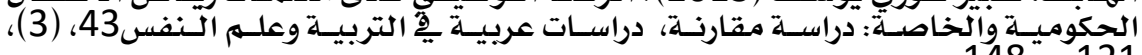
148-121

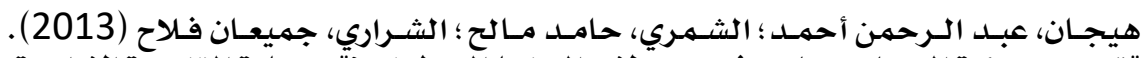

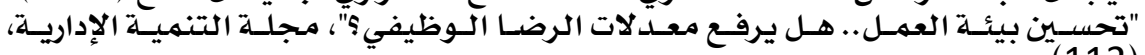

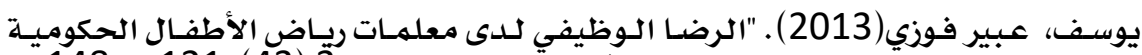

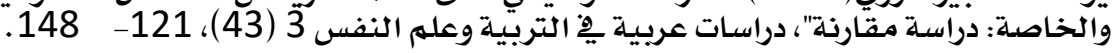

- Al-Zoubi, M. T. (2005). Job design in the third millennium. Unpublished thesis. University of Surrey. Surrey, UK.

- Brackett, Marc A.; Palomera, Raquel; Mojsa-Kaja, Justyna; Reyes, Maria Regina; Salovey, Peter. (2010). Emotion-Regulation Ability, Burnout, and Job Satisfaction among British Secondary-School Teachers. Psychology in the Schools 47، (4), April2010، 406-417.

- Brown, D. (2007). Job Satisfaction, Organizational Commitment, And Religious Commitment Of Full-Time University Employees. Journal of Research on Christian Education, (16), 211-241.

- Collmer. (1990). A correlational study of principals leadership styles and teachers job satisfaction, Dissertation Abstract International 51. (1). 30-A.

- Demorouti, E. Bakker, A., Nach reiner, F. Schaufeli, W. (2001). The job demands-resources model of burnout . Journal of Applied Psychology ،86, 499-512.

- Eddins, Gregg. M.(2012). The Influence of Principal Gender, Teachers' Years of Experience, and Retention on Teacher Perceptions of Principal Leadership Style, Qualities, and Job Satisfaction. University of Missouri - Columbia, 12(1), 407-420.

\section{7}


- Friedl Ander, F. (2009). Mul Tiple Impacts Of organizational climate And Individual value Systems Upon job Satisfaction، personnel Psychology journal 22 ، Issue 2, pages 171- 183. 2009 Wiley Periodicals, Inc.

- Graen, G. and Uhl- Bien, M. (1995). Development of Leader member exchange theory of leadership over 25 years. Applying a multi-level multi-domain perspective. Leadership Quarterly 6, 219247 .

- Garen, G. \& Scandura, T. (1987). Toward a psychology of dyadic organizing. Research on Organizational Behavior 9, 175-208.

- Hill, E.A (2004). The Impact Self-Role Congruence Length of Service, Job satisfaction and Organizational Cmmitment on Propensity to Leave". Dissertation Abstract International 45، (01), 92-A.

- Kram, K. E. \& Isabella, L. A. (1985). Mentoring alternatives: The role of peer relationships in career development. The Academy of management Journal 28، (1), 110- 132.

- Macula, (1998). An Assessme of Job Snt atisfaction of Elementary public School Teachers in New Jersey and Analysis of its Relationship to demographic Variables . Dissertation Abstract International, Vol 56, (3), 953-A.

- Mathis, Mesha R. (2010). Factors that Affect Teacher Job Satisfaction among Title I School Teachers in Georgia. Capella University Proquest Dissertations and these10 (1), 128-140

- Miharty. (2013). The Influence of Organizational Culture on Job Satisfaction towards Improving the Quality of Education in University of Riau' Asian Social Science12 ( 9), 1911-2017.

- Ofilir A. Usiholo, E \& ‘Oronsaye, M. (2009). Psychological Morbidity, Job Satisfaction and Intentions to Quit among Teachers in Private Secondary Schools in Edo-State. Nigeria، Annals of African Medicine 8 (1), 7-32.

- Rahaman، H. M. S. (2012). Organizational Commitment, Perceived Prganizational Support and Job Satisfaction among School Teachers: Comparing Public and Private Cectors in Bangladesh، South Asian Journal of Management19، (3), 7-17.

- Saari,L.\& Judge,T. (2004). Employees Attitudes And Job satisfaction، Human Resource Management 43، (4), 395-407.

- Schroder, R. (2008). Job satisfaction Of Employees A.T.A. Christian University. Journal of Research on Christian Education17 ‘(2), 225-246.

\section{8}

در اسات عربية في التزبينة و عنم النفس (ASEP) 
- Young, B. J (1988). Teacher job satisfaction: a study of the overall job job satisfaction of K-8 Teacher. Dissertation Abstract International 49, (7), 1665-A.

- Zembylas، M \& Papanastasiou, E. (2004). Job Satisfaction among School Teachers in Cyprus. Journal of Educational Administration 42، (3), 357-374.

\section{9}

در اسات عربية في التزبينة و عنم النفس (ASEP) 